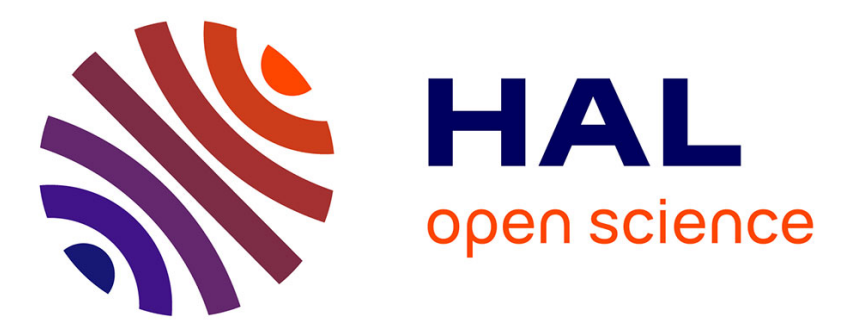

\title{
Les armes des sanctuaires poitevins d'époque préromaine de Faye-l'Abbesse (Deux-Sèvres) et de Nalliers (Vendée)
}

Thierry Lejars

\section{- To cite this version:}

Thierry Lejars. Les armes des sanctuaires poitevins d'époque préromaine de Faye-l'Abbesse (DeuxSèvres) et de Nalliers (Vendée). Gallia - Fouilles et monuments archéologiques en France métropolitaine, 1989, 46, pp.1-41. 10.3406/galia.1989.2890 . hal-01939630

\section{HAL Id: hal-01939630 \\ https://hal.science/hal-01939630}

Submitted on 14 Jun 2020

HAL is a multi-disciplinary open access archive for the deposit and dissemination of scientific research documents, whether they are published or not. The documents may come from teaching and research institutions in France or abroad, or from public or private research centers.
L'archive ouverte pluridisciplinaire HAL, est destinée au dépôt et à la diffusion de documents scientifiques de niveau recherche, publiés ou non, émanant des établissements d'enseignement et de recherche français ou étrangers, des laboratoires publics ou privés.

\section{(이) $\$$}

Distributed under a Creative Commons Attribution - NonCommercial - NoDerivatives 44.0 


\title{
LES ARMES DES SANCTUAIRES POITEVINS D'ÉPOQUE PRÉROMAINE DE FAYE-L'ABBESSE (DEUX-SËVRES) ET DE NALLIERS (VENDÉE)
}

\author{
par Thierry LEJARS
}

L'étude des anciennes collections des musées de Niort et de Fontenay-le-Comte a permis de réexaminer le nobilier métallique de deux ensembles découverts au siècle dernier à Faye-l'Abbesse (Deux-Sèvres) et Nalliers ¿Vendée).

Le matériel conservé est composé pour l'essentiel d'armes en fer. La nature des objets et l'analyse des documents relatant les conditions de découverte et le contexte archéologique nous amènent à envisager une A stination cultuelle de ces ensembles qui rappellent à bien des égards les dépôts des sanctuaires du nord-est de a France. L'étude typologique, complètée pour les épées par une série d'analyses métallographiques, a montré pérennité de ces aires cultuelles depuis le III $^{e} \mathbf{s}$. avant $\mathbf{J}$.-C. jusqu'à l'époque romaine.

Malgré les nombreuses incertitudes concernant ces découvertes, leur importance se révèle capitale pour une région comme le Poitou où le second Age du Fer n'est connu que par quelques trouvailles fortuites. L'avènement de sanctuaires de tradition celtique en Centre-Ouest, au iII ${ }^{e}$ s. avant $J$.-C., pourrait témoigner de la venue de nouveaux groupes et de la celtisation, tout au moins partielle, de cette région.

The study of the ancient collections of the museums at Niort and Fontenay-le-Comte made possible a new scrutiny of the metallic furniture of two sets which were discovered last century at Faye-l'Abbesse (Deux-Sèves) and Nalliers (Vendée).

The preserved items are mainly iron weapons. The nature of these things, the sludy of the documents reporting the conditions of their discovery and the archaeological context, lead us to contemplate that these sets, which remind as in many respects of the sanctuary trusts in the north-east of France, were possibly meant for worship. A typologic study, completed, for the swords, by a whole range of metallographic analyses, showed the perenniality of the worship areas from the IIIrd century $B C$ till the roman period.

Though many doubts arise about these discoveries, they appear of essential importance for a region like Poitou, where the IInd Iron Age is only known through some casual discoveries. It is possible that the appearance of cellic traditional sanctuaries in the central-western region during the IIIrd century BC, bears witness of the arrival of new groups, and, up to a certain degree, of the celticization of the region. 
Avec la redécouverte d'anciennes collections dans les musées régionaux, à Niort (Deux-Sèvres) et à Fontenay-le-Comte (Vendée), en 1984 et 1985, c'est un pan entier et capital du second Age du Fer en Centre-Ouest qui vient d'être exhumé. L'étude de ces ensembles dont on ignorait jusqu'alors et l'existence et l'importance fut accompagnée d'une campagne de restauration ${ }^{1}$. Conjointement à la mise en valeur de ces mobiliers, en fer pour l'essentiel, nous avons, plus particulièrement dans le cas des épées, complété l'approche typologique traditionnelle par une analyse des structures internes du métal. Ce mode d'investigation qui est plus le fait des métallurgistes a porté sur une douzaine d'épées; à ce groupe, il nous faut aussi joindre les armes de Mazerolles et de Valdivienne (Vienne) ainsi que les épées à sphères de Germond (Deux-Sèvres) et de Juac (Charente) auxquelles nous nous sommes également intéressés et sur lesquelles nous aurons à revenir. Les lames métallographiees, sans être nombreuses, n'en constituent pas moins un bon échantillonnage puisqu'elles représentent près des deux-tiers des épées actuellement connues en Poitou. L'étude technique limitée à cette seule catégorie de l'armement permet de s'interroger plus longuement sur un type particulier de la production métallurgique, conçu par des artisans, sur différents schémas, en fonction de la matière, de la finalité de l'objet et de son destinataire (fig. 1).

1 Cet article est extrait d'un mémoire de Maitrise soutenu en 1986 à l'université de Poitiers, sous la direction de G. Nicolini, Professeur à l'université de Poitiers, et de J. Gomez de Soto et J.-P. Pautreau, chargés de recherche au CNRS: Les épées de l'Age du Fer en Poitou: contexte archéologique et étude paléométallurgique. Un premier article consacré aux épées à sphères du Centre-Ouest a été publié en collaboration avec C. Gendron, J. Gomez de Soto, J.-P. Pautreau et L. Uran : Deux épées à sphères du CentreOuest de la France, Aquitania, 4, 1986, p. 39-54. Une dernière partie consacrée au détail des analyses métallurgiques, réalisée en collaboration avec L. Uran qui a effectué ces recherches, devrait clore cette série d'études sur l'armement du second Age du Fer en Centre-Ouest.

Qu'il nous soit également permis de remercier pour leur aide : 0 . Buchsenschutz, Directeur de recherche au CNRS; G. Chalant, École nationale supérieure de Mécanique et d'Aérotechnique de Poitiers; P. Drugeon, propriétaire à .Valliers; C. Gendron, Conservateur des Musées de Niort; A. Rapin, Institut de Recherches archéologiques et paléométallurgiques de Compiègne; F. Ribemont, Conservateur des Musées de Vendée; et L. Uran, Institut universitaire de Technologie de Compiègne.

Les travaux de restauration ont èté confiés à l'Institut de Recherches archéologiques et paléométallurgiques de Compiègne, tandis que l'étude métallurgique fut réalisée au laboratoire de Métallurgie et de Physico-chimie des matériaux de l'université de Technologie de Compiègne sous la responsabilité de L. Uran.

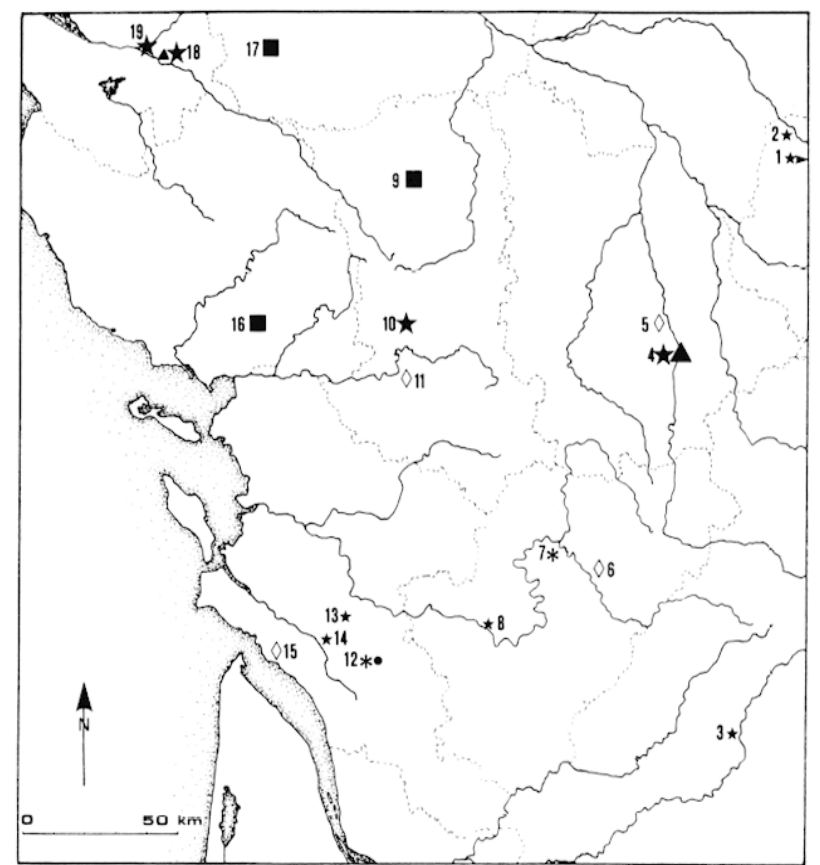

Epées $* 1 \star_{2}$ a 3 fourreau* Fers de lance $\Delta 1 \Delta 2$ a 3 Umbo $\bullet$

Dépot avec armement divers Mobilier métallique laténien autre $\nabla$

Fig. 1 - Les armes du second Age du Fer en Centre-Ouest:

1 - Palluau-sur-Indre (Indre)

2 - Châtillon-sur-Indre (Indre)

3 - Corgnac-sur-Isle (Dordogne)

4 - Mazerolles, Lussac-les-Châteaux (Vienne)

5 - La Croix de Laps, Civaux (Vienne)

6 - Les Perrats, Agris (Charente)

7 - Puyréaux, Mansle (Charente)

8 - Le Pont de Juac, Saint-Simon (Charente)

9 - Les Crânières, Faye-l'Abbesse (Deux-Sèvres)

10 - Les Mottes de Germond, Germond-Rouvre (DeuxSèvres)

11 - Le Pain Perdu, Niort (Deux-Sèvres)

1,2 - La Font-Barbot, Pons (Charente-Maritime)

13 - Tesson (Charente-Maritime)

14 - Saint-André-de-Lidon, Gémozac (Charente-Maritime)

15 - Le Moulin du Fà, Talmont (Charente-Maritime)

16 - L'llot-les-Vases, Les Serres, Nalliers (Vendée)

17 - La Ségourie, Le Fief-Sauvin (Maine-et-Loire)

18 - Le Pont-de-Louen, Goulaine (Loire-Atlantique)

19 - La Loire, Nantes (Loire-Atlantique)

Avant de présenter le mobilier, il nous faut apporter quelques précisions. Toutes les pièces ne sont pas encore restaurées; pour Nalliers, seules quatre épées l'ont été. Contrairement aux objets découverts à Faye-l'Abbesse, ceux provenant de Nalliers n'avaient reçu jusqu'ici aucun soin particulier. Ils se sont fortement détériorés sous l'action des agents de corrosion qui ont irrémédiablement ruiné la plus grande partie des surfaces originelles.

L'état fragmentaire d'un grand nombre de pièces doit nous inciter à la prudence quant aux considérations typologiques et chronologiques. Aucune des épées n'est intégralement conservée, deux 


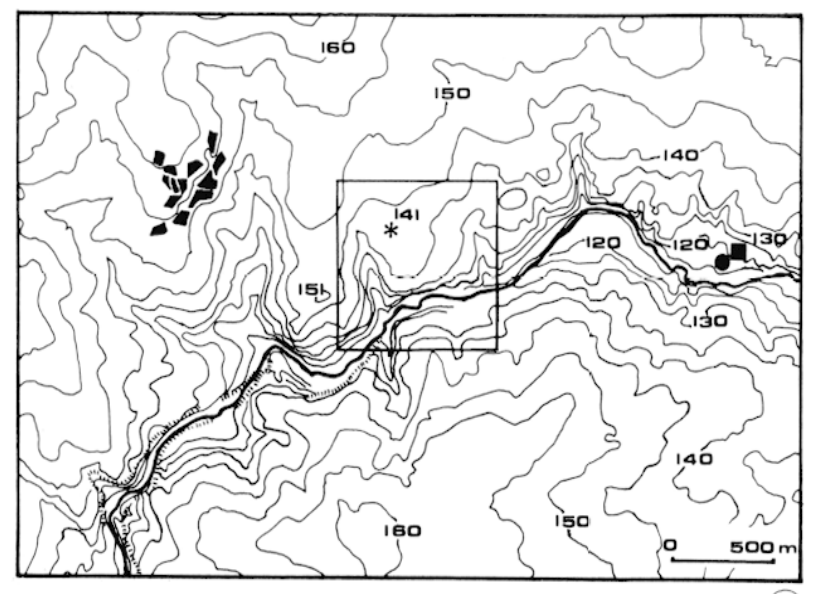

(a)

*Gisement des Crânières - Tumulus de la Fontenille

Dolmen: Pierre levée de la Fontenille

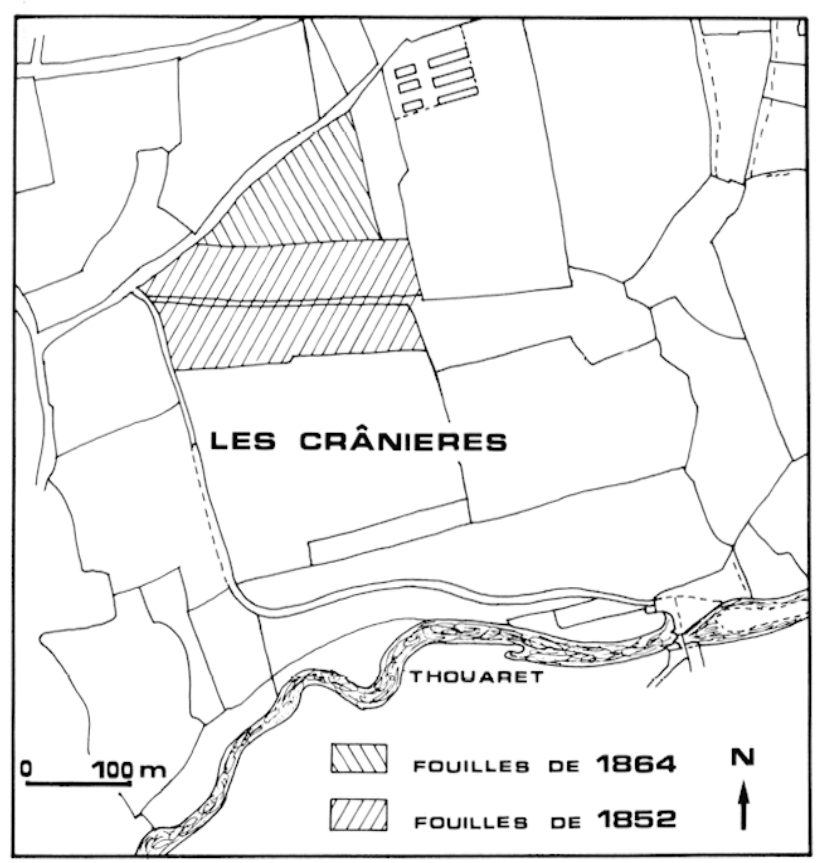

(b)

ont leur soie complète mais nous ne leur connaissons pas de croisière. Pour les fourreaux, les données sont encore plus aléatoires.

\section{L'ENSEMBLE PROTOHISTORIQUE DE FAYE- L'ABBESSE}

Non loin de Faye-l'Abbesse, au lieu-dit Les Crânières (fig. 2) un important complexe monumental gallo-romain fut mis au jour à partir de 1851 et fouillé sous l'égide de la Société de Statistique des Deux-Sèvres. Le rapport préliminaire publié en 1853 par deux sociétaires, L. Lunier et A. Monnet, est notre principale source d'information ${ }^{2}$.

2 Fouilles du sanctuaire : Lunier, Monnet, 1853; Bau-

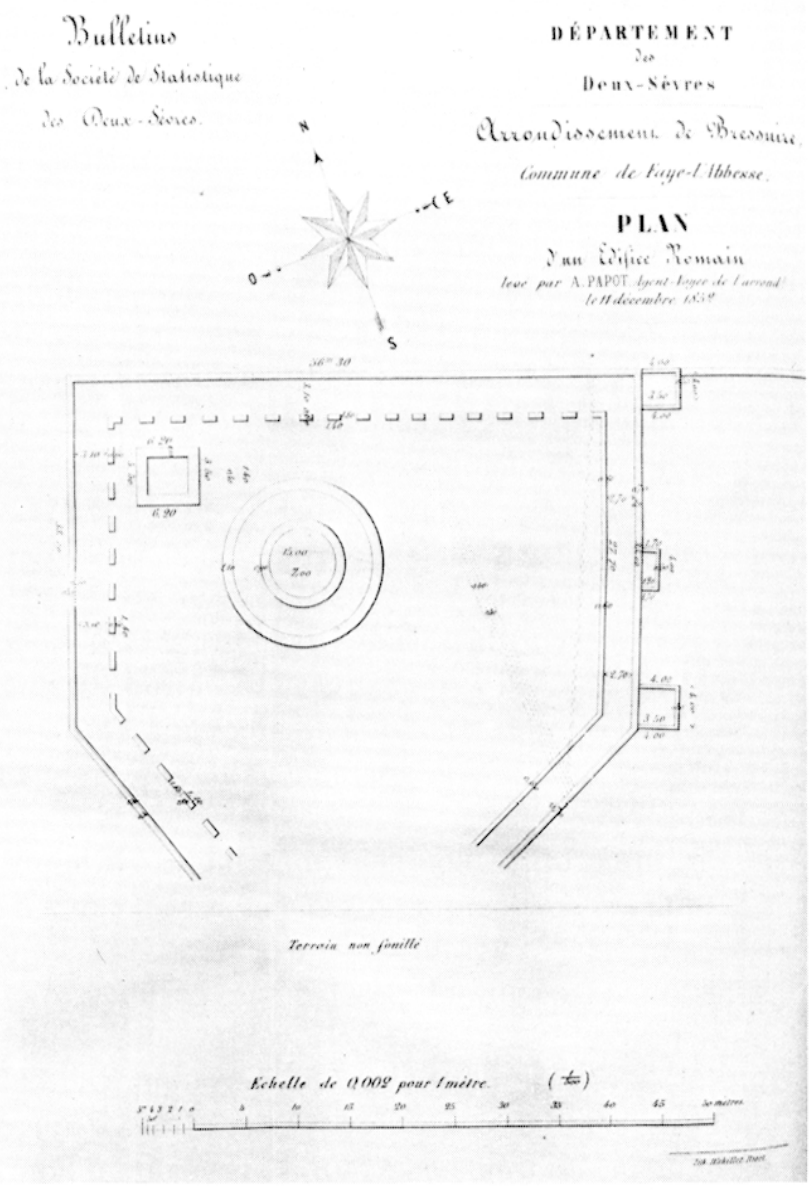

(C)

Fig. 2 - Le sanctuaire de Faye-l'Abbesse.

a, cadre topographique ;

b, relevé cadastral :

c, plan du sanctuaire, extrait de Lunier, Monnet, 1853.

gier, lettre manuscrite du 10.10.54, Archives départementales, Niort, 9 F $40 n^{\circ} 20$; Dumarest, correspondance, Archives départementales, Niort, $9 \mathrm{~F} 40$.

Fouilles du vicus : Touchard, Bulletin de la Société des Antiquaires de l'Ouest, 1841/43, p. 18-19 : In., Rapport sur la découverte d'une ville gallo-romaine aux Crânières près de Faye-l'Abbesse (Deux-Sèvres), Bulletin de la Société des Antiquaires de l'Ouest, 1851, p. 240-244; C. Barbaud, Bulletin de la Société de Statislique des Deux-Sèvres, 1864/66, p. 57-61.

Voir ègalement: G. Grrmond, De quelques découvertes archéologiques dans le bocage bressuirais, Bulletin de la Socièté historique el scientifique des Deux-Sèvres, 1968, p. 118-128; In., Inventaire des mégalithes de France : 6-Deux-Sèvres, $1^{\text {er }}$ suppl. à Gallia Préhistoire, Paris, Ed. du C.NRS, 1980, p. 67; ID., L'implantation humaine dans le quart nord-ouest du département des Deux-Sèvres aux premiers siècles de notre histoire, Bulletin de la Socièté historique et scientifique des Deux-Sèvres, 1982, p. 192-198 (l'auteur évoque en outre l'environnement archéologique du site: dolmen, tumulus, enceintes...); R. Delage, Le sanctuaire el le vicus de Faye-L'Abbesse, université de Poitiers, mémoire de Licence (dactylographiè), 1983. Voir aussi C. Gendron et J. Gomez de Soto, 1986. 


\section{LE GISEMENT ARCHÉOLOGIQUE}

Les fouilles de 1852 concernèrent exclusivement le sanctuaire qui se trouvait dans un champ nommé "Les Terres Noires», enregistré sous le numéro 541 de l'ancienne matrice cadastrale.

A l'intérieur d'une enceinte polygonale, furent découverts les soubassements d'un temple circulaire de $15 \mathrm{~m}$ de diamètre. Dans la cella de $7 \mathrm{~m}$ de diamètre, où la plupart des monnaies furent découvertes, plusieurs "excavations évasées, de $30 \mathrm{~cm}$ environ de profondeur" avaient été aménagées. Des fosses de ce genre ont souvent été rencontrées au sein d'ensembles cultuels d'époque romaine et préromaine; en Centre-Ouest, ces structures ont été identifiées à Sanxay dans la Vienne (Brunaux et alii, 1985, p. 90) et à Chassenon en Charente (Gendron, Gomez de Soto, 1986, note 4). Un bassin quadrangulaire, alimenté par un aqueduc, parachevait l'ensemble au nord-ouest.

Un important mobilier (métallique, lithique, céramique et ostéologique) fut découvert au cours de cette campagne. Les auteurs du rapport précisent que les objets ne furent pas trouvés en un seul et même endroit: "Les armes étaient presque toutes accumulées près des restes de murailles qui limitent à l'est les constructions découvertes. On a trouvé dans le même endroit beaucoup d'ossements d'hommes et d'animaux, et même des squelettes entiers dont les différentes pièces se touchaient encore. Malheureusement, presque tous ces ossements tombent facilement en poussière, et on ne peut guère en conserver que les extrémités". D'autre part, ils remarquent que tous les objets ne se rencontrent pas à la même hauteur et justifient leur constat par une description stratigraphique :

- couche superficielle : elle est essentiellement composée de terre végétale. Elle a livré des fragments de briques et de céramiques (épaisseur: environ $33 \mathrm{~cm}$ );

- couche 2 : elle se caractérise par une importante concentration de briques, de tuiles, de tessons de céramiques, d'enduits de béton, et de morceaux de tuf (ćpaisseur : $15 \mathrm{~cm}$ );

- couche 3: elle est constituée d'une terre noirâtre où se mêlent cendres, charbons et poussières calcaires. "C'est surtout dans la partie inférieure de cette couche que l'on a trouvé des médailles, des эrmes et des ossements" (épaisseur : environ $15 \mathrm{~cm}$ );

- "plus profondément encore... on rencontre dans quelques endroits une couche solide et épaisse de béton, et partout ailleurs la roche granitique».

A partir de ces affirmations, nous pouvons établir qu'il existait à proximitè du mur oriental de l'enceinte du sancluaire, dans l'un des niveaux anciens, un dépôt concentré dans une couche de faible épaisseur (une dizaine de centimètres tout au plus) mais dont on ignore l'étendue. Cet ensemble constitué d'armes (pas toutes semble-t-il), d'ossements (humains et animaux; les squelettes en connection anatomique appartenaient-ils à l'un ou l'autre, ou aux deux?) et de monnaies (gauloises?) rappelle des dépôts d'offrandes connus en d'autres lieux (Brunaux, 1986). La constitution de ce dépôt à même le sol est fort peu probable; l'hypothèse la plus vraisemblable est que le mobilier fut déposé en plusieurs phases - la présence d'objets anciens tels que les ceinturons métalliques et d'autres plus récents comme les monnaies ou l'agrafe de ceinturon plaident en ce sens - dans une structure creuse (fosse ou portion de fossé) non reconnue au moment de la fouille (Brunaux, 1984, p. 126).

Le mobilier métallique étant constitué uniquement d'armes, on souhaiterait connaître la provenance des autres objets tant en bronze qu'en fer (chaînons, anneaux, outils, clés, clous... doit-on inclure les couteaux dans l'armement?). L'absence de certitude quant au lieu d'origine des chaînes de suspension de fourreaux d'épée - il ne s'agissait que de chaînes pour les auteurs du rapport - est encore plus ennuyeuse. Ce silence est d'autant plus regrettable que ces ceinturons métalliques bipartis - un brin court d'une quinzaine de centimètres et un brin long d'environ cinquante centimètres -constituent, aux $\mathrm{II}^{\mathrm{e}}$ et. $\mathrm{II}^{\mathrm{e}} \mathrm{s}$, avant J.-C., une constante de l'équipement guerrier. A défaut d'éléments particulièrement sûrs pour la datation tels que fibules et fourreaux d'épée, les ceinturons métalliques font figure d'indicateur chronologique de première importance, pour la connaissance des phases d'occupations anciennes. Nous ne pouvons malheureusement affirmer qu'ils accompagnaient les armes comme nous pourrions nous $y$ attendre.

L'association d'objets en fer manifestement mutilés (torsion, bris, crantage...) et de restes d'individus probablement sacrifiés (un tibia fut découvert engagé dans l'un des anneaux d'une entrave) conforte les rapprochements que nous suggérions précédemment avec les dépôts de sanctuaires préromains du nord-est de la France. La destruction rituelle d'objets en fer est une pratique bien attestée au second Age du Fer; en Poitou, nous la rencontrons à Nalliers ainsi que dans l'ensemble sépulcral de Mazerolles (Nicolini, 1983).

La confrontation du mobilier avec le compte rendu de la campagne de 1852 révèle bien plus qu'une simple occupation protohistorique du site, 
elle suggère l'existence d'un sanctuaire préromain. Le fait que les fouilleurs n'en aient alors relevé aucune trace ne doit pas nous surprendre; recherchant les structures monumentales, il leur était difficile de mettre en évidence des structures antérieures dont il ne subsistait que le négatif (trous de poteaux, fosses, fossés). Lorsqu'ils le firent, ils ne surent pas les identifier. Les constats concernant la pérennité des aires cultuelles n'ont cessé de se multiplier, cependant la réutilisation d'un site consacré n'implique pas nécessairement la perpétuation des rites (Brunaux, 1984, p. 126-127). Seule la reprise des fouilles permettrait de préciser ce qui n'est que supposition en espérant que celles du $\mathrm{XIX}^{\circ}$ s. n'aient pas partout atteint la roche granitique.

Le produit des fouilles fut déposé au musée de la Socièté de Statistique des Deux-Sèvres à Niort; seuls, quelques objets des plus représentés furent laissés en dépôt à la mairie de Faye-l'Abbesse (ces derniers, dont nous ne savons rien, n'ont pu être retrouvés). La partie que nous présentons a récemment été retrouvée par C. Gendron, conservateur des Musées de Niort (présentée à Angoulême, 1984: Gendron, Gomez de Soto, 1986).

\section{LE MOBILIER}

Bien que nous ne connaissions pas le dénombrement exact du mobilier découvert à l'intérieur de l'enceinte du sanctuaire gallo-romain au cours de cette campagne (sauf en ce qui concerne le numéraire), nous pouvons affirmer que les objets dont nous disposons actuellement, soit un peu plus d'une cinquantaine de pièces, ne représentent qu'une infime partie de celui-ci.

Toutes les pièces comptabilisées n'appartiennent évidemment pas au dépôt préromain ; pour s'en convaincre, il suffira de considérer le grand couteau à lame ondulée (fig. 14, $\mathrm{n}^{\circ} 43$ ) et les hachettes (fig. 14, $\left.n^{\circ} 45\right)$. Dans cette description nous envisagerons uniquement le problème du mobilier métallique, bronze et fer, d'époque préromaine.

Il faut ajouter au mobilier cité par L. Lunier et A. Monnet le lot d'objets déposé en 1854 au musée de la Socièté par les soins de M. Baugier. L'auteur indique qu'il ne pût tout rapporter tant leur nombre était grand. Il donna sa préférence aux monnaies ainsi qu'aux pièces présentant de nouvelles formes : "40 ustensiles en fer, 13 armes en fer, 62 objets en bronze, 1 fragment de sculpture, 70 fragments de poterie, 1 fragment de bois de cerf, 1 hache en silex, 20 fragments de verre, 40 monnaies celtiques, 71 monnaies romaines".

\section{Chaînes de sUSPENSION DE FOURREAU D'ÉPÉE}

"Une trentaine de chaînes entières ou en morceaux, de toute grosseur et de toute dimension". En fait, ces chaînes sont des éléments de suspension de fourreau d'épée; 13 d'entre elles nous sont connues dont 7 brins courts (fig. 12).

ÉPÉES

- «4 épées romaines, dont deux sont encore dans le fourreau. Elles ont 65 à $80 \mathrm{~cm}$ de longueur et 3 à 4 de largeur;

- 2 épées plus longues, probablement des épées barbares, dont la longueur est de 1,20 m et la largeur de $4 \mathrm{~cm}$;

- 1 épée plus mince et plus flexible, à pointe mousse dont la longueur est de $1,10 \mathrm{~m}$ et la largeur de $3 \mathrm{~cm}$;

- 2 poignées d'épées".

Malgré la difficulté d'identifier les épées à l'une ou l'autre de ces catégories, il semble que nous possédions l'ensemble des exemplaires. D'autre part, nous ne pouvons pas négliger les dommages subis en un peu plus d'un siècle; en effet, les épées les plus longues (F.A. 1 et 4) ne mesurent pas plus de $810 \mathrm{~mm}$. Des fourreaux, nous ne connaissons que fort peu de choses puisque seule l'épée F.A. 5 en a conservé quelques vestiges. La plupart des lames présentent les marques de destructions volontaires et anciennes (bris, ployage, mutilations partielles des tranchants (fig. 3 et 4 ).

\section{FERS DE LANCE}

- «36 fers de lance, de toute forme et de toute grandeur. Il y en a de fort bien conservés. Les plus longs ont $30 \mathrm{~cm}$, et les plus courts 12 à 15 de longueur».

- " 2 fers de javelot, de $20 \mathrm{~cm}$ de longueur». Avec les onze fers de lance connus à ce jour, nous sommes bien loin du total (fig. 9). Ces armes fortement nervurées, à l'exception de deux d'entre elles, sont pour la plupart atypiques et présentent des marques de mutilations (destruction des tranchants). Les fers de javelot cités correspondent vraisemblablement à des spécimens à flamme étroite.

- 7 talons de lance, non mentionnés dans le descriptif, ont également été retrouvés. Le plus gros de ces talons qui sont tous à soie, mesure près de $180 \mathrm{~mm}$ (soie : $80 \mathrm{~mm}$ ) et se caractérise par une section polygonale d'un diamètre d'environ $40 \mathrm{~mm}$. Deux d'entre eux montrent une torsion de la soie qui pourrait être en rapport avec le sacrifice de l'arme. Nous ne pouvons assurer avec certitude l'appartenance à cette catégorie du mobilier de deux 
exemplaires de petite taille non inventoriés (fig. 9, $\left.\mathrm{n}^{\mathrm{os}} 27,28\right)$.

\section{CouteauX et HaCHETtes}

"7 couteaux et hachettes de différentes formes».

Deux couteaux sont connus : l'un est à douille (fig. 14, $\mathrm{n}^{\circ} 44$ ) tandis que le second, beaucoup plus grand, est à soie et à lame ondulée (fig. $14, \mathrm{n}^{\circ} 43$ ). Ce dernier est très certainement d'époque romaine (Lintz, Vuaillat, 1984).

Les deux hachettes peuvent être comparées à celles du sanctuaire gallo-romain de Flavier à Mouzon dans les Ardennes (Tisserand, 1980, p. 63 et 73).

\section{MOBILIER DIVERS}

- «2 entraves, l'une d'elles est si bien conservée, que les différentes pièces sont encore mobiles".

- «3 chaînons, 5 anneaux duubles, 25 anneaux simples». Peu de ces objets nous sont parvenus (fig. $14, \mathrm{n}^{\mathrm{os}} 46,47$ ).

- " 2 bracelets grossiers en fer». Il s'agit en fait de deux bagues servant au raccord des conduites d'adduction d'époque romaine.

- "4 entrées de serrures, 2 clefs». L'une des clefs est conservée et restaurée.

- «1 poignée de porte, 1 loquet, 1 romaine, 15 poids de romaines, 1 compas, 1 mèche de menuisier, 3 ou 4 instruments de jardinage». La poignée de porte désigne vraisemblablement une anse d'œnochoé en bronze d'époque romaine; elle est ornée d'une superposition de personnages. Les collections du Musée ont également livré une serpe avec appendice, une faucille et une paire de forces qui ont èté restaurées.

Les auteurs mentionnent aussi une grande quantité de clous : "une quantité considérable de clous, de 6 à $12 \mathrm{~cm}$ de longueur. Leur usage a toujours été le même; il n'est donc point étonnant qu'on en trouve presque partout, et cela surtout dans la couche la plus profonde", ainsi que "beaucoup d'autres objets en fer, dont nous n'avons pu déterminer la nature". L'agrafe de ceinture (fig. 12, $n^{\circ} 42$ ) devait probablement compter au nombre de ces derniers.

\section{MOBILIER EN BRONZE}

L'anse en bronze mise à part, le site a produit une autre pièce du même métal tout à fait exceptionnelle. Il s'agit d'un bronze creux figurant un sanglier. Cette pièce encore inédite pourrait correspondre au "fragment de cimier de casque en bronze ou quelque chose d'analogue" cité par Lunier et Monnet. Ces auteurs parlent également de " 4 ou 5 agrafes en bronze, dont quelques-unes fort bien conservées", de " 2 cachets sans pierre", "d'un petit pied en bronze, d'une forme très gracieuse", ainsi que de "plusieurs autres objets en bronze, dont l'usage nous est inconnu". A ces pièces qui ne sont autrement connues, il faut ajouter un fragment de bouterolle en bronze (fig. $14, \mathrm{n}^{\circ} 48$ ) retrouvé avec les brins courts de chaines de suspension de fourreau d'épée.

\section{ÉPÉES : DESCRIPTION}

Les dimensions des épées sont données en millimètres.

\section{ÉPÉE F.A. 1 (fig. $3, \mathrm{n}^{0} 1$ ) \\ Longueur : 809.}

Soie : longueur : 54, largeur : 7, épaisseur : 3 à 4 .

Lame: largeur de la garde: 36 , largeur: 34 , épaisseur : 4 à 5 .

L'épée, brisée et ployée aux deux extrémités, se singularise par l'étonnant contraste qui existe entre sa longueur (supérieure à $800 \mathrm{~mm}$ ) et sa section, mince et étroite.

Les tranchants de la lame, dont la section est biconvexe, sont parallèles, sauf à la hauteur de la garde, légèrement plus large. La soie de frêles dimensions est effilée et de section quadrangulaire.

L'épée s'avère, de par sa morphologie, être un instrument extrêmement fragile.

ÉPÉE F.A. 2 (fig. $3, \mathrm{n}^{\circ} 2$ )

Longueur : 713 .

Soie : largeur à la cassure : 13 .

Lame : largeur : 43 à 47, épaisseur : 5 à 6 .

Incomplète, cette épée n'a ni extrémité distale ni soie dont seul subsiste le départ. La lame aux tranchants parallèles et de section biconvexe (losangée dans la partie proximale) devait mesurer au moins $800 \mathrm{~mm}$.

ÉPÉE F.A. 3 (fig. $3, \mathrm{n}^{\circ} 3$ )

Longueur : 486.

Soie : longueur : 120, largeur: 12, épaisseur: 6 , diamètre de l'extrémité sommitale : 16 .

Lame : largeur : 46, épaisseur : 7.

La lame, contrairement à la soie, n'est que partiellement conservée. Les bords, rongés par la corrosion, sont singulièrement amoindris aux deux endroits qui correspondent à des pliures d'origine probablement accidentelle.

La lame est de section biconvexe. Les tranchants peuvent être considérés, d'après ce qu'il en subsiste, comme parallèles. La soie, intacte offre une 
ARMES DE SANCTUAIRES POITEVINS

(1)

(2)

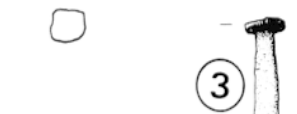

(4)
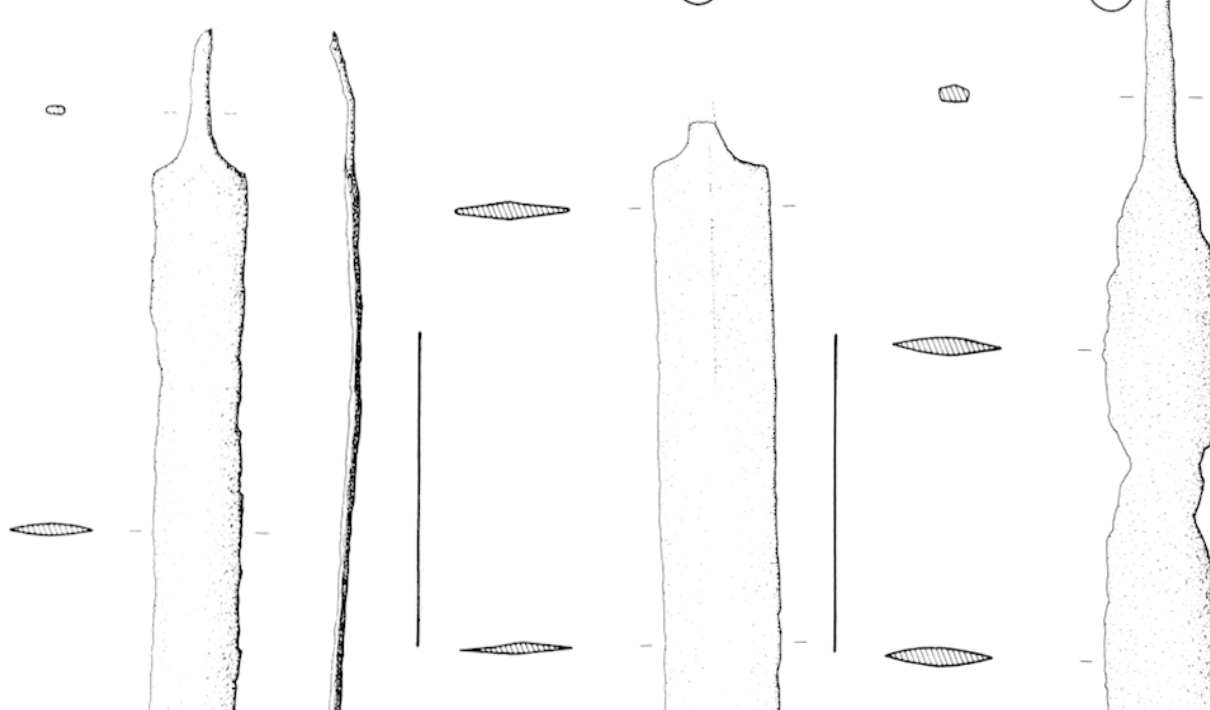


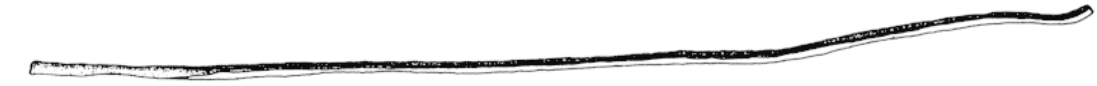

(a)

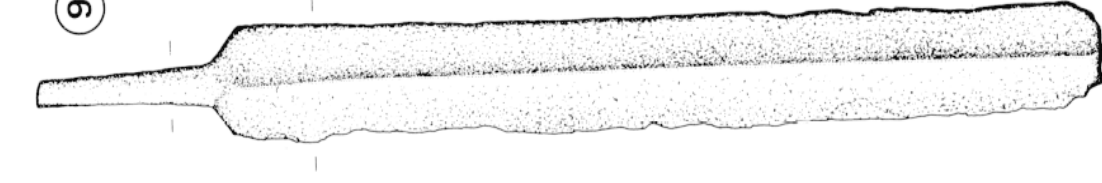

()

自

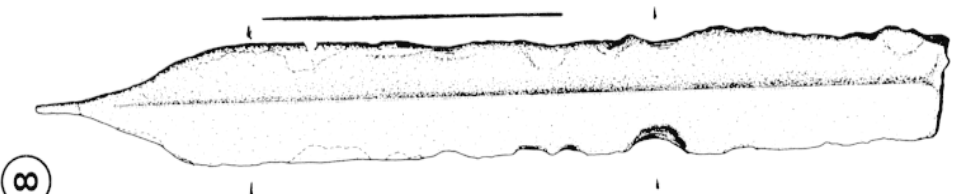

5

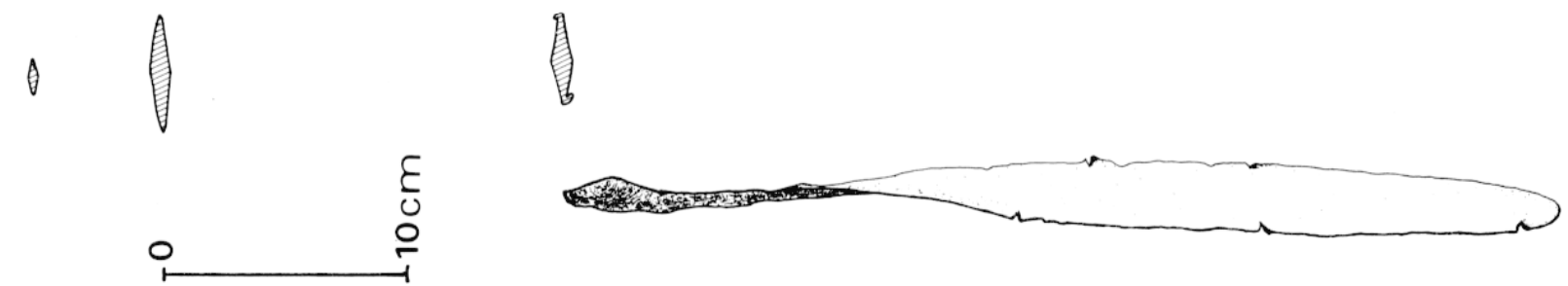

(N)

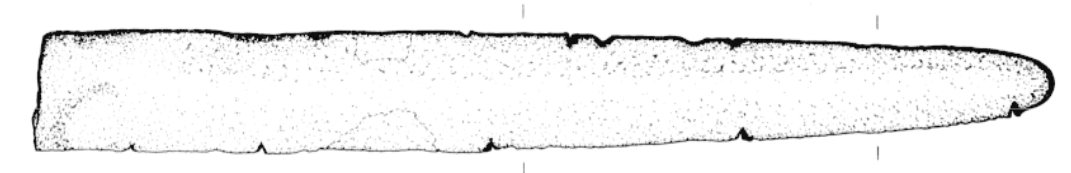

(0)
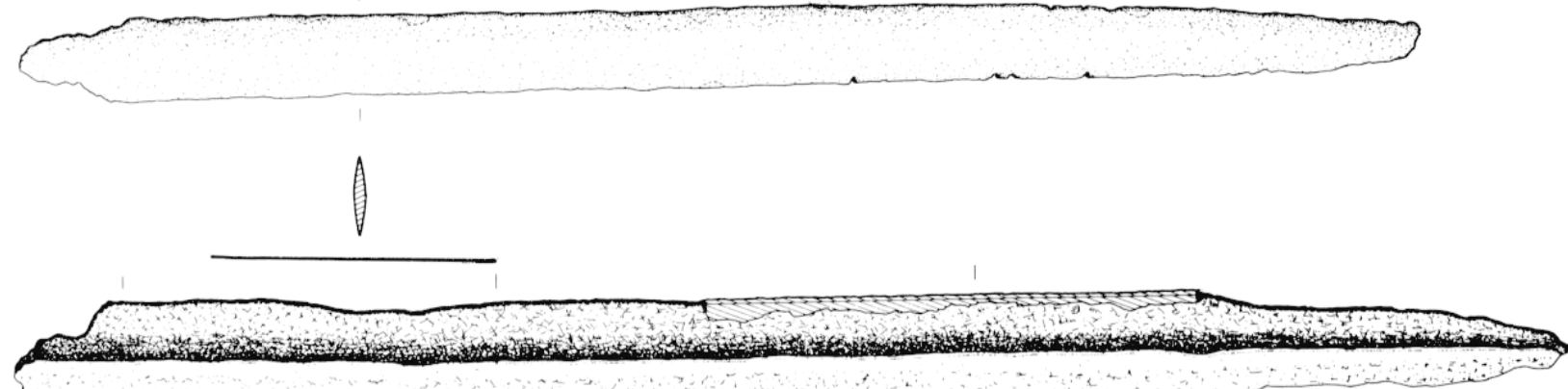

(1)

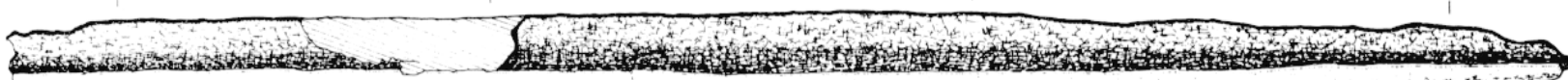

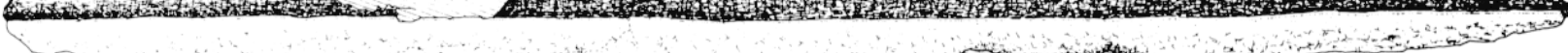<smiles>C=CC=C</smiles><smiles>C=CCCCCCCCCCCCCCCCCCCC</smiles> 
section sensiblement quadrangulaire, avec sur l'une des faces une légère arête médiane. Effilée, elle s'évase et se fond avec la lame pour former la garde. La différence de largeur constatée en ce point peut être interprétée avec vraisemblance comme la marque d'un épaulement usé. L'extrémité sommitale de la soie s'achève en un large bouton obtenu par écrasement.

\section{ÉPÉE F.A. 4 (fig. $3, \mathrm{n}^{\circ} 4$ )}

Longueur : 810.

Soie : longueur : 63 , largeur : 9 , largeur de l'épaulement : 27 , épaisseur : 4.

Lame : largeur de la garde : 33 , largeur moyenne : 29 à 30 , épaisseur : 4 .

Cette arme dont l'extrémité distale ne nous est pas connue, a partiellement conservé sa soie. Relativement frêle, cette dernière s'évase pour former la garde, tout en ménageant dc part et d'autre un épaulement. La lame, longue et étroite, a une section biconvexe et des tranchants parallèles. La soie qui est brisée, a été ployée comme la lame.

ÉPÉE F.A. 5 (fig. $4, \mathrm{n}^{\circ} 5$ )

Longueur : 652 , largeur maximale : 46 , épaisseur : 7 à 9 .

Tôle du fourreau : épaisseur : 1,5 à 2 .

Cette arme incomplète, dont il ne subsiste que la lame et quelques fragments du fourreau, appartient au lot des plus anciens objets de cet ensemble. Dégradée et mutilée par un ployage récent - à $260 \mathrm{~mm}$ de l'extrémité la plus large - l'épée a été restituée dans sa forme primitive; les tranchants également endommagés ont été partiellement restaurés.

La lame de section losangée est de largeur sensiblement constante. Contrairement aux apparences, il semble que l'extrémité la plus étroite corresponde à la partie proximale. En effet, l'épaisseur de la lame est trop importante pour qu'il s'agisse de la pointe.

Le fourreau se compose de deux tôles de fer; l'une des plaques se rabattant sur l'autre de manière à former deux gouttières latérales pour assurer le sertissage de l'étui.

ÉPÉE F.A. 6 (fig. 4, $\mathrm{n}^{\circ} 6$ )

Longueur : 585 , largeur maximale : 32 à 33 , épaisseur : 3 à 5 .

C'est une arme incomplète, n'ayant ni extrémité proximale ni extrémité distale. La lame effilée, étroite et de section biconvexe, se différencie des autres exemplaires de ce site. La radiographie et la restauration ont permis de mettre en évidence plusieurs marques attestant la mutilation intentionnelle de l'objet (crantage); le léger ployage affectant la lame résulte probablement d'un acte accidentel.

ÉPÉE F.A. 7 (fig. $4, \mathrm{n}^{\circ} 7$ )

Longueur : 409, largeur à la cassure : 44, largeur à $155 \mathrm{~mm}$ de la pointe : 40, épaisseur : 4 .

Il ne subsiste que l'extrémité distale. La lame de section biconvexe tend à s'effiler et sa pointe, sans être aiguë, se profile en ogive. Ce fragment de lame reflète plusieurs procédés de mutilation : les tranchants ont été crantés ou plus simplement déformés tandis que la lame a été brisée consécutivement à plusieurs ployages et torsions.

ÉPÉE F.A. 8 (fig. $4, \mathrm{n}^{\circ} 8$ )

Longueur : 370 .

Soie : longueur : 55 , largeur minimale : 4, largeur maximale : 22, épaisseur : 4.

Lame : largeur : 45 à 48, épaisseur : 7 à 9 .

Épée incomplète. Il ne subsiste que l'extrémité proximale et une infime partie de la soie. La section de la lame est losangée. L'épée a été brisée après avoir été pliée. Les tranchants présentent les marques de nombreuses mutilations (bords partiellement pliés dans un sens ou un autre). La pliure de la soie est, en revanche, de date récente.

ÉPÉE F.A. 9 (fig. $4, \mathrm{n}^{\circ} 9$ )

Longueur : 432.

Soie : longueur : 80 , largeur : 10 à 15 , épaisseur : 4 à 5 .

Lame : largeur : 44, épaisseur : 5 .

Épée incomplète, de section losangée. La soie partiellement conservée, est de section quadrangulaire. La lame est légèrement ployée dans sa partie inférieure et plus particulièrement à la hauteur de la cassure.

\section{L'ENSEMBLE PROTOHISTORIQUE DE NALLIERS (VENDÉE)}

La localité de L'Ilot-les-Vases (commune de Nalliers) connue de longue date pour ses "dépôts de cendres" et ses vestiges gallo-romains, a révélé au siècle dernier l'existence d'un ensemble du second Age du Fer. A peu près ignoré depuis sa publication en 1865 par B. Fillon, il connait aujourd'hui à la lumière de la redécouverte de Faye-l'Abbesse un regain d'intérêt. Les armes mises au jour, au gré des labours, depuis une quinzaine d'années permettent 

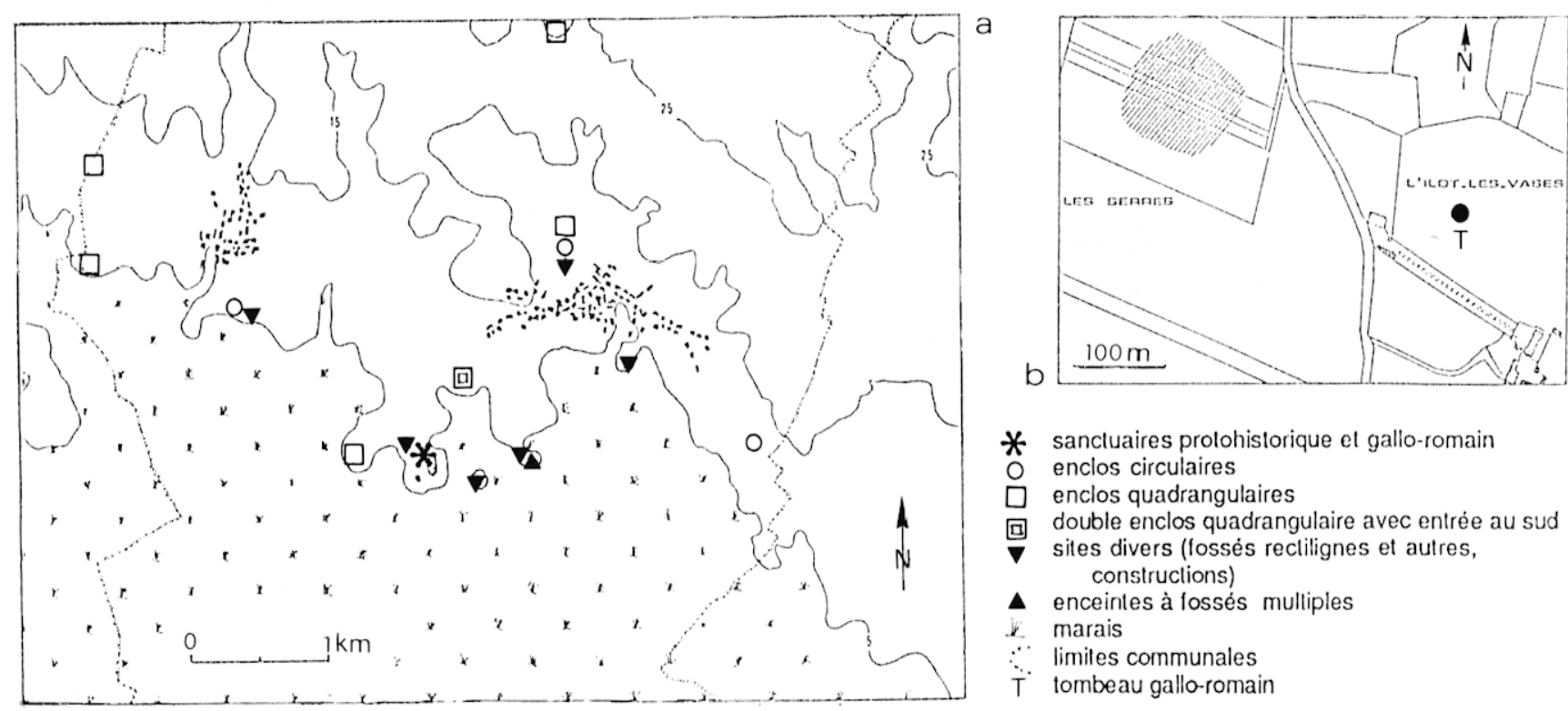

Fig. 5 - Nalliers. a, inventaire des principaux sites repérés par photographie aćrienne (d'après Marsac, 1975); $b$, plan cadastral avec, en hachuré, la localisation approximative du gisement.

de situer plus précisément ce gisement dans un lieu contigu à la ferme de L'Ilot-les-Vases appelé Les Serres. Ce site qui borde au nord le marais repose directement sur le plateau calcaire légèrement surélevé en cet endroit. Les prospections aériennes menées ces deux dernières décennies y ont révélé l'existence d'un important ensemble monumental d'époque romaine qu'il serait tentant d'identifier à un sanctuaire (fig. 5$)^{3}$.

3 B. Fillon et 0 . de Rochebrune, 1862/87; C. Gendron et J. Gomez de Soto, 1986, note 13. Pour les "dépôts de cendres", voir bibliographie dans A. Villard, 1983.

En dépit de sa notoriété de faussaire, il ne semble pas que B. Fillon ait falsifiè dans le cas présent. Pour s'en convaincre il suffit de se référer aux descriptions de l'auteur qui ne sut ni interpréter ni comprendre l'intérêt de la découverte, ainsi qu'aux nombreuses trouvailles faites depuis le siècle dernier sur le site et ses environs immédiats : F. Fygun, Arts des Pays d'Ouest, 1965, p. 8, app. 1. Le site localisé par la seule indication "dans un champ situé au sud-ouest du bourg" correspond indubitablement au lieu-dit de l'llot-les-Vases/Les Serres où furent fortuitement trouvés plusieurs fragments d'épées au cours des dernières décennies. A l'occasion d'une communication sur les "dépôts de cendres", B. Fillon fait état de la découverte d'armes en ce lieu : B. Filıon, communication au Congrès Archéologique de France, XXXI" session, Fonienay-le-Comte, 1864, p. 297. Cet ensemble s'intègre aux collections mises au jour depuis le siècle dernier: haches en bronze; tesson décoré du Bronze final IIIb, J.-P. Pautreau, C. Gendron et J. Gomez. DF. Soto, Une figuration anthropomorphe hallstattienne à l'llot-les-vases, commune de Nalliers, Vendée, Revue du Bas-Poitou, 1972, p. 247-250; bracelet à tampons ornés d'incisions concentriques de la fin du premier

\section{LE GISEMENT ARCHÉOLOGIQUE}

En 1857, M. Auger mit au jour dans un champ au sud-ouest du bourg, les vestiges de constructions dites "romano-gauloises". Il découvrit auprès des restes "d'une assez grande habitation... les assises inférieures d'une petite chambre carrée, dont les côtés avaient environ $4 \mathrm{~m}$ \%. A l'intérieur de ce périmètre fut exhumé un important mobilier métallique composé d'armes et d'ustensiles. Cependant, l'absence de céramique dans ce dépôt surprit Fillon et Rochebrune pour qui la destination funéraire de l'ensemble ne faisait aucun doute.

Le mobilier est brièvement décrit en fonction des différents types, à l'exception de certains objets dont la finalité ne put être déterminée. Le nombre des épées, dont on ignore le chiffre exact, s'élevait à

Age du Fer (des exemplaires identiques ont èté retrouvés à Port-d'Envaux en Charente-Maritime et à Biganos en Gironde) J.-P. Pautreau, 1984, p. 3 ; céramiques à pâte noire provenant des fouilles du marais de 1880, Musée des Sables-d'Olonne, ancienne collection du Dr. Baudouin (Dr. Baudouin, Collections préhistoriques, catal. II, vol. II (manuscrit) 1918, p. 4445).

A ces découvertes, il faut joindre les données de la prospection aérienne qui a permis de déceler de nombreuses structures sur l'ensemble de la commune : enclos circulaires et quadrangulaires de petites et grandes tailles, fossés, fosses et diverses traces de constructions; M. Marsac, Inventaire archéologique par photographie aérienne des abords du golfe des pictons (région nord-est), diplôme de l'EPHESS, Paris, 1975; In., Vendée, prospection aérienne autour du golfe des Pictons, Dossiers de l'Archéologie, 22, 1977, p. 32. 
plus d'une vingtaine. L'auteur les distingue en quatre groupes illustrés par "plusieurs exemplaires".

Nous avons donc à Nalliers comme à Fayel'Abbesse, un dépôt d'objets métalliques où l'armement tient une place de premier ordre. L'abondance de ce matériel et l'absence d'ossements et de céramiques annihilent l'hypothèse du dépôt funéraire. Il ne s'agit pas non plus d'une incinération, puisqu'il n'a été remarqué ni cendres ni fragments osseux calcinés, contrairement à une sépulture découverte en 1859 à proximité de L'Ilot-les-Vases et présentée dans le même article. La présence d'éléments caractéristiques de La Tène moyenne, tels que les ceinturons métalliques, infirme d'autre part la datation du $\mathrm{IV}^{\mathrm{e}} \mathrm{s}$. de notre ère avancée par B. Fillon.

L'antériorité du mobilier sur le monument, qui reste à définir, paraît maintenant bien assurée. Cependant, nous ne savons rien de la situation des objets à l'intérieur de l'édifice - étaient-ils étalés sur l'ensemble de la surface ou concentrés en un ou plusieurs endroits? proviennent-ils tous d'un même niveau? - ni des liens existant entre eux et la construction qui éventuellement, pourraît être identifiée à la cella d'un temple de type fanum. Nous pouvons supposer, en raison de la fragilité du métal, que les objets, trouvés en assez bon état de conservation, n'ont pas été déplacés. Le mobilier qui se trouvait vraisemblablement «à l'intérieur de structures creuses (fosses ou fossés)" non reconnues, fut intégré fortuitement ou non au bâtiment galloromain. Toutefois, seule une reprise des fouilles apporterait un élément de réponse. La découverte de plusieurs épées, il y a une dizaine d'années, par C. Gendron, en prouverait au besoin l'intérèt.

A Nalliers comme à Faye-l'Abbesse, les objets ont presque tous été mutilés volontairement: "la plupart des armes et pièces de harnachement avaient été mises hors de service... Beaucoup nous sont venues cassées, ébréchées, martelées ou tordues, après avoir été passées au feu ".

Par conséquent, il est probable que nous soyons ici en présence d'un sanctuaire préromain à l'instar de Faye-l'Abbesse, dont l'unique témoin serait le mobilier déposé rituellement. Les modalités et les circonstances de ce ou ces dépôts, non comprises à l'époque de la découverte, nous sont à ce jour complètement inconnues. Cette hypothèse calquée sur des exemples plus ou moins identiques du nord-est de la France n'a rien doriginal, mais demande simplement à être vérifièe. Une autre éventualité pourrait être envisagée si cet ensemble était considéré comme un dépôt fermé se présentant sous la forme d'une masse compacte, essentiellement composé de produits utilitaires en fer comme pour le célèbre "Massenfund" de Tiefenau en Suisse (Muller, 1986).

\section{LE MOBILIER}

Les renseignements concernant la découverte sont vagues et aléatoires. B. Fillon avoue ne pas connaître les circonstances exactes de la découverte et spécifie que les objets furent "rétablis dans leur état primitif " par l'aquafortiste 0 . de Rochebrune, sur la planche qu'il dessina, afin d'être plus suggestifs. La reconstitution de ces objets qui n'avaient alors pas encore trop souffert de la corrosion, ne va pas sans poser quelques problèmes pour certaines pièces comme les épées. Nous pouvons nous interroger sur la valeur d'une détermination des longueurs au centimètre près alors que les lames sont qualifiées des termes "brisées" et "recoupées». Malgré ces légèretés, ce document s'avère des plus précieux pour la connaissance du mobilier de ce site (fig. 6).

Les objets qui étaient en relativement bon état à l'époque de la découverte, aux dires de l'auteur, ont, faute de soins, énormément souffert du temps et des conditions de conservation. Leur identification compliquée par leur état actuel fortement dégradé, est bien souvent difficile (contrairement à ceux de Faye-l'Abbesse, ils n'ont pas été enduits de vernis et seules les pièces contenant suffisamment de métal comme les chaînes et les anneaux ont pu être correctement préservées). D'autre part, le mélange de découvertes anciennes de différentes provenances (Nalliers, Le Bouillé-Courdault, Le Langon...) ne nous permet pas d'identifier toutes les pièces; les plus litigieuses n'ont pas été prises en compte.

L'inventaire effectué lors de la publication semble concerner uniquement le mobilier du dépôt. En dépit de sa brièveté et de ses nombreuses lacunes, il est possible d'y reconnaitre certains des objets conservés au Musée de Fontenay-le-Comte.

Comme l'avaient précédemment fait Lunier et Monnet pour les trouvailles de Faye-l'Abbesse, B. Fillon a préféré signaler les principaux types plutôt que de réaliser un calalogue exhausif.

\section{ÉPÉES}

"1 - Épée (fig. 6, n 20). Lame mince, avec arête médiane, la pointe recoupée à environ $0,12 \mathrm{~m}$ de son extrémité. Pommeau de cuivre rond et uni, en forme de bouton (fig. $6, \mathrm{n}^{\circ} 20 \mathrm{bis}$ ). Longueur totale : $0,86 \mathrm{~m}$; largeur : $0,042 \mathrm{~m}$, au talon. La soie triangulaire est longue de $0,115 \mathrm{~m}$. Plusieurs exemplaires.

2 - Lame d'épée brisée et repliée sur elle-même (fig. $6, n^{\circ} 21$ ). Elle est de forme analogue à la 


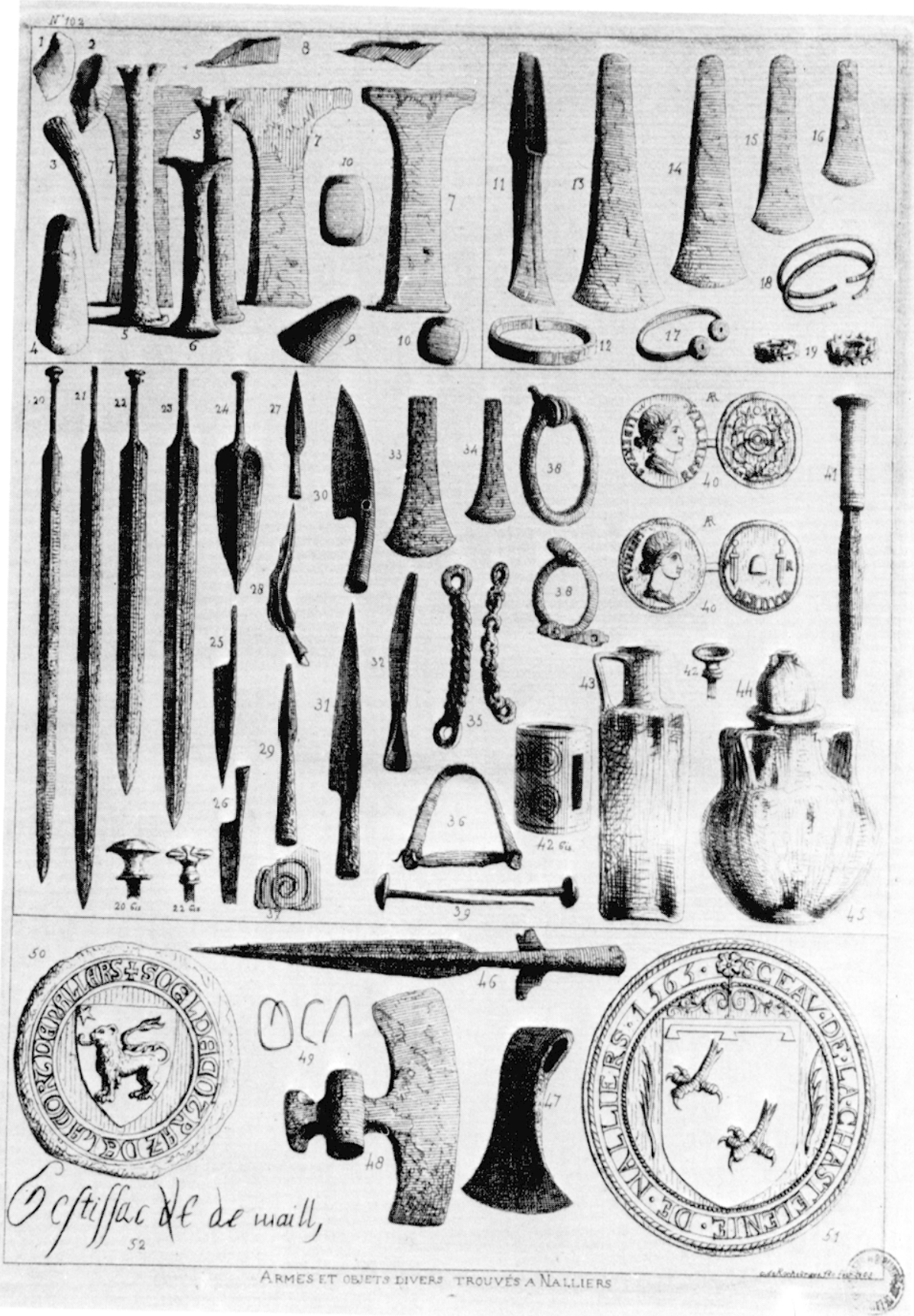

Fig. $6-$ Valliers : armes et objets divers, gravure extraite de Fillon, Rochebrune, 1862-1887.

précédente. Longueur : $0,91 \mathrm{~m}$; largeur : $0,041 \mathrm{~m}$. Plusieurs exemplaires.

3 - Épée de ceinture (fig. 6, n" 22). Lame plus épaisse que celle des armes précédentes, allant en diminuant dans toute sa longueur: arête peu saillante; pointe recoupée; pommeau en forme de fleuron (fig. 6, $\mathrm{n}^{\circ} 22 \mathrm{bis}$ ). Longueur : $0,63 \mathrm{~m}$; largeur : 0,046 m. Plusieurs exemplaires. L'une de ces épées a été mise en terre avec son fourreau.

4 - Épée de ceinture (fig. 6, $\mathrm{n}^{\circ}$ 23). Lame encore plus lourde et plus large que celle qui vient d'être décrite. Côte saillante dans toute sa longueur; pointe recoupée à une certaine hauteur. La soie ronde est brisée. Longueur : $0,71 \mathrm{~m}$; largeur : $0,052 \mathrm{~m}$. Plusieurs exemplaires".

L'identification des épées à l'une ou l'autre de ces catégories s'avère des plus difficile. Que faut-il penser des propos tels que "la pointe recoupée à environ $0,12 \mathrm{~m}$ de son extrémité", "la soie triangulaire" ou "pommeau de cuivre rond et uni en forme de bouton ... ou de fleuron"? Cependant, le texte a le mérite de décrire l'état des objets (pointe recoupée ou lame d'épée brisée et repliée sur elle-même) et de préciser certains détails que les armes ne fournissent 
plus ou que très partiellement (fourreau, arête médiane plus ou moins saillante). Les nervures qui sont toujours sensibles sur les parties proximales des lames Nal. 1 et 2 (fig. $7, n^{o s} 1,2$ ) se retrouvent nettement sur les armes trouvées par C. Gendron (fig. $8, \mathrm{n}^{\mathrm{os}} 1,2$ ); ces dernières présentent également des marques de mutilation. Les pommeaux de cuivre qu'ils soient ronds ou en fleuron, n'ont pas été retrouvés. Plutôt que d'une simple falsification, il peut s'agir d'une restitution abusive d'éléments oxydés; en effet, la soie d'une épée de La Tène finale provenant de Leiden aux Pays-Bas est coiffée d'un cabochon campaniforme en bronze (Verwers, Ypey, 1975 , p. 82).

Plusieurs fragments de lames, dont une ou deux extrémités distales et proximales, ont été retrouvés (fig. $7, \mathrm{n}^{\mathrm{os}} 4$ à 7 ).

\section{Poignards et couteaux}

«5- Poignard (fig. 6, n ${ }^{\circ} 24$ ). Lame tranchante des deux côtés, ayant une côte saillante qui va en diminuant du talon à la pointe. Longueur de la soie : $0,092 \mathrm{~m}$; de la lame : $0,22 \mathrm{~m}$; largeur au talon : $0,064 \mathrm{~m}$.

6 - Autre poignard brisé. La lame ne présente point de côte saillante. Pointe renforcée. Longueur de la lame : $0,20 \mathrm{~m}$; largeur : $0,068 \mathrm{~m}$.

7 - Couteau aigu ou secespita (fig. 6, no 25). Lame renforcée du côté du talon. Longueur : $0,13 \mathrm{~m}$; largeur : $0,029 \mathrm{~m}$.

8 - Autre couteau (fig. $6, \mathrm{n}^{\circ} 26$ ). La soie est large et plate. Lame de $0,10 \mathrm{~m}$ de longueur».

Seule, la pièce $\mathrm{n}^{0} 7$ a pu être retrouvée et identifiée; il s'agit en définitive d'une branche de force qui a éventuellement servi comme couteau (fig. 15, $n^{\circ} 29$ ).

\section{FERS DE LANCE}

"9 - Fer de javelot (fig. 6, n ${ }^{\circ} 27$ ). Sans arête médiane. Longueur : 0,19 m. La douille en partie brisée devait être plus longue. Plusieurs exemplaires.

10 - Fer de javelot de forme allongée (fig. 6 , $\mathrm{n}^{\circ}$ 28). Arête médiane très saillante. Longueur : $0,24 \mathrm{~m}$. Il a été tordu et martelé pour être mis hors service.

11 - Fer de javelot de moindre dimension (fig. 6, $\mathrm{n}^{\circ}$ 29). Arête médiane saillante; renflement près de la douille, qui a $0,12 \mathrm{~m}$ de longueur. La pointe a $0,10 \mathrm{~m}$.

12 - Autre semblable, mais un peu moins grand. Plusieurs exemplaires".

Contrairement aux cas précédents, nous sommes en mesure d'identifier nos fers de lance aux types cités ci-dessus : le 10 (fig. $6, n^{\circ} 28$ ) n'est autre que l'exemplaire de la fig. $10, \mathrm{n}^{\circ} 11$, le 9 (fig. 6, $\mathrm{n}^{0} 27$ ) celui de la fig. $10, n^{\circ} 8$, ceux de la fig. $10, n^{\text {os }} 9$ et 10 s'apparentent aux 11 et 12 (fig. $6, \mathrm{n}^{\circ} 29$ ).

\section{USTENSILES TRANCHANTS}

"13 - Ustensile de campement, ou sorte de dolabre analogue à celle dont se servaient les victimaires (fig. $6, \mathrm{n}^{\circ} 30$ ). Longueur : 0,26 m.

14 - Autre ustensile à douille plus large.

15 - Ustensile de campement en forme de coutelas avec douille (fig. 6, $\mathbf{n}^{\circ} 31$ ). Longueur : $0,29 \mathrm{~m}$.

16 - Autre analogue (fig. $6, n^{\circ} 32$ ), n'ayant que $0,18 \mathrm{~m}$ de longueur".

Plusieurs de ces instruments ont été retrouvés dont le 13 (fig. $6, \mathrm{n}^{0} 30$ ), non figuré parce que très certainement d'époque romaine; l'exemplaire 15 (fig. 6, no 31 ) n'a pas conservé sa douille (fig. 15, $\left.\mathrm{n}^{\circ} 24\right)$.

\section{HACHETTES}

"17 - Hachette sans douille, rappelant celles de l'Age du Bronze, gravées aux $\mathrm{n}^{\mathrm{os}} 13$ à 16 de la planche (fig. $6, \mathrm{n}^{\circ} 33$ ). Longueur : $0,17 \mathrm{~m}$.

18 - Hachette plus petite (fig. 6, $\mathrm{n}^{\circ} 34$ ). Longueur : 0,13 m».

Ces objets que nous supposons en fer n'ont pu être retrouvés. Ne connaissant pas d'ustensiles semblables pour la période considérée, on peut envisager une erreur d'interprétation comme pour les "gourmettes de mors de chevaux".

\section{Plaques DE BRONZE}

"19 - Fragments de lames de cuivre, avec clous rivés et ornements estampés en forme de volute, paraissant avoir fait partie d'une cuirasse (fig. 6 , $\left.\mathrm{n}^{\circ} 37\right)$ ».

Deux de ces fragments nous sont parvenus (fig. $15, \mathrm{n}^{\text {os }} 36,37$ ). Le second est bombé et porte encore les rivets sur l'un des bords, le premier est orné de motifs géométriques.

\section{ChaÎNES DE SUSPENSION DE FOURREAU D'ÉPÉE}

"20 - Huit gourmettes de mors de chevaux (fig. $6, \mathrm{n}^{\circ} 35$ ). Leur longueur varie de 0,12 à $0,15 \mathrm{~m}$ ".

Ces chaînes qui sont en fait des éléments de suspension de fourreau d'épée étaient alors généralement interprétées comme des pièces de harnachement. Seuls, les brins courts sont ici comptabilisés; quatre ont été retrouvés. Certains fragments de brins longs ont également pu être confondus avec lesdites "gourmettes"; l'un d'eux porte encore son étiquette d'origine (fig. 13, n'13). Les brins longs, sans étiquette de provenance et non inventoriés par 
B. Fillon, ne semblent pourtant pas devoir être isolés. Leur appartenance au gisement s'explique aisément si l'on considère la complémentarité des deux types de chaînes (fig. $13, \mathrm{n}^{\mathrm{os}} 12,14$ ). Le silence de l'auteur ne nous permet pas d'attribuer avec certitude la chaîne longue (fig. $13, \mathrm{n}^{\circ} 12$ ) à l'ensemble découvert en 1857 ; était-elle au nombre des objets indéterminés?

\section{ANNEAUX}

"Six paires d'anneaux de trois dimensions différentes (fig. $6, n^{\text {os }} 38$ ). Et croyons-nous, les débris d'éperons de fer dont le dard était très court. Deux des anneaux sont à double charnière (fig. $6, \mathrm{n}^{\circ} 38$ ). Leur diamètre est de $0,14 \mathrm{~m}, 0,10 \mathrm{~m}, 0,07 \mathrm{~m}$ ".

Cinq de ces anneaux sont représentés; deux ayant $80 \mathrm{~mm}$ de diamètre, les "éperons" semble-t-il, constituent en fait les éléments d'un mors brisé dont manquerait l'articulation centrale (fig. $15, \mathrm{n}^{\text {ns }} 32$, 33). Les anneaux avec bague d'articulation (fig. 15, $\mathrm{n}^{\text {os }} 34,35$ ) sont tout ce qui reste d'anciens récipients tels que les chaudrons; la corrosion a complètement détruit le relief côtelé des bagues que le graveur avait pris soin de faire figurer (fig. $6, \mathrm{n}^{\circ} 38$ ). Un anneau avec bague à côte centrale, retrouvé dans les réserves du musée avec les précédents, se caractérise par sa taille (diamètre : $160 \mathrm{~mm}$ ) et de nombreuses traces de destruction (fig. $15, n^{\circ s} 30,31$ ); son appartenance à cet ensemble n'est cependant pas certaine. Un des anneaux à double charnière a été retrouvé; il s'agit probablement d'un élément d'entrave d'époque romaine.

\section{AUTRE MOBILIER}

"M. Auger a recueilli, en outre, plusieurs larges clous (fig. $6, n^{\circ} 39$ ) et plusieurs crampons ayant dû servir à maintenir ensemble d'épaisses planches de cercueil... Enfin, une certaine quantité d'autres objets, dont la destination est difficile à déterminer...".

Nous n'avons pas retenu ces objets peu caractéristiques, le plus souvent mêlés au mobilier d'autres sites. B. Fillon signale d'autre part la découverte de plusieurs monnaies gauloises et romaines aux abords de la construction quadrangulaire dans laquelle était déposé le mobilier métallique.

\section{ÉPÉEs : DEscription}

ÉPÉE $N_{A L} .1$ (fig. $7, \mathrm{n}^{\circ} 1$ )

Longueur : 668.

Soie : longueur : 62 , largeur minimale : 6 , largeur maximale : 14 , épaisseur : 3 à 5 .

Lame : largeur : 40 à 42 , épaisseur : 3 à 5 .
La lame, incomplète, n'a plus d'extrémité distale et s'achève par une cassure nette. La section biconvexe de la lame devient losangée dans la partie proximale où subsistent les vestiges d'un renflement médian. Les bords sont pratiquement parallèles sur l'ensemble de la longueur (les tranchants de la partie proximale qui était fortement délabrée, ont été reconstitués lors de la restauration sur une dizaine de centimètres).

La soie, tronquée, est ployée en arc de cercle; il s'agit vraisemblablement d'un acte intentionnel. De section rhomboïdale, elle s'évase au contact de la lame pour former la garde. L'épée dont nous ignorons la longueur originelle, ne devait mesurer pas moins de $800 \mathrm{~mm}$. Ainsi que le suggère sa morphologie actuelle, cette arme était destinée à frapper exclusivement de taille.

ÉPÉF NAI. 2 (fig. 7, $\mathrm{n}^{\circ}$ 2)

Longueur : 729.

Soie : longueur : 115, largeur minimale : 7, largeur maximale : 14, épaisseur : 5 à 7 .

Lame : largeur de la garde : 42 , largeur minimale : 38 , épaisseur : 3 à 6 .

L'épée est incomplète; l'extrémité sommitale n'est pas conservée et la lame est brisée à la même hauteur que celle de l'épée Nal. 1.

De losangée, dans la partie proximale, la section devient par la suite biconvexe; le vestige d'arête médiane qui se prolonge dans la soie évoque une nouvelle fois l'épéc précédente, Nal. 1. Les bords sont sensiblement parallèles (les tranchants, très endommagés, ont été partiellement reconstitués lors de la restauration) à l'exception de la zone proximale, où la lame est légèrement plus large. La soie est de section rhomboïdale; cependant, les arêtes ne sont pas aussi saillantes sur les deux faces. Légèrement effilée, elle s'évase au contact de la lame pour former la garde.

Cette épée dont nous ignorons la longueur, offre de nombreuses analogies avec la lame précédente.

ÉPÉE NAL. 3 (fig. 7, $\mathrm{n}^{\circ} 3$ )

Longueur : 524.

Soie : longueur : 126 , largeur minimale : 6 , largeur maximale : 17 , épaisseur : 4 à 5 , diamètre de l'extrémité sommitale : 12 à 13 .

Lame : largeur : 4 , épaisseur : 2 à 5 .

L'extrémité distale ayant disparu, la lame n'est plus conservée que sur une quarantaine de centimètres. La soie est exceptionnellement intacte.

La lame, non nervurée, est légèrement renforcée dans sa partie proximale. Sa section est biconvexe 


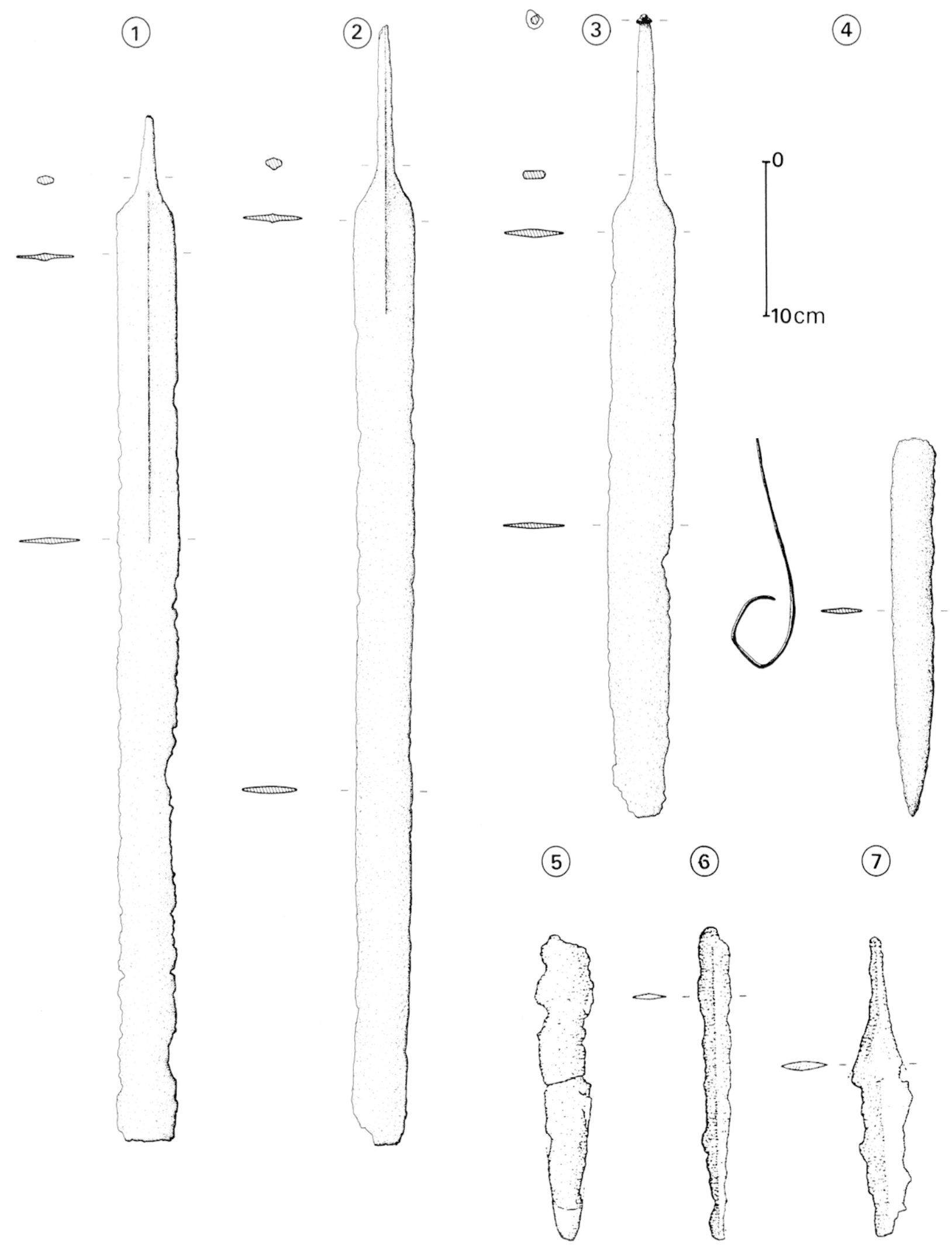

Fig. 7 - Valliers : épées nos 1 à 7 (les lames 5 à 7 ne sont pas restaurées). 


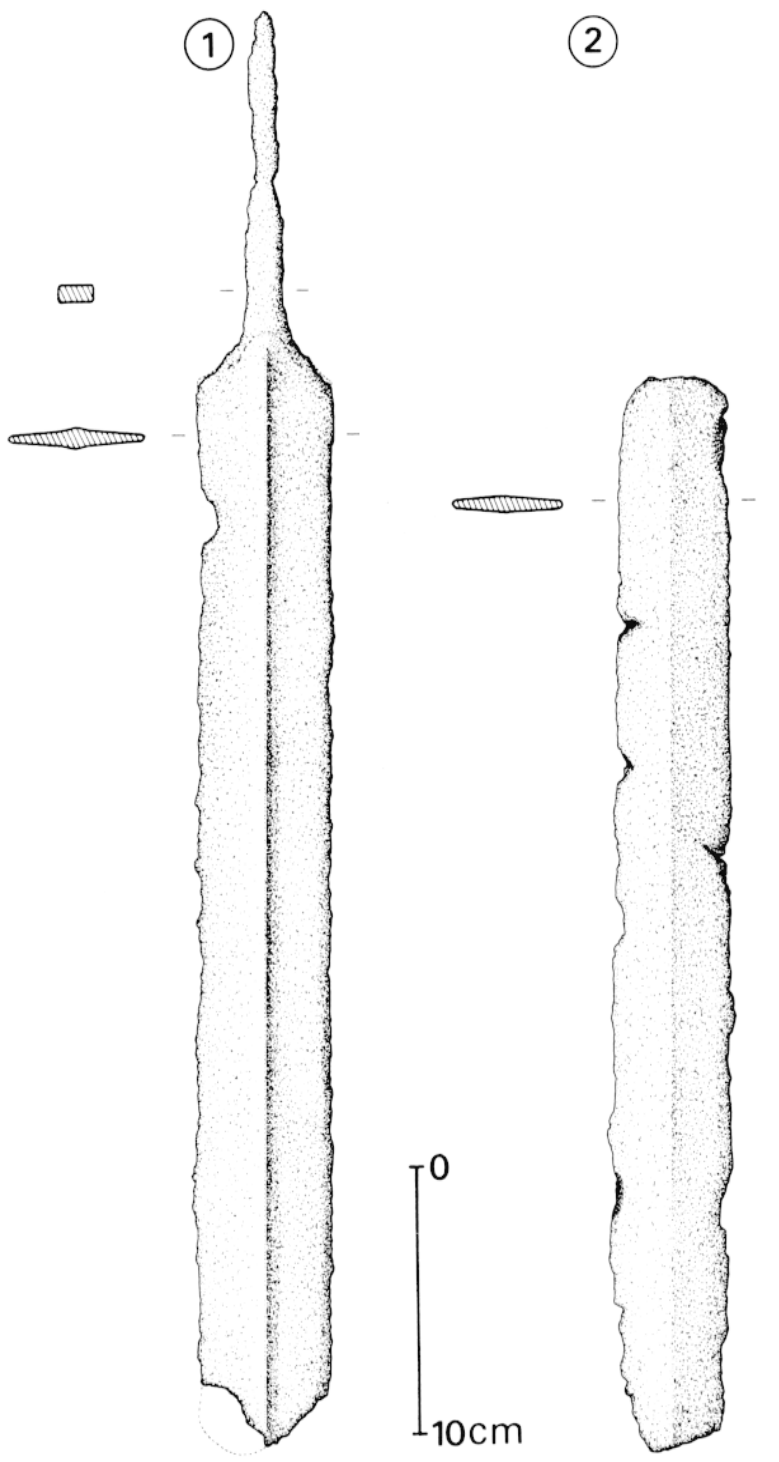

(4)

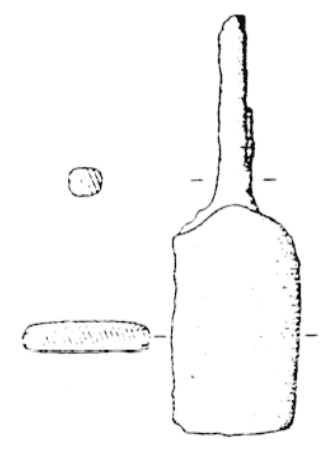

Fig. 8 - Les Serres : épées nos 1,2 et 4 (les lames ne sont pas restaurées).

sur toute la longueur. Les bords relativement bien conservés n'ont pas nécessité une importante restauration, sauf dans la zone de ployage située à une vingtaine de centimètres de la garde (ce ployage est peut-être récent). Les tranchants sont sensiblement parallèles. La soie de section rectangulaire est effilée et s'évase vers la lame pour former la garde. L'extrémité sommitale n'est pas composée d'un simple bouton obtenu par écrasement, mais d'une rondelle enfilée sur la soie localement amincie; la pièce est maintenue sur l'épaulement par rivetage.

ÉPÉE NAL. 4 (fig. 7, n ${ }^{\circ} 4$ )

Longueur : 245. Largeur maximale à la cassure : 29, épaisseur : 3.

Il ne subsiste que l'extrémité distale. La lame, brisée perpendiculairement aux tranchants, présente une section biconvexe et se caractérise par son étroitesse et son profil très effilé.

Le fragment, brisé, ployé et enroulé sur luimême, présente toutes les marques d'une mutilation volontaire.

\section{DÉCOUVERTES RÉCENTES, COMMUNE DE NALLIERS, VENDEE}

Les épées découvertes il y a une dizaine d'années, consécutivement à un labour au lieu-dit Les Serres, par C. Gendron, sont restées jusqu'ici inédites. Actuellement déposées à la Conservation des Musées de Niort, elles devraient une fois leur restauration achevée, rejoindre les collections du Musée Vendéen de Fontenay-le-Comte.

Cependant, leur état de conservation suscite quelques remarques. L'extraction de ces pièces par des engins aratoires, aussi nuisible soit-elle, n'est en rien comparable aux méfaits du temps et de la corrosion (une fois l'objet exhumé, la corrosion s'aggrave considérablement en l'absence de tout traitement). La confrontation de documents photographiques anciens et récents permet de prendre la mesure des dégradations subies par les lames et de mieux comprendre l'importance des différences existant entre l'état actuel du mobilier découvert à Nalliers en 1857 et l'état décrit par B. Fillon. En effet, les lames se délitent en fines lamelles tant et si bien qu'elles sont parfois perforées; les arêtes médianes s'estompent et tendent à disparaître en plusieurs endroits.

A ces épées, il faut ajouter les quelques pièces provenant de la collection de P. Drugeon, propriétaire d'un des terrains situés aux Serres.

Pour ne pas confondre ces armes avec celles découvertes au siècle dernier, nous préférons les désigner par l'appelation «Ser.", plus explicite quant à leur origine.

Les épées, Ser. 1, 2 et 3, découvertes par C. Gendron sont partiellement conservées (fig. 8). 
Elles sont toutes mutilées : bris, crantage et ployage, notamment pour l'épée Ser. 3 que nous n'avons pas représentée en raison de son trop mauvais état. Par sa section fortement nervurée, large d'environ $55 \mathrm{~mm}$, Ser. 1 s'apparente à d'autres spécimens régionaux comme les épées de Mazerolles ou celles de Nalliers décrites par B. Fillon dans sa quatrième catégorie.

Parmi les pièces de la collection Drugeon, nous avons retrouvé, outre deux fers de lance dont un à forte nervure médiane : Ser. 5 et 6 (fig. 11) et un couteau à douille d'un type déjà rencontré à Fayel'Abbesse (Ser. 7, fig. 16) le fragment proximal d'une épée : Ser. 4 (fig. 8, $n^{\circ} 4$ ). Cette arme est la seule en Poitou qui soit encore pourvue de l'entrée de son fourreau (droit et revers, non nervurés, type A2 de De Navarro). Du système d'attache, on ne devine que les traces d'une barrette à la base de la patte inférieure du pontel.

\section{L'ARMEMENT : UNE AUTRE APPROCHE DE L'AGE DU FER POITEVIN}

\section{L'ÉTUDE PALÉOMÉTALLURGIQUE}

L'objectif de la paléométallurgie est de déterminer au moyen de la métallographie, la nature d'un produit qui est l'aboutissement d'un long processus de transformation de la matière. La métallographie s'entoure de différentes méthodes d'examen et d'essais des métaux afin d'en définir les propriétés chimiques, mécaniques et physico-chimiques en relation avec leur structure à l'échelle macroscopique et microscopique.

Pour ce faire, il nous a fallu procéder à un choix méticuleux de l'échantillonnage pour tenir compte de l'hétérogénéité structurale qui caractérise les fers anciens. Ainsi, la systématisation de la radiographie permit, entre autres choses, d'apprécier au mieux l'importance des zones métalliques résiduelles et, de ce fait, d'effectuer judicieusement les prélèvements d'échantillons afin de minimiser les pertes d'informations dues à la corrosion. Pour ne pas trop altérer la morphologie et la résistance des épées, nous avons limité les prélèvements à un tranchant et une portion de la zone centrale, soit à une demi-section.

Le prélèvement, réalisé au moyen d'un microtour de prothésiste, est fait suivant deux traits de coupe parallèles transversaux et un troisième perpendiculaire aux précédents; le vide est ensuite colmaté avec une résine synthétique teintée. Pour faciliter les manipulations ultérieures, l'èchantillon est enrobé dans une résine. Il est ensuite soumis à un polissage mécanique puis à une attaque chimique avec une solution alcoolique d'acide nitrique à $5 \%$ afin de révéler les joints de cristaux et de différencier les constituants de l'alliage. Ces préparatifs achevés, vient l'analyse métallographique proprement dite. Elle a pour but d'examiner "l'architecture interne" de l'alliage qui dépend de la constitution et de la structure, ainsi que d'en déterminer le système de cristallisation et les transformations qu'il a subies sous l'action des contraintes mécaniques ou thermiques.

Pour compléter ces données, on a aussi procédé à une série d'essais de dureté pour mesurer "la résistance qu'oppose le métal à la pénétration d'un autre corps plus dur que lui, c'est-à-dire la résistance à une déformation permanente de sa surface" (Encyclopaedia Universalis, art. Métallographie, p. 33). Ces mesures très localisées nous renseignent sur la dureté des différents constituants du métal.

\section{PREMIERS RESULTATS}

L'étude a porté sur 47 échantillons prélevés sur les lames de 17 épées. L'échantillonnage varie dans une proportion de 2 à 4 prélèvements (exceptionnellement 1) selon les lames. Toutefois, seuls les plus déterminants ont été pleinement exploités et présentés.

Nous pouvons d'ores et déjà dégager de l'analyse structurale quelques caractères généraux. Ces fers se caractérisent en premier lieu, comme l'ensemble de la production protohistorique, par une extrême hétérogénéité. Sensible d'un échantillon à l'autre pour une même lame, elle l'est tout autant au sein d'un même spécimen. La composition du métal se

4 . Nous présentons dans ce chapitre un rapide exposé des résultats de l'analyse métallographique. Pour les problèmes spécifiques à la métallurgie, cf. C. Chaussin et G. Hilly, Métallurgie 1: alliages métalliques, Dunod, $2^{\mathrm{e}}$ éd., 1976; P. Fluzin, Notions élémentaires de sidérurgie, Métallurgies africaines, nouvelles contributions, Mémoires de la Société des Africanistes, 9, 1983, p. 13-44; H. DE LeIRIs, Metaux et alliages : fers, aciers et fontes, Paris, Masson, 1971 ; R. Maddin, J. D. Muhly et T. S. Wheeler, 1977, p. 12-20.

Pour être plus complet, nous évoquerons également les épées de Valdivienne (S. Camus, J.-P. Pautreau et C. Richard, Le tumulus de l'Age du Fer de la Bataillerie à Valdivienne, Vienne, Bulletin de la Socièté Préhislorique Française, 77, 1980, p. 429-441), de Mazerolles (G. Nicolini, 1983, p. 7-24), de Germond et de Juac (C. Gendron, J. Gomez de Soto, T. Lejars, J.-P. Pautreau et L. Uran, 1986, p. 39-54). Un résumé succinct des études métallographiques est présenté dans l'article consacré aux épées à sphères alors que celles des deux premières sont encore inédites. 
présente essentiellement sous forme de structures ferritiques et ferrito-perlitiques, avec localement d'étroites plages perlitiques. Le pourcentage de carbone varie parfois de façon importante. Nous avons enfin constaté, dans la matrice, la présence de nombreuses inclusions plus ou moins bien organisées.

\section{Structure ferritique}

La ferrite est une solution solide de carbone dans le fer $\alpha$ ou fer à structure cubique centrée. La solubilité du carbone y étant presque nulle, la ferrite correspond à un fer presque pur (pourcentage de carbone inférieur à $0,02 \%$ ). Ce matériau possède une grande souplesse mais une assez mauvaise résistance mécanique et se déforme facilement. Sa dureté moyenne, de l'ordre de 80 à $100 \mathrm{Hv}$ (Hardness Vickers), est inférieure à celle d'un bronze à $11 \%$ d'étain, non travaillé à froid (125 Hv). De tels objets ont cependant une résistance à la corrosion beaucoup plus importante que les fers aciérés.

Les objets constitués de ferrite sont rares (fig. 17, p. 34). Ils se composent le plus souvent d'alternance de zones de ferrite et de perlite. La transition entre les deux domaines est généralement progressive. Les systèmes plus complexes comme les structures feuilletées, dérogent à cette règle (fig. 17). Il n'est pas inhabituel de rencontrer à la périphérie des lames, des plages de ferrite pure qui trahissent dans bien des cas une décarburation accidentelle (Valdivienne; Mazerolles 1; F. A. 1, 2, 7; Nal. 1, 2, $3,4$ et $\mathrm{Juac})$. Ce vice de fabrication est révélateur d'une maîtrise imparfaite de la température lors des chauffes successives.

Les cristaux de ferrite indiquent par leur physionomie, taille et orientation, le sens de la mise en forme. Il est fréquent de constater d'importantes variations dans la taille des grains (F. A. 4) lesquels peuvent aussi se présenter de manière relativement homogène sur l'ensemble de la structure. Leur distribution n'est pas toujours révélatrice d'une organisation particulière, comme elle a pu être déterminée pour certaines lames (Mazerolles 1 et 2).

La structure granulaire fine, caractéristique d'un bon travail de forge, singularise certaines des lames étudiées (Mazerolles 1 et 2; F. A. 5 et 6 ; Germond et Juac). L'épée de Germond, de structure ferrito-perlitique à grains très fins sur l'ensemble des sections, apparaît à cet égard tout à fait exemplaire. La taille du grain est d'autant plus fine que le métal a été travaillé à assez basse température ou a subi un recuit de recristallisation consécutivement à une importante déformation comme l'écrouissage (F.A. 7 et 8 ) (fig. 17). Un recuit suffisant dans le domaine ferritique donne naissance à de nouveaux grains équiaxiaux à partir des anciens joints de grains écrasés. Un choix judicieux de la température et de la durée d'exécution permet d'aboutir à une structure granulaire plus fine que celle qui existait à l'origine puisque la vitesse de germination augmente plus vite que la croissancè des grains. Cependant, la recristallisation est souvent partielle. Elle se traduit par la formation de zones à grains localement fins ou gros. La finesse de la structure granulaire contribue, par conséquent, à améliorer la résistance de la lame.

L'une des épées (F. A. 4) présente une alternance sensiblement verticale des domaines ferritiques à gros et petits grains. Aucune soudure ne souligne les changements de zones. Cette organisation, qui résulte d'un gradient du taux de déformation, est beaucoup moins perceptible dans les deux échantillons de la partie distale.

L'orientation préférentielle des inclusions comme celle des grains, nous renseigne sur le sens du martelage. Le sens de la mise en forme se fait essentiellement selon la direction âme-fil. Les structures ferritiques peuvent être remarquablement épurées et indiquer un travail de forge soigné (Coghlan, 1956/57a, p. 135, épée $\left.n^{\circ} 1947-639\right)$. Cependant, elles contiennent dans la plupart des cas de nombreuses inclusions plus ou moins alignées. Ces impuretés sont aussi présentes dans les structures ferrito-perlitiques. Les inclusions disséminées dans la matrice sont l'indice d'une purification du métal insuffisante. Celles qui sont disposées en alignements continus sont, contrairement aux précédentes, la marque de soudures imparfaitement réalisées (Mazerolles 1 et 2 ; F. A. 6 et 8). L'atmosphère oxydante qui entoure l'opération en est vraisemblablement responsable. Il est par conséquent très difficile de suivre une soudure parfaite, seule la juxtaposition de structures différentes en révèle l'existence (Mazerolles 1 et 2) (fig. 17).

Lil soudure de fers différemment aciérés représentait. ¿ n'en pas douter, une difficulté majeure (Pleiner, 1980, p. 404; Fluzin et alii, 1983a, p. 187). Chauffé au jaune ou à blanc, soit environ $1200^{\circ} \mathrm{C}$, le fer doux pouvait par sa chaleur causer une décarburation à l'acier qui a une température optimale de soudure de l'ordre de 830 à $880^{\circ} \mathrm{C}$.

Comme l'avaient auparavant constaté plusieurs auteurs, nous avons observé dans la matrice ferritique quelques cristaux maclés (F. A. 1, 4, 6, 7; Nal. 2,3) (fig. 17). Ces macles ne se rencontrent pas sur tous les échantillons d'une même lame. A Gournay, elles ont été identifiées sur la moitié des 85 épées étudiées (Coghlan, 1956/57a, p. 135 ; Uran, 1983, p. 91-98; Fluzin el alii, 1983a, p. 187). 
Les macles représentent un mode de déformation peu courant de nos jours dans les métaux à structure cubique centrée. Elles se forment uniquement dans les cristaux de ferrite et plus particulièrement dans ceux de relativement grande taille, de forme équiaxe. Les macles, de direction unique, sont limitées aux joints de grains. Il arrive qu'elles se superposent à un maclage antérieur, différemment orienté.

Leur apparition peut tout aussi bien résulter de la phase d'élaboration que de violents chocs ou de torsions ultérieurs (combat, sacrifice). Leur concentration dans les zones de torsion ne constitue en aucune façon un caractère d'exclusivité (F. A. 4, 7). Cependant, leur présence dans ces régions rend peu probable une déformation de l'arme par chauffage puisqu'une recristallisation aurait dû les faire disparaître. Plusieurs lames ou portions de lames, intactes, en conservent les marques (Nal. 2, 3; ct dans une certaine mesure F. A. 1,6) (Coghlan, 1956/ 57a, p. 135; Roualet et alii, 1982, p. 33; 1983, p. $18 ; 1985$, p. 26-27). Ce phénomène relativement courant nuit évidemment aux qualités mécaniques de ces armes.

\section{STRUCTURE FERRITO-PERLitique}

Nous n'avons pas rencontré au cours de cette étude de lames purement ferritiques (F. A. 4 constitue une exception). L'hétérogénéité de ces matériaux se traduit par un mixage des structures de ferrite et de perlite. Il n'y a généralement pas de ségrégation évidente entre les différents domaines. La transition se fait par une évolution du pourcentage des phases.

La teneur en carbone des aciers observés ne dépasse jamais la valeur de l'eutectoïde, soit $0,8 \%$. La composition eutectoïde est un mélange particulier de deux types de cristaux juxtaposés, caractérisée par une température de solidification fixe et inférieure à celle de chaque constituant. Des teneurs localement proches de l'eutectoïde ont occasionnellement été rencontrées (Valdivienne; Mazerolles 1; F. A. 1, 2). Ces compositions isolées sont pour l'essentiel à mettre au compte du hasard.

La perlite est constituée d'un agregat de cémentite et de ferrite, qui forment une structure particulière correspondant à l'eutectoïde. Dans la lame de Germond, elle se présente sous forme de petits îlots noyés dans la masse ferrito-perlitique. Une structure presque entièrement perlitique, de type lamellaire et, localement globulaire a été identifièe sur l'épée du type de Hatvan Boldog de la tombe 13 de Bromeilles (Uran, 1983, p. 106). De telles structures, ferrito- perlitiques fortement carburées, sont attestées jusqu'en Pologne, sur des lames de Gardzienice et de Głownin (Schulz, Pleiner, 1965, p. 47).

Les aciers protohistoriques, généralement hypoeutectoïdes, se présentent sous différents aspects en fonction de leurs constituants et de la nature des éventuels traitements thermiques. La disparité de structure d'un échantillon à l'autre d'un même objet, consécutif à quelques aléas de fabrication, traduit une insuffisance dans la maîtrise des processus de carburation. La structure devient cellulaire lorsque, pour des teneurs en carbone avoisinant 0,6 à $0,7 \%$, il se forme des liserés autour de la perlite (F. A. 2). Des grains relativement fins et un refroidissement lent favorisent la formation de telles structures (Valdivienne; F. A. 2; Nal. 1, 2).

Il n'est pas inhabituel d'observer aux marges des plages de ferrite et de perlite des motifs en aiguillc de type Widmanstätten (F. A. 1, 2, 3; Nal. 1, 3; Juac) (fig. 17). Cette structure résulte d'un refroidissement à l'air assez rapide, consécutif à une surchauffe de l'acier. Les aiguilles de ferrite se forment suivant des plans de direction bien définis, parallèlement aux faces des grains d'austénite. Cette structure néfaste fragilise l'acier en le rendant cassant. Ce défaut, couramment observé sur les fers anciens, pouvait être éliminé par un recuit de recristallisation. Cette dernière étape n'est pas encore, à l'évidence, parfaitement maîtrisée.

La ferrite aciculaire se rencontre aussi bien dans les domaines ferrito-perlitiques que ferritiques. Elle résulte comme la structure précédemment définie, d'une surchauffe dans le domaine austénitique suivie d'un refroidissement relativement rapide. De la même façon, elle favorise la fragilisation du matériau.

Nous avons également constaté à maintes reprises une décarburation, parfois importante, des structures ferrito-perlitiques, à l'approche de la périphérie (Mazerolles 1; F. A. 1, 7) et des tranchants (Nal. 4 ; Juac). Ce phénomène est aussi sensible dans la structure interne du métal, à proximité des fissures (Valdivienne; Nal. 1, 2, 3).

\section{DURETÉs}

Les essais de microduretés soulignent, tout comme l'étude structurale, l'importance de l'hétérogénéité des matériaux (F. A. 4, exceptée). La variation des valeurs enregistrées dépend de la teneur en carbone et de la texture cristalline. Ainsi, les mesures effectuées, tant dans les structures ferritiques que ferrito-perlitiques, révèlent de grandes disparités. Les duretés relevées dans les zones ferritiques varient de 90 à $250 \mathrm{Hv}$ (les $250 \mathrm{Hv}$ ont été 
enregistrés dans l'un des tranchants de F. A. 1) et de 150 à $300 \mathrm{Hv}$ pour les régions ferrito-perlitiques.

Pour 11 lames, nous avons mesuré à proximité des tranchants des duretés $(190$ à $250 \mathrm{Hv}$ ) équivalant à celles d'aciers mi-durs. Ces valeurs n'atteignent pas, pour la plupart, la dureté d'un bronze à $11 \%$ d'étain travaillé à froid $(250 \mathrm{Hv})$; le fer a cependant l'avantage d'être beaucoup moins cassant. Ces duretés correspondent pour deux des lames (F. A. 7, 8) à des structures écrouies qui résultent d'une déformation du métal à froid ou à basse température. Cette opération accroît la résistance et la limite d'élasticité, mais réduit l'allongement et la résilience lorsqu'elle n'est pas suivie d'un recuit de recristallisation. La taille des cristaux (ils sont deux fois plus longs que hauts) implique une déformation résultant d'un forgeage final. Cette opération ne peut être imputée à l'usager qui aurait été confronté au problème d'une lame devenue trop large pour son fourreau.

\section{Traitements chimiques et thermigues}

Les échantillons examinés n'ont révélé aucun traitement susceptible d'améliorer les qualités mécaniques des lames considérées; ces techniques sont attestées de longue date dans le domaine Procheoriental (Maddin et alii, 1977, p. 12-20). Toutefois, la dégradation des zones superficielles ne doit pas nous faire oublier qu'une partie de l'information n'est plus accessible. Les structures carburées constituent des domaines privilégiés pour le développement de la corrosion. Cette dernière agit également en fonction de l'environnement (ex. terre, tissus pour les sépultures). La couche corrodée, parfois très importante (Valdivienne; F. A. 3, 5, 8; la corrosion a complètement éliminé les zones superficielles des lames de Nalliers) ne permet pas d'identifier d'éventuelles traces de cémentation. Ce traitement chimique consiste en un enrichissement des couches externes de l'objet par diffusion du carbone, à partir d'un feu de charbon de bois. Les lames ayant conservé leurs tranchants ne présentent aucun indice de cémentation (Mazerolles 1; Juac).

Aucune structure modifiée par refroidissement plus ou moins rapide n'a été constatée. De telles pratiques ont toutefois été signalées dans des travaux antérieurs, mais elle ne semblent jamais être le résultat d'une action intentionnelle. Ces structures particulières sont toujours très localisées. Une structure martensitique aciculaire avec des îlots de troostite, suggérant une trempe rapide, a été observée dans un tranchant d'une épée de Borgovercelli (Italie) (Leoni, 1973/75, p. 121). Une épée tardive de
Gournay a révélé une structure localement ferritobainitique prouvant un refroidissement assez rapide (Uran, 1983, p. 114). Des structures de type perlitosorbitique ou localement sorbitique ont plusieurs fois été signalées (Pleiner, 1978, p. 205-208; 1983; Emmerling, 1967/68, épées $\mathrm{n}^{\text {os }} 24663,24709,24745$, 26177 ; 1975, p. 208-210).

\section{CONSIDÉRATIONS GENERRALES SUR LES ÉPÉES POITEVINES}

\section{Techniques de fabrication}

Les lames poitevines relèvent dans l'ensemble de schémas de construction relativement élémentaires.

La loupe de métal est préalablement comprimée, régularisée, nettoyée et épuréc dc ses particules métalliques. Cependant, cette dernière opération laisse souvent à désirer. Le forgeage, ou corroyage, est une tâche répétitive qui consiste à assembler ou à replier la matière première. Le forgeage à haute température augmente d'une part la compacité du métal, et d'autre part, en affinant les grains d'austénite et la microstructure, améliore les caractéristiques mécaniques de l'acier.

Dans le cas des épées à structure simple, l'ébauche est formée d'une certaine quantité de métal qui est inlassablement mise au feu et repliée sur elle-même. Le repli médian est particulièrement net sur deux de nos lames (F. A. 6 et 8). Les inclusions donnent le sens de la déformation qui est généralement de direction âme-fil. Pour la réalisation d'une lame de $700 \mathrm{~g}, \mathrm{~A}$. France-Lanord estime à peu près au double la quantité initiale de métal, compte tenu des importantes pertes au feu lors des différentes chauffes (France-Lanord, 1964, p. 317-320). La lame, allongée à la panne du marteau, prend sa forme définitive. Les tranchants sont façonnés, puis finis par abrasion et aiguisés. La qualité souvent médiocre de ces produits incita peut-être les artisans à soigner le profil des lames, afin de les renforcer. La présence d'arètes médianes ne doit cependant pas nous faire préjuger de la structure interne. Il n'est pas impossible que les forgerons aient, en certains cas, essayé d'améliorer les tranchants pour suppléer aux insuffisances de la structure métallique (F. A. 2, 6 ; Nal. 1, 2).

La technique du feuilletage est attestée dès le III s. avant J.-C. (Mazerolles 2) (Schulz, Pleiner, 1965; Emmerling, 1967/68; Uran, 1983, p. 80; Roualet et alii, 1982, p. 32). Elle consiste en l'association de feuilles métalliques corroyées hori- 
zontalement. L'ébauche est réalisée à partir d'un assemblage de lamelles plus ou moins aciérées, soudées à chaud et travaillées dans le plan de l'objet. Cette technique contribue, en dépit d'une faible carburation, à l'amélioration des lames par l'association de qualités complémentaires telles que souplesse (fer doux) et dureté (fer plus aciéré). La lame $\mathbf{n}^{\circ} 2$ de Mazerolles se caractérise par la juxtaposition de trois bandes de métal. La partie centrale, constituée d'une alternance de domaines ferritiques et de minces filets ferrito-perlitiques, est flanquée de bandes ferritoperlitiques à grains très fins. Ce mode de fabrication était également connu en Étrurie; l'analyse d'une falcata provenant de Vetulonia a révélé un produit d'excellente qualité (Coghlan, 1956/57b, p. 168-170). Une arme identique, trouvée à Almedinilla (Espagne) apparaît au contraire bien médiocre (Coghlan, $1956 / 57$ b, p. 168-171).

Ces lames montrent l'habileté des forgerons dans le choix des fers. Toutefois, elles apparaissent relativement simples au regard des sructures mises en évidence par A. France-Lanord sur certaines épées de la fin du second Age du Fer.

\section{Qualité des ÉPÉEs CELTiques}

Les études de structure réalisées sur les épées celtiques, tant en France qu'à l'étranger, ont révélé de considérables différences de texture et de qualité. Nous ne reviendrons pas sur les différentes classifications, mais nous essaierons de définir les lames en fonction de leur bonne ou mauvaise qualité (Schulz, Pleiner, 1965, p. 46-48 ; France-Lanord, 1964 ; Emmerling 1967/68).

Cette répartition simpliste recouvre en fait de nombreux aspects. Il convient en effet de considérer les lames comme autant de cas particuliers. Elles sont le fruit du travail d'un artisan et de son aptitude à maîtriser l'ensemble des techniques de forge. La grande dimension de ces objets obligeait le maître d'œuvre à procéder par touches successives. Cela nécessitait une grande habileté pour les traiter uniformément lors du forgeage et éviter les phénomènes de décarburation locale, caractéristiques des lames protohistoriques. Le résultat dépendait du mode de mise en forme, ainsi que de la température et du taux de déformation qui variaient en tous points. L'hétérogénéité des structures et des modes de fabrication qui en résulte, explique la multiplicité des systèmes de classement. C'est pourquoi nous ne pouvons actuellement envisager l'objet métallique dans sa dimension typologique, structurale et chronologique.

Les lames de piètre qualité procèdent d'une organisation généralement simple et uniforme. Elles peuvent être à l'occasion plus complexes ainsi que l'attestent certaines lames de Münsingen (âme plus carburée que les flancs; âme de fer doux flanquée de fers insuffisamment aciérés) (Emmerling, 1967/68). Quel que soit le système choisi, les fers sont peu carburés et n'ont jamais fait l'objet de traitements particuliers. De nombreuses inclusions caractérisent souvent ces matériaux, notamment dans les zones de soudure ou à la jonction des replis.

Ces insuffisances sont considérables puisqu'elles touchent les deux tiers de la production. Ces épées évoquent et tendent donc à accréditer les propos de Polybe, fermement discutés par quelques auteurs de ce début de siècle: J. Déchelette à la suite de $\mathrm{S}$. Reinach, voyait dans le rituel funéraire du ploiement des armes une origine possible à cette "légende" (Pleiner, 1980, p. $393 ; 1983$, p. 8). Le constat de Polybe est celui d'un homme décrivant un fait inhabituel et remarquable. Il donne dans sa relation de la bataille de Telamon, en 225, une bien mauvaise image de l'épée gauloise, dont Diodore de Sicile $(\mathrm{V}, 28)$ et Plutarque (Vie de Camille, 41, 4) se feront ultérieurement l'écho: "malgré les pertes qu'ils subissaient, l'ardeur combative des Gaulois ne le cédait en rien à celle des Romains, et leur infériorité, individuelle et collective, tenait uniquement à la nature de leur armement (Polybe, I, $2,30)$ " "leurs épées, comme il a été dit déjà, n'ont d'efficace que leur premier coup et ensuite s'émoussent, se recourbant dans le sens de la longueur et de la largeur de sorte que si l'on ne donne pas à qui s'en sert le temps de la redresser avec le pied en l'appuyant sur la terre, le second coup est totalement inefficace (Polybe, II, 33)». Diodore de Sicile $(\mathrm{V}, 28)$ attire cependant l'attention sur la flexibilité des longues épées, difficilement appréciable aujourd'hui. Si l'étude métallographique semble corroborer les dires de Polybe, nous ne devons pas oublier que l'auteur, romanophile, narre les temps héroïques de la romanisation de l'Italie. Il célèbre ainsi la victoire (pour ne pas dire la revanche) de Rome sur les belliqueux "barbares" du Nord qui menacèrent la péninsule pendant plus de deux siècles.

Les épées de qualité supérieure sont rares et de conceptions variées. Les modes de construction diffèrent peu des précédents, pour certaines d'entre elles. J. Emmerling a observé sur deux des lames de Münsingen une structure faite d'un métal relativement homogène (la teneur en carbone varie de 0,5 à $0,7 \%$ pour la lame 31193 et, de 0,7 à $0,9 \%$ pour la 26177 ) mais constituée de la juxtaposition de plusieurs barres (Emmerling, 1967/68, p. 157, 171, 179-181). Certaines structures feuilletées, plus carbu- 
rées, entrent dans cette catégorie. Le feuilletage est indifféremment vertical ou horizontal (France-Lanord, 1964, p. 320 ; Schulz, Pleiner, 1965, p. 46). Il existe de grandes différences qualitatives parmi ces armes. Cependant, elles sont toutes l'expression d'une technique avancée et traduisent une volonté de mieux faire. D'autres procédés beaucoup plus complexes, consistant en l'assemblage de bandes préférentiellement carburées, ont été étudiés par A. France-Lanord. Ces derniers seraient peut-être à l'origine de la technique du damas par corroyage qui connut un réel succès au Haut Moyen Age (FranceLanord, 1964, p. 324-327).

La teneur en carbone de ces fers est très variable. L'emploi judicieux de fer doux et d'acier nettement carburé, notamment vers les tranchants, est préférable à l'utilisation d'un unique métal carburé qui s'avèrerait de ce fait trop cassant (F.A. 2).

Toutefois, ces armes, dans leur grande majorité, devaient nécessairement remplir la fonction à laquelle elles étaient destinées. Nous ne pouvons envisager sérieusement une éventualité contraire qui aurait remis en cause leur raison d'être même. Si les usagers n'en étaient pas pleinement satisfaits, tout au moins devaient-ils s'en contenter, d'autant plus que leurs adversaires, en Europe moyenne, n'étaient guère mieux lotis (conflits tribaux, luttes intestines). En Italie même, l'épée laténienne fut utilisée chez certaines populations comme les Picéniens ou les Vénètes, ainsi qu'en témoignent les nombreuses découvertes faites en milieu funéraire (Lollini, 1979, p. 61). La confrontation avec des groupes de traditions guerrières différentes (monde méditerranéen) influa sur les techniques de combat dont nous savons fort peu, contribuant indirectement au développement de certains procédés de fabrication. Polybe témoigne de la nécessité de s'adapter, et explique comment les tribuns, lors de la bataille de Telamon, modifièrent avec succès la façon de combattre de leurs troupes, en raison de leurs échecs antérieurs (Polybe, II, 33).

Contrairement à l'évolution morphologique des lames qui relève de tendances générales, celle des techniques de fabrication reste plus que jamais le fait d'individus ou d'ateliers.

La fin du second Age du Fer se caractérise non seulement par d'importantes innovations techniques, notamment dans l'outillage, mais également par un formidable développement de la production. Pour le $\mathrm{I}^{\mathrm{er}} \mathrm{s}$. avant J.-C., R. Pleiner dénombre quelque 90 variétés d'objets en fer : armes, outils, ustensiles divers, ainsi que des éléments de décoration et de construction. L'étude d'un certain nombre d'outils provenant des oppidums de Tchécoslovaquie démontre un usage préférentiel des matériaux et une pratique non négligeable des traitements thermiques (Pleiner, 1980, p. 402, 405).

\section{ÉTUDE DU MOBILIER MÉTALLIQUE DES ENSEMBLES DE FAYE-L'ABBESSE ET DE NALLIERS}

Les raisons invoquées lors de la présentation des gisements rendent difficiles, en dépit de la variété du mobilier, l'établissement d'une chronologie solide et la définition de groupes d'objets. Notre démarche se résume, par conséquent, en une approche aussi fiable que possible des différentes phases d'occupation.

L'état de ruine et l'absence de tout caractère significatif d'une importante partie du mobilier (épées, fers de lance ...) nous ont conduit à privilégier les éléments les moins discutables comme les pièces de suspension de fourreau d'épée. Les rapports de "fouilles" dont nous avons montré les limites, ont également été pris en considération.

\section{LES ÉPÉES}

$F_{A Y E-L}{ }^{\prime} A B B E S S E$ (fig. 3 et 4 )

Nous retiendrons de l'inventaire de 1853 uniquement les points intéressant le nombre et la dimension des épées, ainsi que la mention précisant la découverte in situ de deux armes engagées dans leur fourreau. Il semble que nous possédions toutes les épées, mais les problèmes d'identification demeurent (la lame F.A. 5 est la seule objectivement identifiable). Les commentaires et les mensurations indiqués par L. Lunier et A. Monnet sont considérés comme de simples estimations. Si les différences de longueurs que nous avons enregistrées peuvent être imputées aux aléas du temps, il ne peut en être de même pour les largeurs puisque sur les 9 lames 3 seulement correspondent aux chiffres de l'inventaire, les autres étant nettement plus larges (on peut songer à une évaluation des dimensions des plus approximative comme c'était alors souvent le cas).

La confrontation permet d'individualiser deux groupes typologiquement et chronologiquement distincts. Le premier comprend des lames dont la longueur varie de 650 à $800 \mathrm{~mm}$ (soie incluse). Celles, plus longues de 1100 à $1200 \mathrm{~mm}$, au nombre de trois, sont représentatives du second groupe.

L'épée F.A. 5 se rattache au premier groupe, le seul qui ait des lames avec fourreau. Les lames F.A. 1 et 4 , bien qu'incomplètes, peuvent être raisonnablement attribuées au second. Les épées de 
grande taille ne sont pas rares. Certaines d'entre elles, datant du ve s., atteignent $900 \mathrm{~mm}$ : Altrier (Luxembourg), Somme-Bionne (Marne) (Rapin, $1983 / 84$, p. 70), mais les plus longues datent incontestablement de la phase finale : épées à sphères, jusqu'à $1050 \mathrm{~mm}$ de long (Gendron el alii, 1986, p. 40); Lux (Saône) longueur : $1070 \mathrm{~mm}$ (Bonnamour, 1983, p. 67-78); nous signalons pour finir deux épées de la collection Millon provenant du lit de la Saône longues d'environ $1100 \mathrm{~mm}$ et morphologiquement proches de celles de Faye-l'Abbesse (Déchelette, 1913, pl. XXXVI, nos 4 et 5). Aucune, cependant, n'atteint, à notre connaissance, les "1 $200 \mathrm{~mm}$ " dont il est question dans l'inventaire de 1853. Une telle arme devait être extrêmement embarrassante. Une modification du positionnement du pontet sur le fourreau, comme l'attestent certains exemplaires tardifs, notamment dans les îles Britanniques, pouvait atténuer cette contrainte. Sa morphologie en fait une arme de cavalier. Dans son état actuel, et malgré son étroitesse, nous hésitons à faire de la lame F.A. 6 une arme du second groupe. Son aspect effilé évoque le fragment distal Nal. 4.

La petite taille de la soie de l'épée F.A. 3 (il en va de même pour l'épée Nal. 3) et les sections losangées des épées F.A. 5, 8 et 9 (et probablement F.A. 2) suggèrent une datation relativement ancienne; que ne contredit pas la largeur des lames, 44 à $48 \mathrm{~mm}$ (De Navarro, 1972, p. 39, 128; Stead, 1983). Le fragment distal F.A. 7 peut être daté du Ir s. avant notre ère, en raison de sa forme et des pratiques sacrificielles semblables à celles d'épées contemporaines de Gournay (L'art cellique en Gaule, $\left.1983 / 84, \mathrm{n}^{0} 103\right)$. Une lame du même type existe à Nalliers (fig. $7, \mathrm{n}^{\circ} 5$ ).

\section{NALLIERS ET LES SERRES (fig. 7 et 8)}

L'état actuel des épées de Nalliers ne nous renseigne guère sur leur morphologie et, par conséquent, sur leur appartenance typologique. Il est possible de pallier cette carence en nous référant aux descriptions de B. Fillon.

Nous pouvons, à partir de ses commentaires, individualiser deux groupes définis par les mensurations des lames (si les largeurs sont conformes, nous souhaiterions savoir comment furent déterminées les longueurs, sachant que les épées étaient pour la plupart brisées). Les armes des catégories 3 et 4 (en référence au descriptif de $\mathrm{B}$. Fillon) constituent le premier groupe, elles se caractérisent par des longueurs de 630 à $710 \mathrm{~mm}$ et des largeurs de 46 à $52 \mathrm{~mm}$. Celles des catégories 1 et 2 forment le second groupe et se différencient des précédentes par leurs plus grandes dimensions, 860 à $910 \mathrm{~mm}$ de long pour
41 à $42 \mathrm{~mm}$ de large. C'est à ce dernier qu'appartiennent vraisemblablement les épées $\mathrm{Nal}$. 1 et 2 .

Toutefois, nous remarquons qu'elles se caractérisent toutes par la présence d'une arête médiane plus ou moins saillante, qui devient très prononcée dans le cas des exemplaires de la quatrième catégorie (une caractéristique que partage l'épée F.A. 5). Ces arêtes ne sont plus observables. Cependant, leur signalement revêt une grande importance si l'on prend en compte les découvertes de ces dernières années. L'épée Ser. 1 (fig. 8) évoque, tant par sa largeur que par sa section, les armes de la quatrième catégorie. C'est à ce même ensemble, les catégories 3 et 4, que s'apparente le fragment avec entrée de fourreau, Ser. 4.

La confrontation de ces données aux résultats des travaux de I. M. Stead sur les épées champenoises (Stead, 1983; De Navarro, 1972, p. 39, 128) nous incite à situer le premier groupe au début de La Tène moyenne (et peut-être à la fin de La Tène ancienne), tandis que le second, plus tardif, serait représentatif de la fin de cette même période et des débuts de la suivante.

\section{Fers et talons de lance}

\section{FAYE-L'ABBESSE (fig. 9)}

Seul un tiers du matériel d'hast est connu à ce jour. Aucune forme dominante ne se dégage parmi ces fers de lance, variès et le plus souvent atypiques. Qu'elles soient galbées, longues et larges, ou de forme indéterminée, les flammes se caractérisent (à l'exception de F.A. 20 et F.A. 21) par la présence d'une forte nervure médiane. La dissymétrie des nervures constitue un bon témoignage des difficultés inhérentes à la mise en forme. La morphologie de certaines douilles, fragiles et peu profondes (F.A. $14: 26 \mathrm{~mm}$; F.A. $20: 22 \mathrm{~mm}$ ) ne devait pas permettre un emmanchement solide. Les clous (ou rivets, leur identification n'est pas certaine) de fixation au nombre de deux ont été retrouvés dans deux cas (fig. $9, n^{\text {os }} 10$ et 11). La restauration des fers de lance F.A. 13 et 18 a également permis de reconnaître les trous destinés aux clous de fixalion; les autres semblent n'en avoir jamais eu. La douille du fer de lance F.A. 17 se singularise, chose rare, par un renflement à la base. Le prolongement de la nervure dans la douille (elle est vraisemblablement incomplète) confère à la pique F.A. 19 un profil losangé ; mais il peut aussi s'agir d'un fer de lance ayant perdu sa flamme.

Deux de ces armes (F.A. 20 et 21) diffèrent par leur taille et l'absence de nervure. Ces pièces que l'on peut considérer comme des armes de jet, trouvent 


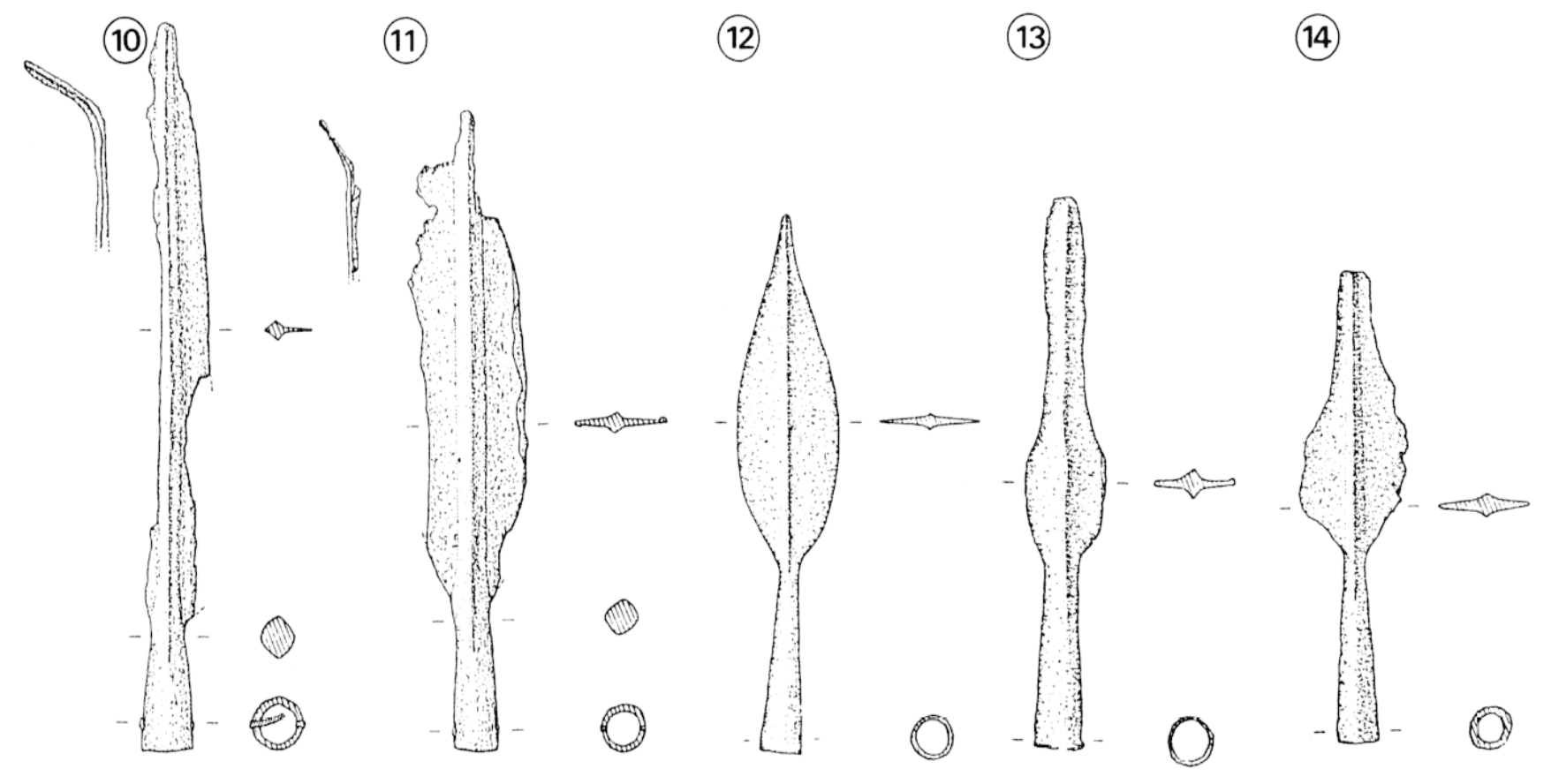

(15)

(16)

(17)

(18)

(19)

(20)
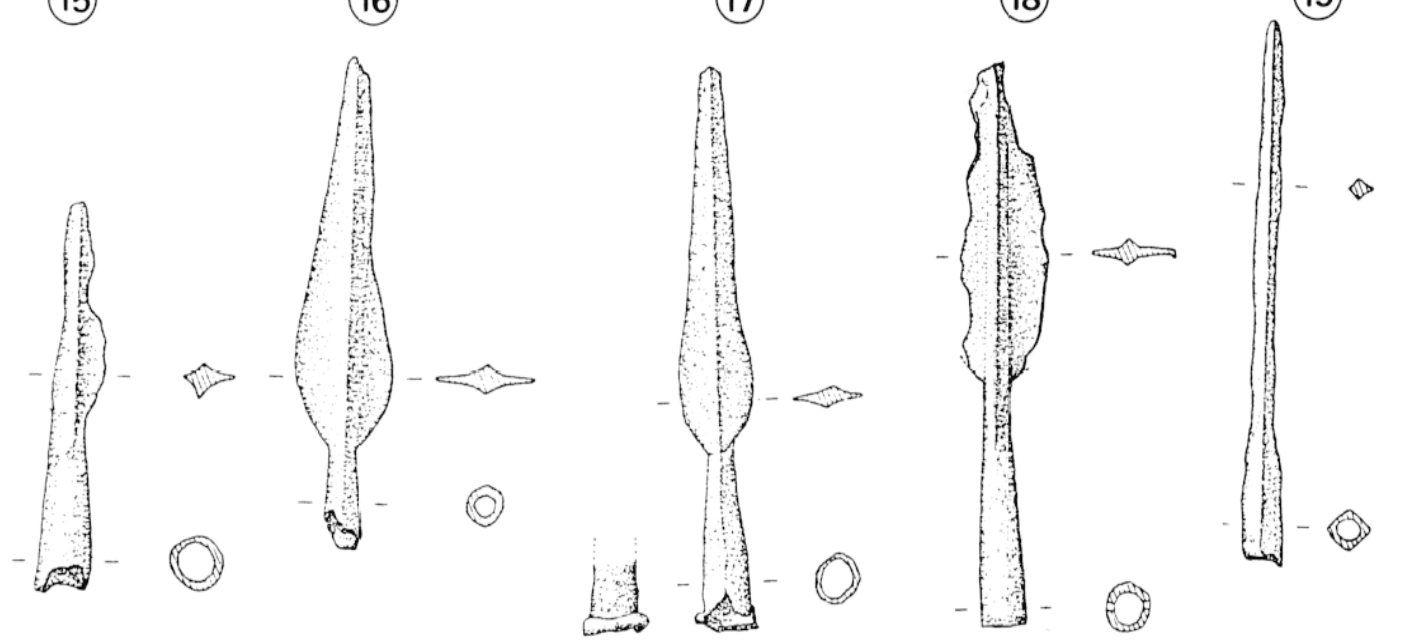

(21)
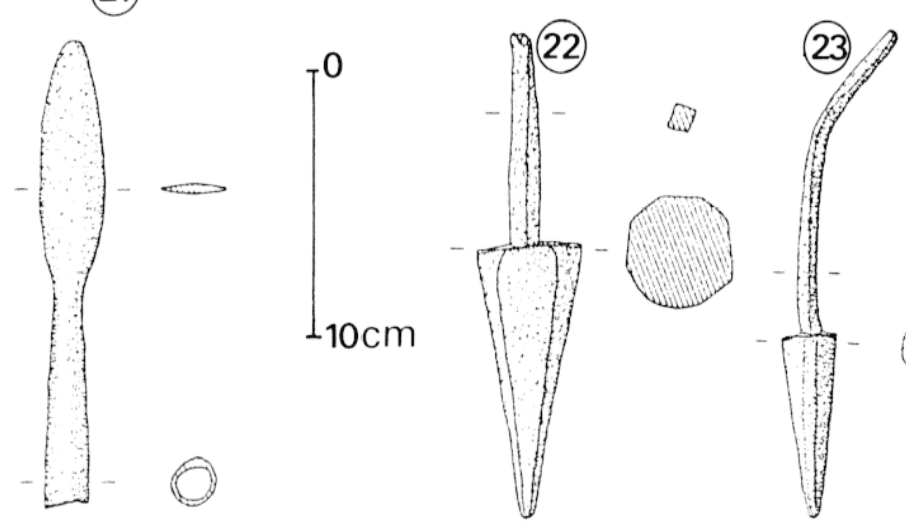

(24)

(25) (26) (27)

(28)

Fig. 9. - Faye-l'Abbesse : fers de lance $n^{\circ \mathrm{s}} 10$ à 21 ; talons de lance $n^{n s} 22$ à 28 (les talons $n^{08} 25$ à 28 ne sont pas restaurés). 
des éléments de comparaison à La Tène en Suisse et plus près de nous à Lacoste en Gironde (Vouga, 1923, pl. XIV; Boudet, 1987, pl. 126).

Les talons de lance varient aussi dans la forme et les dimensions. Tronconiques ou à pans coupés, ils sont tous du type à soie. On les retrouve indifféremment à La Tène (Suisse), à Gournay et à Ribemontsur-Ancre ; ce dernier site a livré des pièces tout aussi imposantes que le talon F.A. 22 (Vouga, 1923, pl. XIV; L'art cellique en Gaule, 1983/84, $\left.\mathrm{n}^{\circ} 110\right)$.

\section{NALLIERS}

L'intérêt des fers de lance de Nalliers, très endommagés et peu nombreux, est fortement réduit. Les commentaires de B. Fillon suggèrent l'existence de deux groupes suivant qu'ils avaient ou non une arête médiane. On remarque aussi la relative homogénéité des dimensions (de 190 à $240 \mathrm{~mm}$ ). Il n'a été trouvé aucun talon de lance (fig. 10 et 11).

\section{SYSTÈMES DE SUSPENSION DES FOURREAUX D'ÉPÉE}

\section{CONSIDÉRATIONS GÉNÉRALES}

Les chaînes de suspension de fourreau d'épée, ou bélières, pièces indissociables de la panoplie guerrière, ont été jusqu'aux récents travaux d'A. Rapin, considérées le plus souvent comme accessoires et indifféremment datées de La Tène movenne. L'usage de ces ceinturons était suffisamment singulier pour que Diodore de Sicile, à la suite de Posidonios, s'y intéresse $(\mathrm{V}, 30)$; pour le port de l'épée, les méditerranéens utilisaient ordinairement le baudrier (Rapin, 1987).

Essentiellement connues par les découvertes en milieu funéraire, aucune étude d'ensemble ne leur avait été consacrée jusqu'à la récente mise au jour d'un important lot, dans le sanctuaire gaulois de Gournay. La restauration qui accompagna l'étude du mobilier en renouvela l'approche typologique.

L'intérêt que nous portons à ce problème peut se justifier de deux manières. Ainsi que nous l'avons déjà souligné, les ceinturons métalliques représentent pour les sites de Nalliers et de Faye-l'Abbesse, des indicateurs de premier ordre pour la datation des phases anciennes. La seconde raison est liée à l'absence jusqu'alors, sur la façade atlantique, de ces objets qui connurent pourtant une large diffusion sur l'ensemble du monde celtique depuis la Yougoslavie jusqu'au Berry.

Les ceinturons métalliques se composent d'un élément court dont la longueur moyenne est de $150 \mathrm{~mm}$ et d'un autre, long de 500 à $550 \mathrm{~mm}$ en règle générale. Le brin court se termine par des anneaux

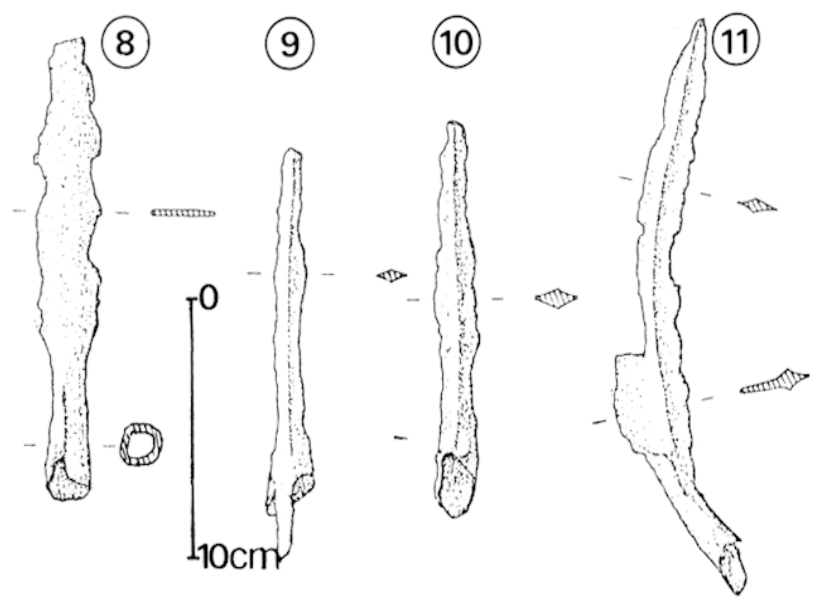

Fig. 10. - Nalliers : fers de lance $n^{\circ s} 8$ à 11 (non restaurés).

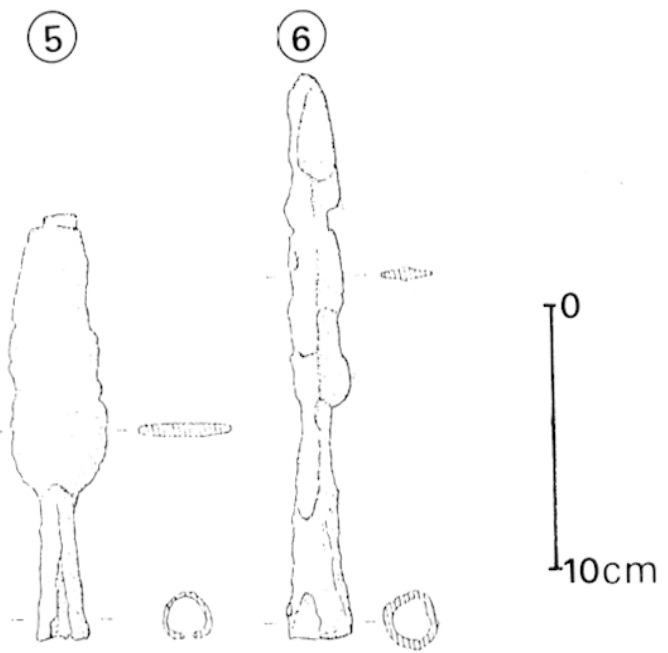

Fig. 11 - Les Serres : fers de lance nos 5 et 6 (non restaurés).

de différentes tailles; l'anneau le plus grand, fixé au fourreau, fait pendant à celui du brin long. Seule une solide fixation au pontet permettait de solidariser le fourreau avec le ceinturon et d'en limiter le flottement. Les chaînes plates à "échelle" ou de type "gourmette» (le "Panzer-Gürtel» des Allemands) présentaient, en raison de leur rigidité, un avantage certain. Le brin long se rétrécit progressivement et légèrement pour s'achever en un crochet à extrémité bouletée. Sur les chaînes anciennes, il arrive que l'agrafe soit comme à Bromeilles, sur le brin court (Willaume et alii, 1977, tombes 4 et 7). A. Rapin a pu, consécutivement à l'étude du mobilier de Gournay et de la sépulture de Rungis, proposer une reconstitution d'ensemble de ce mode de suspension où intervenaient des éléments organiques (ceinture de cuir). Étant donné la disparité de nos pièces nous ne reviendrons pas sur ce problème; les ceinturons métalliques poitevins doivent malheureusement être considérés comme une série d'objets isolés. 


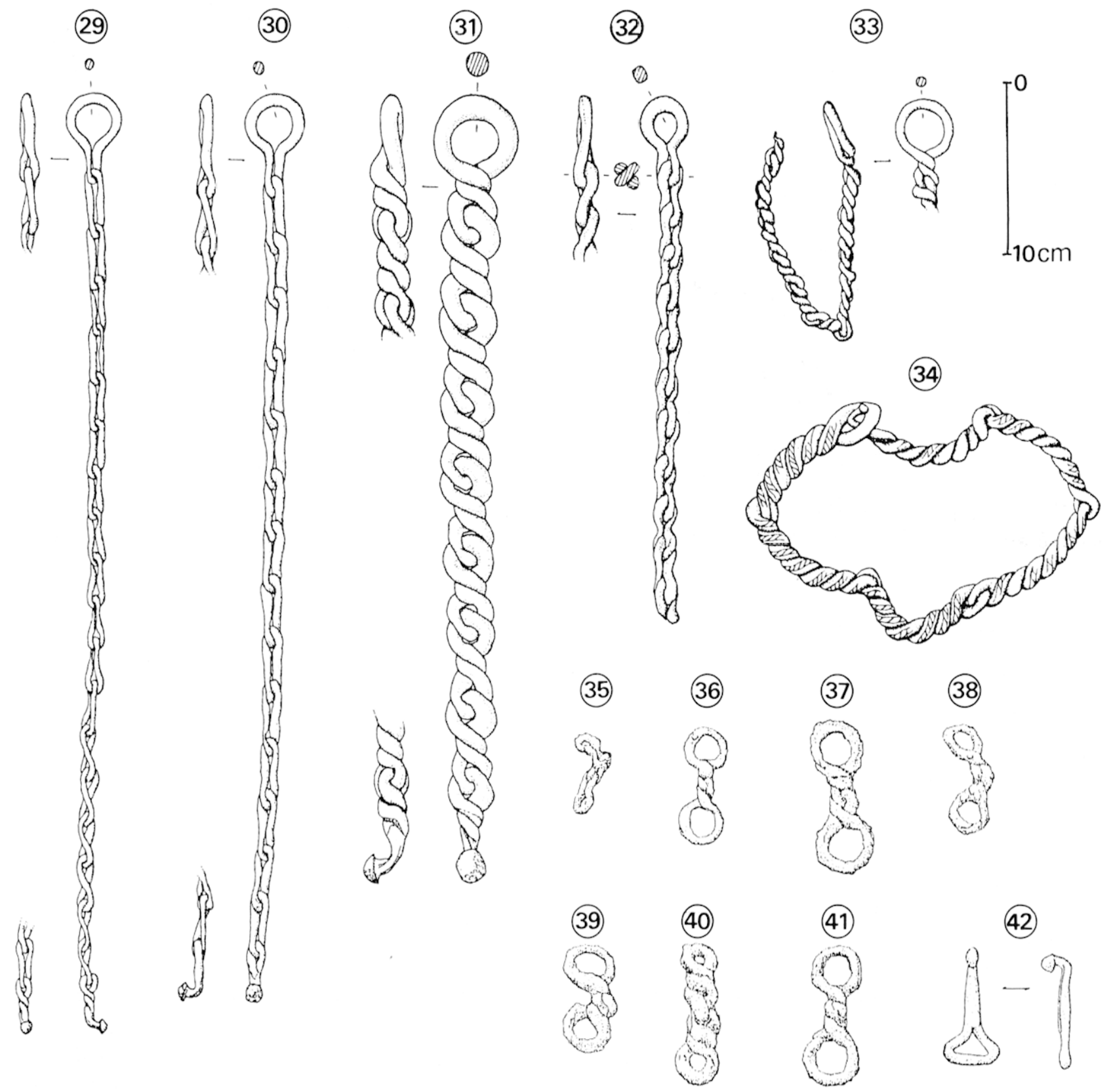

Fig. 12 - Faye-l'Abbesse : éléments de suspension de fourreau d'épée nos 29 à 42 (les chaines nos 35 à 41 ne sont pas restaurées).

\section{FAYE-L'ABBESSE}

Le nombre équivalent de brins courts et de brins longs ne doit pas nous faire oublier que nous ne possédons pas la moitié de la trentaine de chaines répertoriées. Si nous supposons que le lot de Fayel'Abbesse, tout comme celui de Nalliers, provient d'un ensemble plus vaste qui ne put être déterminé lors des fouilles du siècle dernier, on comprend mieux les incompatibilités typologiques entre brins longs et courts et, par conséquent, les problèmes d'association auxquels nous sommes confrontés.
Les brins courts sont représentatifs des types à "maillons torsadés" et à "maillons perpendiculaires" (ce dernier est aussi nommé type à "anneaux alternés»). Seule la chaîne F.A. 35 (fig. 12) appartient à la seconde catégorie, elle s'apparente par ses faibles dimensions aux exemplaires Nal. 17 et 20 (fig. 13). Les autres sont faites de l'assemblage de deux maillons torsadés sur un demi-tour, soit une rotation de $180^{\circ}$. La chaine F.A. 40 constitue au sein de ce groupe un cas particulier et original : elle se compose de deux maillons torsadés sur un tour, 

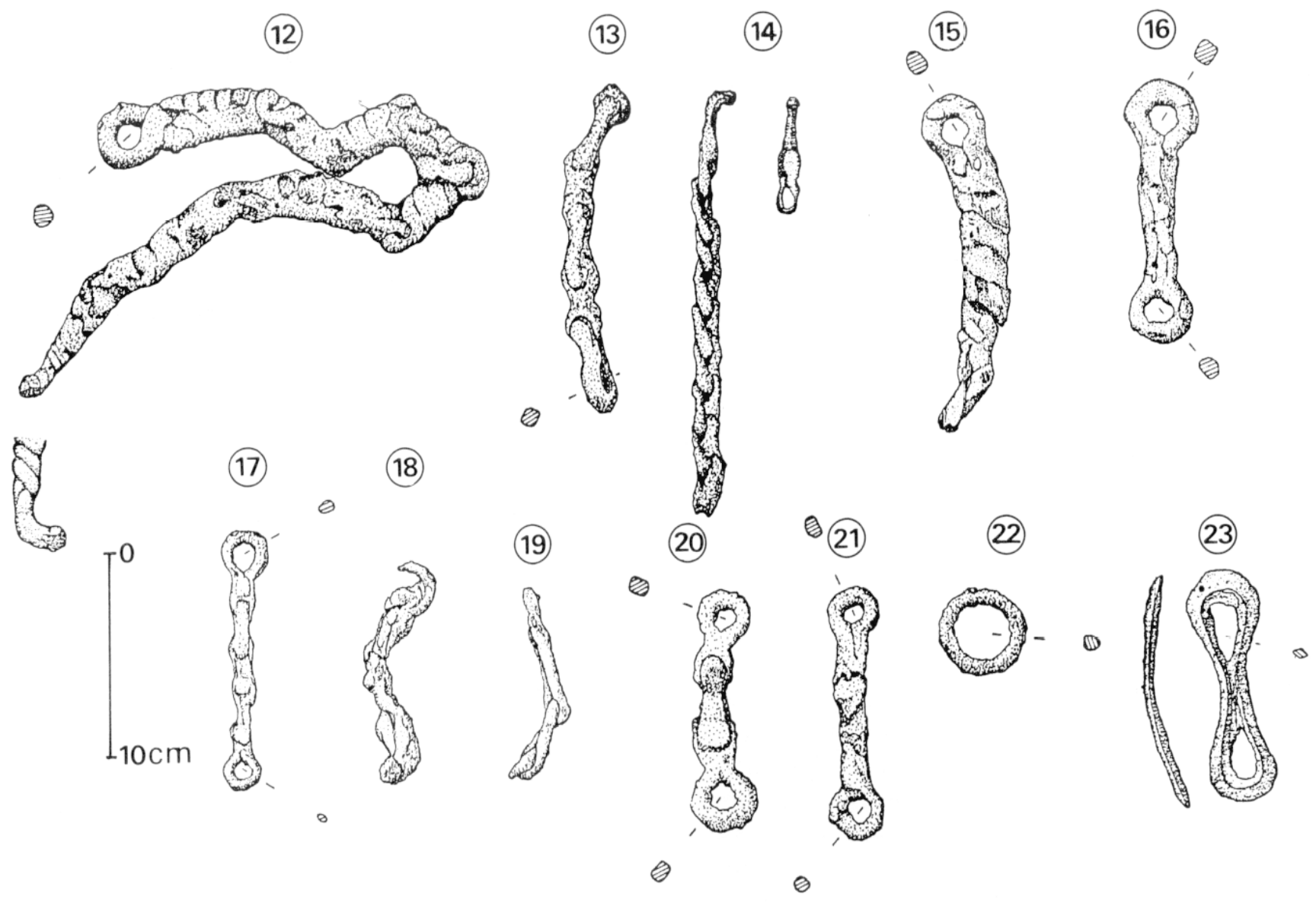

Fig. 13 - Nalliers : éléments de suspension de fourreau d'épée nos 12 à 23 (non restaurés).

réunis par un simple anneau. De longueurs variables $(132$ à $175 \mathrm{~mm})$ elles se caractérisent toutes, à l'exception de la chaîne F.A. 40, par des anneaux de taille relativement grande; ils n'ont cependant rien à voir avec ceux hypertrophiés que l'on rencontre par exemple à Ceretolo en Italie (Kruta-Poppi, 1979, fig. 2, diamètres internes des anneaux : 75 et $40 \mathrm{~mm}$ ). Contrairement aux "maillons torsadés" à un demi-tour (Karaburma, tombe 22, en Yougoslavie : Petres, Szabo, 1986, fig. 13; la chaîne en bronze de Bussy-le-Château reproduit cette technique : MAN, $\mathrm{n}^{\circ}$ 20.933) les maillons à un tour sont très largement répandus (Gournay : Rapin, 1983/84, pl. IV no 23 ; Nogent-sur-Seine, Aube : Joffroy, Thénot, 1976, pl. VIII $\mathrm{n}^{\circ} 4$; Saint-Maur-des-Fossés, Val-de-Marne : MAN; Maubranches, Cher: Willaume, 1985, p. 100, pl. 30 ; Ceretolo, sépulture de 1878, et Bologne-Benacci, sépulture $\mathrm{n}^{\circ} 176$, Italie : KrutaPoppi, 1979, fig. 2 et 7). Nous n'insisterons pas sur les exemplaires en bronze qui reproduisent ces "motifs" puisque leur conception relève d'une toute autre technique (Gournay : L'art cellique en Gaule,
$1983 / 84, \mathrm{n}^{\circ} 106$; Fère-Champenoise, tombe 56 : Brisson et alii, 1970, pl. IX ; Bourges, place du Commandant Martin : Willaume, 1985, p. 26, pl. 2...).

Les éléments longs qui étaient masqués par une importante gangue de corrosion ont pu être étudiés dans les meilleures conditions grâce à la restauration. Cette intervention a permis non seulement de déterminer les différents types mais surtout de mettre en lumière des ornements originaux indécelables aux seuls examens radiographiques.

Les chaînes à maillons de type "quart de tour" sont au nombre de deux : F.A. 29 et 30 (fig. 12); la torsion de $90^{\circ}$ permet de présenter une face légèrement plane contre le corps, les éléments saillants étant orientés vers l'extérieur. La seconde est, chose remarquable, recouverte sur chaque maillon d'une mince feuille de bronze qui ne subsiste plus qu'à l'état résiduel. Apparaissant uniquement lors de la restauration, cette technique peu commune qui consiste à masquer le fer sous une "dorure» a été reconnue sur un certain nombre de pièces d'armement de la fin de La Tène ancienne: anneau de 
suspension de la tombe 3 d'Écury-le-Repos (Marne); ceinturon composé de barres plates incurvées, reliées par des anneaux, de la sépulture de Morains "Les Terres-Rouges" (Marne); certains rivets de bouclier (Roualet et alii, 1982, p. 37; 1983, p. 14). La présence de cuivre à l'état de traces est également attestée en Centre-Ouest sur un fragment de soliferreum de la grotte du Quéroy (Charente) daté de la fin du premier Age du Fer (renseignement: R. M. Legendre, J. Gomez de Soto qui nous signale aussi l'utilisation de cuivre, mais cette fois en incrustation, dans l'ornementation des mors de la tombe à char de Condé-sur-Marne). La chaîne F.A. 32 tend par ses anneaux légèrement couchés et sa section quadrangulaire en une forme mixte qui tient à la fois des types à "maillons perpendiculaires", "quart de tour" et "gourmette». Elle apparaît de ce fait comme un prototype des véritables chaînes du type "gourmette». Les autres sont représentatives des types à "maillons torsadés" simples ou multiples. Les chaînes F.A. 31 et 33 , à «maillons torsadés courts", restent classiques et trouvent de nombreux équivalents tant en fer qu'en bronze. La chaine F.A. 31 se singularise par la grosseur de ses maillons faits d'un "fil" dont le diamètre avoisine ou dépasse le centimètre; il s'agit d'une pièce assez ancienne. Enfin, la chaîne F.A. 34, enroulée sur elle-même, revêt ici un caractère particulier puisqu'elle appartient au type le plus ancien des chaînes à "maillons torsadés". Les tombes 4 et 7 de la nécropole de Bromeilles, datées de la première moitié du $11 I^{\circ} \mathrm{s}$. avant $J$.-C., en ont livré de semblables, sauf en ce qui concerne le crochet qui appartient non plus au brin long mais au court (Willaume et alii, 1977). Les maillons sont faits de torsades multiples mesurant environ $80 \mathrm{~mm}$ et sont incurvés de manière à épouser l'arrondi des hanches. La restauration a révélé en outre la présence d'un décor gravé. Le motif recouvre uniformément la totalité de la chaîne sur sa face convexe. La rareté de ce type d'ornementation doit être soulignée mais elle est surtout due à l'absence de recherches systématiques - dans le même ordre, l'attention portée depuis une dizaine d'années aux fourreaux d'épée a permis d'accroître considérablement le répertoire des exemplaires décorés. Nous sommes redevables à D. Božič de nous avoir indiqué l'existence de pièces semblables en Yougoslavie; il s'agit de chaînes à torsades simples ornées de motifs un peu plus élaborés mais moins bien conservés : tombe 2 de Brežice, sépulture de Smihel et peut-être celle de la tombe 233 de Horný Jatov, Trnovec en Slovaquie. Ainsi que nous l'avons dit, le petit nombre d'objets de ce type actuellement restaurés ne nous autorise pas à être affirmatif en ce qui concerne la signification de ces décors et les rapprochements que l'on serait tenté d'établir avec des régions aussi lointaines à une période où le monde celtique semble animé par d'incessants mouvements de groupes humains.

\section{NAI.I.JERS (fig. 13)}

Nous sommes ici confrontés aux mêmes problèmes qu'à Faye-l'Abbesse; malheureusement, toutes les pièces n'ont pu être identifiées en l'absence d'examens radiographiques (Nal. $15,16,18$ et 21) leur classification demeure par conséquent incertaine.

Les brins courts se singularisent par leurs faibles dimensions (120 à $130 \mathrm{~mm}$ ) et des anneaux de petite taille. Ils sont représentatifs des types à «maillons perpendiculaires" ( $\mathrm{Nal} .17$ et 20) et à "maillons quart de tour" (Nal. 16 et 21 ?).

Les brins longs, souvent brisés, relèvent des mêmes types et se caractérisent aussi par la petite taille de leurs anneaux. Le fragment de chaîne Nal. 14 est formé d'un assemblage de «maillons quart de tour". Les chaînes Nal. 12 et 15 procèdent tout autrement, elles sont faites de maillons à torsades multiples, longs et aplatis ; cela est particulièrement sensible dans le cas de la seconde, malheureusement incomplète. Cette dernière évoque à bien des égards des exemplaires tardifs de type "Panzer-Gürtel»; il ne semble pourtant pas qu'elle soit faite comme ces derniers d'un assemblage de maillons simples et aplatis, à la façon des gourmetles. La chaîne Nal. 12 présente, pour sa part, des analogies avec les chaînes de type relativement ancien, dont nous connaissons un exemplaire à Fayel'Abbesse (F.A. 34). Ces deux dernières chaînes n'ont pas leur semblable parmi les brins courts.

Les chaînes à "maillons perpendiculaires", bien attestées localement, ne semblent pas avoir connu une grande diffusion; elles sont également présentes à Gournay ainsi qu'en Tchécoslovaquie.

L'usage du ceinturon métallique pour la suspension des fourreaux d'épée ne constitue pas, en dépit de son originalité, un précédent dans le monde antique. Au vi's. avant notre ère, en Italie, les Sabins attachaient leurs courtes épées au ceinturon par deux petites chaînettes de fer fixées latéralement par rivetage (Rapin, 1987, p. 529). Ce système fut aussi utilisé sur un poignard de La Tène ancienne, provenant de Chassemy (Aisne; MAN, n³8.138). Les chaînettes fixées par la corrosion sur le fourreau en fer sont positionnées de part et d'autre du pontet. Ce phénomène isolé ne suffit cependant pas à expliquer l'adoption, deux siècles plus tard, du ceinturon métallique. 
Ce n'est qu'au cours du in' $\mathbf{s}$. avant J.-C. que se répand son usage. D'abord, simples bandes de métal incurvées et articulées par des anneaux intermédiaires (sépultures de Morains et d'Écury-le-Repos : Roualet et alii, 1982, p. 37; 1983, p. 14-15) ils devinrent ensuite de vraies chaînes faites d'un assemblage de maillons simples ou torsadés (Bromeilles, tombes 4 et 7). Les bélières se substituèrent progressivement à l'ancien mode de suspension où se combinaient ceinture de cuir et anneaux métalliques (fer ou bronze). V. Kruta et M. Szabo ont montré dans une récente étude que les ceinturons torsadés plats apparaissaient, dans la Celtique orientale, au sein d'ensembles datés du deuxième quart du III $^{\mathrm{e}} \mathbf{s}$. avant J.-C. (Karaburma, t. 41 : Kruta, Szabo, 1982, p. 62). A. Rapin suggère une datation tout aussi haute pour les premières chaînes à maillons longs et torsadés. Leur évolution est encore mal connue.

L'abandon de ce mode de suspension vers le milieu du II $^{\mathrm{e}} \mathrm{s}$. avant $J$.-C. ne manque pas de nous surprendre; à cela plusieurs raisons possibles. Ce système, devenu trop pesant et encombrant, en raison d'un allongement général des épées, se révéla vite inadapté (les chaînes ne doivent être considérées que dans leur rapport avec l'ensemble fourreauépée). On lui substitua un autre système, proche de l'ancien, basé sur le ceinturon de cuir avec anneaux et agrafe. A. Rapin souligne la parenté d'aspect entre certains types tardifs de "Panzer-Gürtel" et les ceintures de cuir tressé; se référer à la statuette en bronze, trouvée à Rome, d'un guerrier celte nu brandissant une arme (?) qui a pour toute parure un casque, un torque et une ceinture tressée (Staatliches Museum, Berlin).

La nouvelle tendance est illustrée à Nalliers comme à Faye-l'Abbesse par quelques pièces caractéristiques telles que agrafe et anneaux :

- Anneau en forme de "8» provenant de Nalliers (fig. 13, Nal. 23).

La fonction et la datation de ce genre d'anneau, peu fréquent, ont pu être précisées grâce aux anciennes découvertes du gisement de La Tène (Suisse). Un anneau simple, une agrafe et deux anneaux de ce type accompagnaient une épée dont le fourreau est caractéristique du groupe B défini par De Navarro. Les anneaux, étranglés en forme de 8 , étaient disposés de part et d'autre du pontet. Le profil courbe de ces pièces n'avait d'autre but que de s'adapter à la forme de la hanche. Le dépôt de Tiefenau a lui aussi livré des anneaux de ce type (Vouga, 1923, p. 44-46, pl. III et VII; Müller, 1986, p. 191-192).
- Anneau simple provenant de Nalliers (fig. 13, Nal. 22).

Il peut provenir d'un ceinturon de ce type mais nous ne pouvons être affirmatif.

- Agrafe de ceinturon provenant de Fayel'Abbesse (fig. 12, F. A. 42).

Elle est l'unique témoin de ce mode de suspension à Faye-l'Abbesse. Ces objets, bien attestés à La Tène (Suisse) et à Gournay, sont aussi datés de la fin $\mathrm{du} \mathrm{II}^{\mathrm{e}} \mathrm{s}$. et du début du $\mathrm{I}^{\mathrm{er}} \mathrm{s}$. avant J.-C. (Vouga, 1923, pl. VIII ; Rapin, 1983/84, p. 79).

Pour conclure, on peut affirmer que l'usage du ceinturon métallique s'est développé à une époque où tendait à s'uniformiser la panoplie guerrière, la "Dreierausrüstung" des auteurs germaniques. Cette standardisation est liée à la circulation de groupes d'hommes en armes. En effet, les revers subis tant en Grèce qu'en Italie entraînèrent un reflux et une disponibilité de la masse guerrière (Kruta, 1983, p. 71-77). Connu dès le deuxième quart du III $^{e} \mathrm{~s}$. avant J.-C. (sous diverses formes), l'emploi de ces chaînes ne se généralisa que dans la seconde moitié de ce siècle et se perpètua jusque vers le milieu du II $^{\mathrm{e}} \mathrm{s}$. (Vouga, 1923, p. 44; curieusement, le site de La Tène n'a livré aucun ceinturon métallique). Si leur typologie nous est aujourd'hui assez familière, il n'en va pas de même pour les considérations d'ordre typo-chronologique. Ce problème est crucial pour les types à "maillons quart de tour" et à "maillons perpendiculaires" particulièrement bien représentés à Nalliers et à Faye-l'Abbesse. Une reconsidération globale des ensembles clos (sépultures avec chaînes, épée, umbo ...) s'avère d'ores et déjà nécessaire.

Nous retiendrons donc pour les ceinturons métalliques poitevins une datation comprise entre le milieu du III $^{e} \mathrm{~s}$. avant J.-C. et la première moitié du $\mathrm{II}^{\mathrm{e}} \mathrm{s}$. Une dominante des formes anciennes (deuxième ou troisième quart du III ${ }^{e}$ s. avant J.-C.) paraît désormais assurée pour les exemplaires de Fayel'Abbesse.

\section{AUTRE MOBILIER}

\section{Couteaux À Douille}

Quatre couteaux à douille proviennent des découvertes de Nalliers (fig. 15, Nal. 24, 25 et fig. 16, Ser. 7) et un de Faye-l'Abbesse (fig. 14, F.A. 44).

Peu communs, ces ustensiles se rencontrent essentiellement dans le nord de la France, mais leur datation varie selon les sites, de La Tène ancienne à l'époque romaine. Deux couteaux de ce type provenant de Ciply (Belgique) sont datés de la fin de 


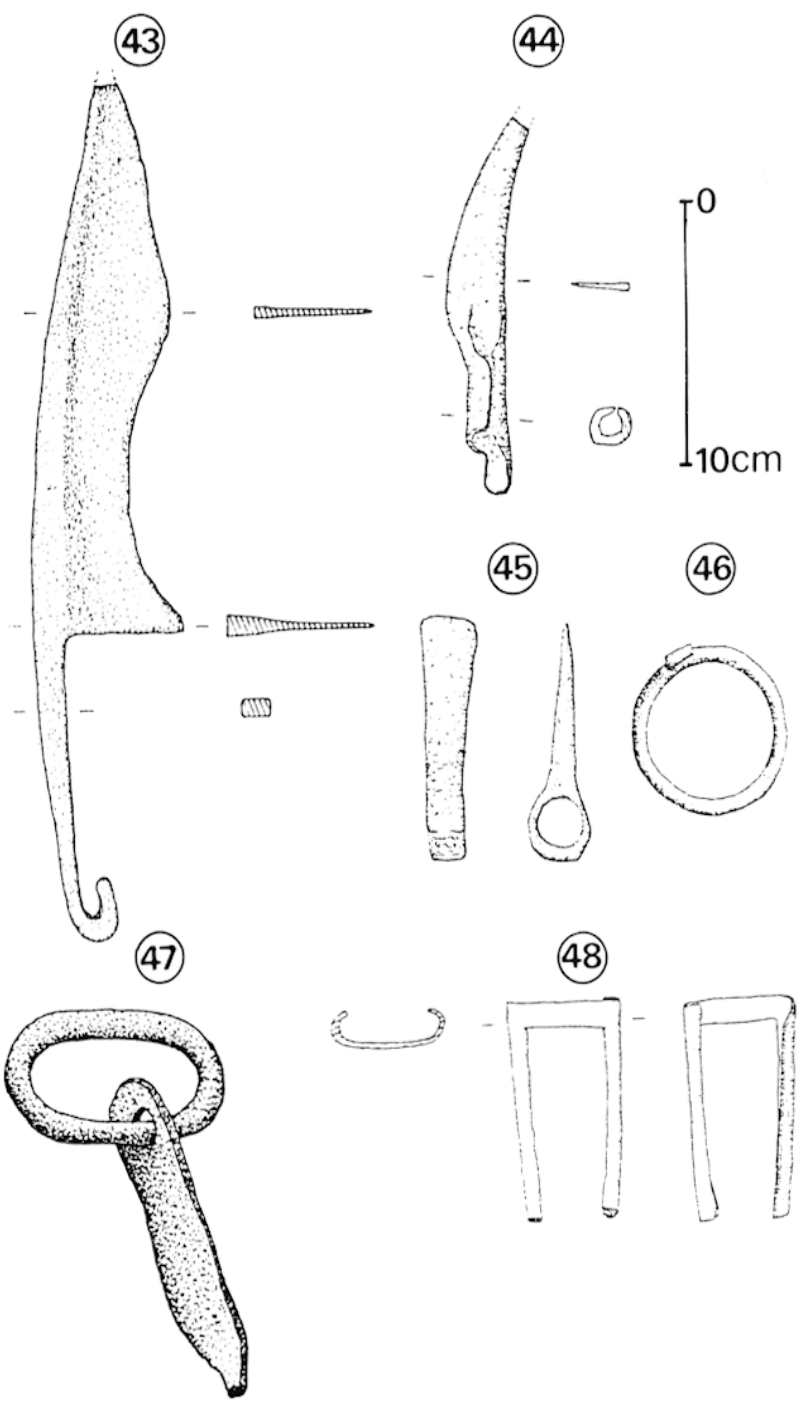

Fig. 14 - Faye-l'Abbesse : mobilier divers no* 43 à 48 .

La Tène ancienne; sommaire, la douille est formée du repli de deux ailerons (Marien, 1961, p. 85-90, 179 et 185). Légèrement postérieurs, les trois exemplaires de Breuil-le-Sec (Oise) ainsi que celui de Tartigny (Oise) sont datés d'après leur contexte céramique des débuts de La Tène moyenne (Degenne, Duval, 1983, p. 78-84; Massy et alii, 1986, p. 61). Le couteau de Menil-Annelles (Ardennes) a été trouvé en association avec des fibules de La Tène III, à pied continu avec l'axe formant un porte-ardillon rectangulaire (Flouest, Stead, 1981, p. 27-28). Le site de La Tène, en Suisse, a également produit plusieurs couteaux de ce type, mais leur datation (La Tène moyenne ou finale) n'est pas assurée. De même, un exemplaire de Peronnes-les-Binches pourrait éventuellement dater de la période romaine (Vouga, 1923, p. 109; Marien, 1961, p. 179).

En Centre-Ouest, ces couteaux sont en outre connus par deux spécimens provenant d'Agris (Charente) et des Pichelots (Maine-et-Loire), datés de la fin de La Tène moyenne ou du début de la période suivante (renseignement J. Gomez de Soto; Gruet, 1987). Les comparaisons régionales et les ressemblances morphologiques avec les exemplaires de La Tène et de Menil-Annelles suggèrent une datation tout aussi basse pour les pièces de Nalliers et de Fayel'Abbesse.

\section{Couteau Ȧ SOIE et LAME ONDULÉE,} FAYE-L'ABBESSE (fig. 14, F.A. 43)

Ces ustensiles sont bien connus et généralement datés de la période romaine; ils figurent également dans les trophées d'armes gauloises qui ornent l'arc d'Orange. Un couteau de ce genre a jadis été trouvé à Civaux (Vienne; musée de Civaux), mais il se caractérise par une plus petite taille et une échancrure de la lame plus prononcée (Gendron, Gomez de Soto, 1986).

\section{HACHETTES, FAYE-L'ABBESSE (fig. 14, F.A. 45)}

Sa taille réduite en fait probablement un exvoto. De tels objets sont fréquents dans des sanctuaires comme celui de Flavier à Mouzon (Ardennes) (Tisserand, 1980, p. 63-73). Plus près de nous, l'habitat de Lacoste (Gironde) en a également livré (Boudet, 1987, pl. 112).

\section{FRAGMENT DE BOUTEROLLE EN BRONZE, $F_{A Y E-L}$ 'ABBESSE (fig. 14, F.A. 48)}

Incomplète, elle retient néanmoins notre attention par son matériau et surtout parce qu'elle est actuellement la seule bouterolle connue en Poitou au second Age du Fer.

Sans être exceptionnels, les fourreaux et bouterolles de bronze restent rares. Ils sont attestés dans l'ensemble du monde celtique aussi bien à La Tène ancienne (Bavilliers-Méroux : L'art cellique en Gaule, 1983/84, n 46; Vert-la-Gravelle et Hallstatt : Jacobsthal, $1969, \mathrm{n}^{\text {os }} 90$ et 96 ) qu'à La Tène finale (fourreau à échelle de Basse-Marne : L'art cellique en Gaule, 1983/84, $\mathrm{n}^{\circ} 221$; Tesson (Charente-Maritime) : Duval et alii, 1986; Little Wittenham et Isleham, Angleterre : Stead, 1985, ${ }^{\text {os }} 63$ et 67 ; les liens avec les îles Britanniques sont attestés de longue date, comme en témoignent à La Tène finale les poignées d'épées anthropoïdes de Tesson, de Châtillon-surIndre et de Ballyshannon en Irlande).

ANSES DE RÉCIPIENTS, NaLLIERS (fig. 15, Nal. 30, $31,34,35)$

Malgré leur mauvais état de conservation et leur petit nombre, nous pouvons, en nous référant aux 

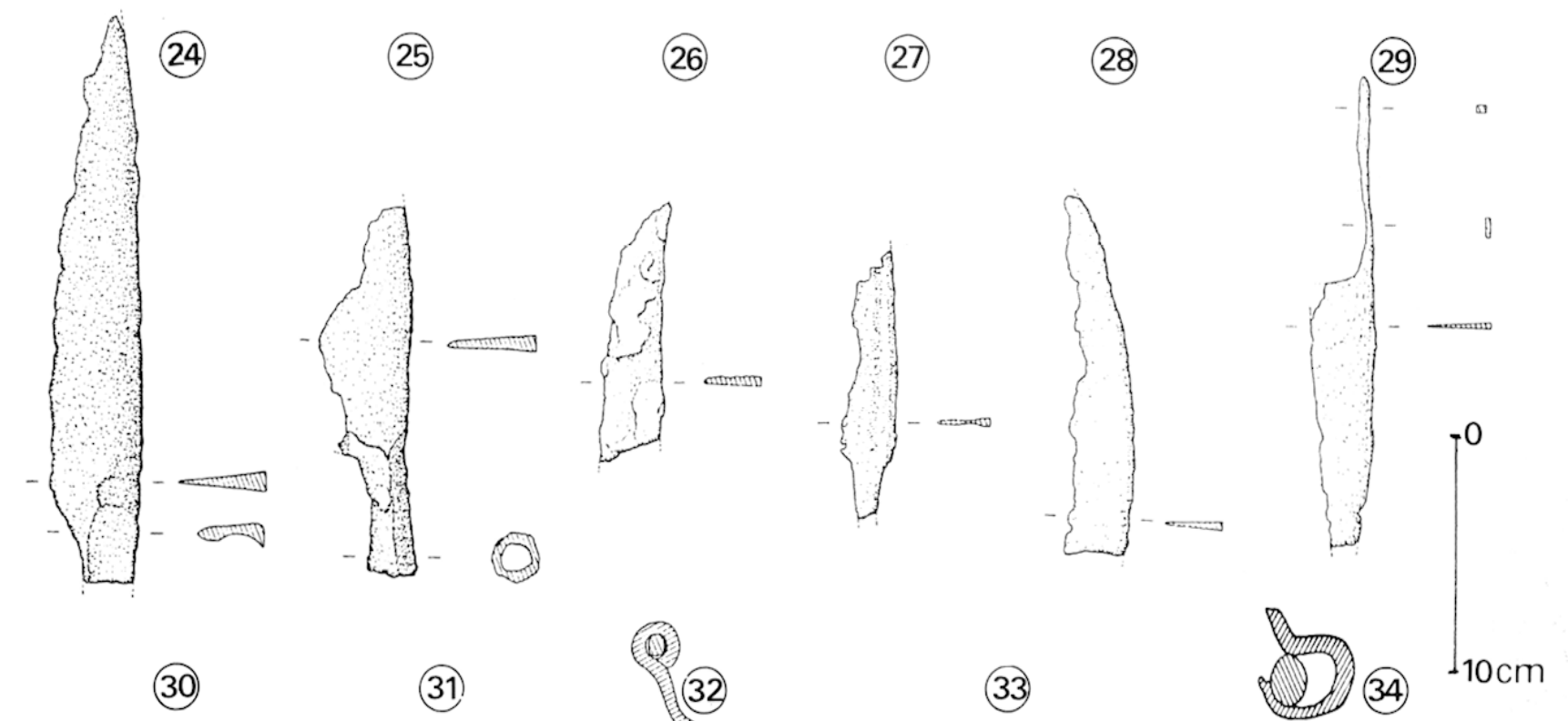
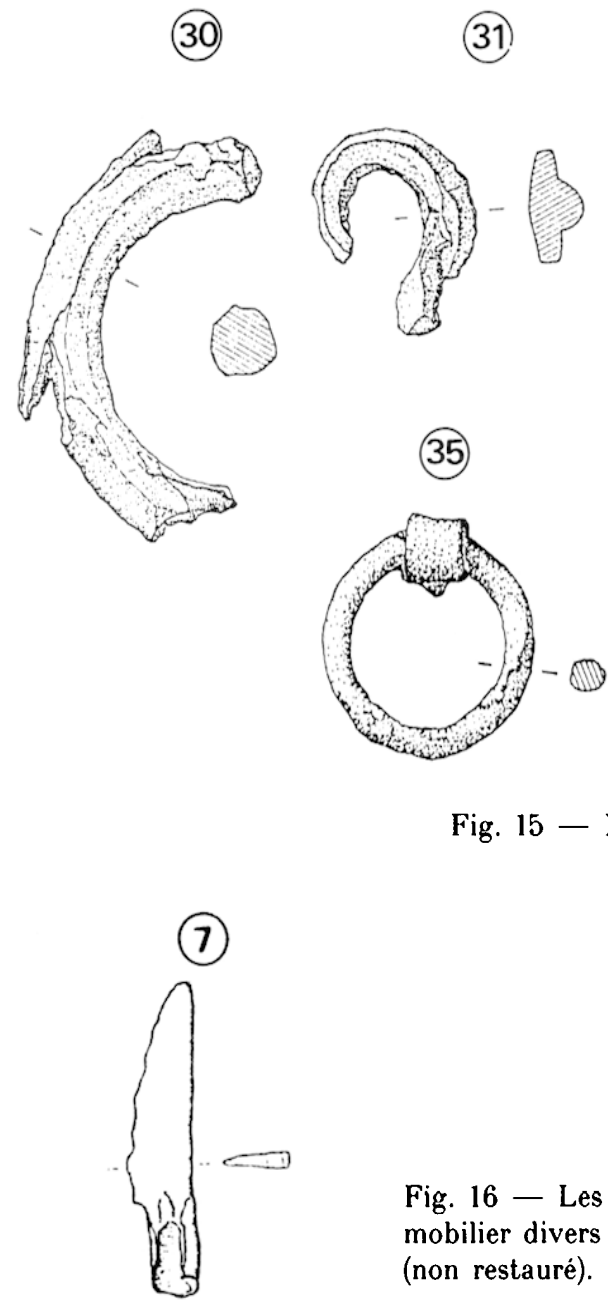
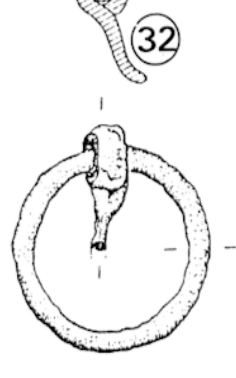

(36)

(33)

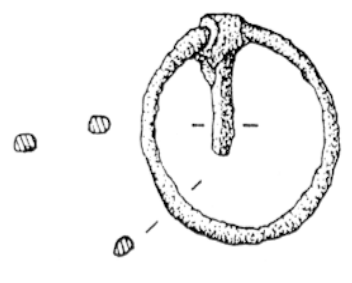

(37)
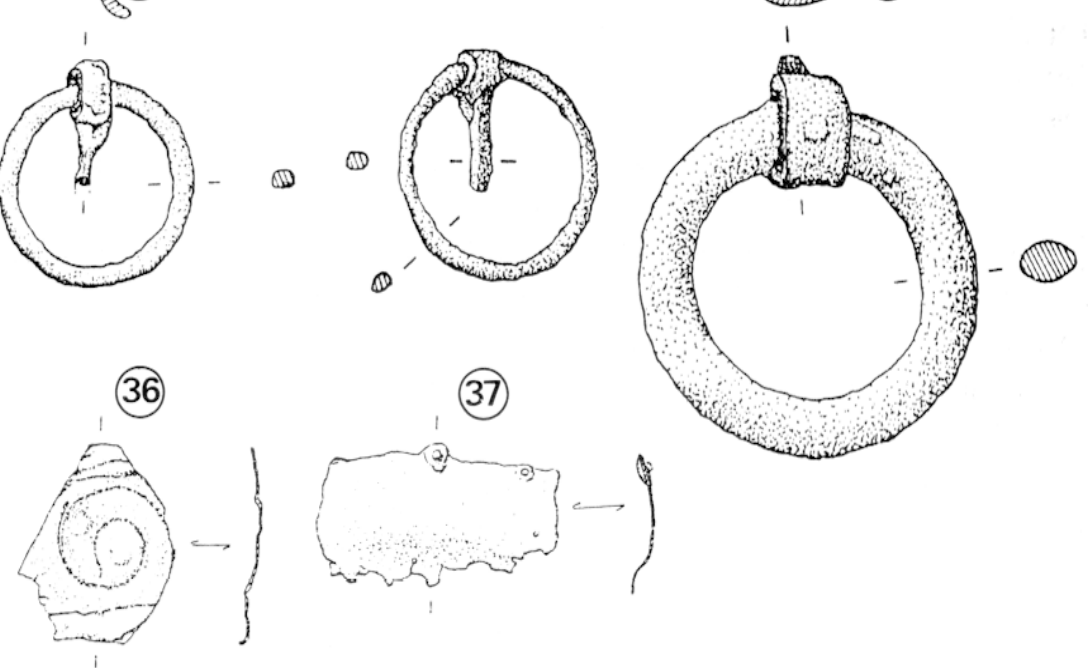

Fig. $15-$ Nalliers : mobilier divers ${ }^{\text {os }} 24$ à 37 (non restauré).

Fig. 16 - Les Serres : mobilier divers $\mathrm{n}^{\circ} 7$ (non restauré). gravures d'O. de Rochebrune (fig. $6, \mathrm{n}^{\circ} 38$ ), en restituer la physionomie originelle. Ces objets, avec bague d'articulation côtelée, sont connus en différents endroits comme à La Tène (Vouga, 1923, p. 8082 , pl. XXVII). Le mobilier ancien du sanctuaire du Pain-Perdu à Niort a livré une anse de chaudron dont l'âme, en fer, est recouverte d'une feuille de bronze ornée d'un motif typique du style de Waldalgesheim (Gomez de Soto, 1986a, p. 136). Le fragment d'anse et la bague d'articulation présentent plusieurs entailles qui pourraient suggérer une similitude de traitement avec les armes (seule leur restauration permettra de déterminer s'il s'agit de coups volontairement assénés ou de fractures provoquées par l'oxydation).

\section{Pratiques sacrificielles}

La "destruction" des armes est un phénomène qui dépasse largement l'univers celtique dans le temps et l'espace. Cette pratique commune aux rituels funéraires et cultuels, ne revêt peut-être pas la même signification dans l'un et l'autre cas. Le 
traitement de la céramique dans certains ensembles sépulcraux relève d'une démarche comparable. L'enclos circulaire $n^{0} 4 / 5$ de Coulon, daté du début du second Age du Fer, a livré une série de vases systématiquement brisés (Pautreau, 1986).

Dans les sépultures, le bris et le ployage des épées sont attestés dès le viri ${ }^{e} s$. avant $J .-C$., en Grèce (Snodgrass, 1980, p. 349) ainsi que dans la sphère hallstattienne et, un peu plus tard, dans le Sud-Ouest de la France. Au premier Age du Fer, le Berry et le Centre-Ouest ne semblent pas concernés par ce phénomène. En Champagne, ces pratiques sont connues à La Tène ancienne (Bretz-Malher, 1971, p. 106). Cependant, leur généralisation ne date que de la période suivante et peut être mise en parallèle avec la diffusion du rite de l'incinération (même si les inhumations ne sont pas rares, le rite de l'incinération semble avoir été à l'honneur pendant tout le premier millénaire avant notre ère en CentreOuest). En Poitou, les pratiques sacrificielles sur les armes ont été constatées à Mazerolles (sépultures), à Nalliers et à Faye-l'Abbesse. Un démantèlement rituel a aussi été envisagé pour le casque d'Agris (Gomez de Soto, 1986c, p. 181). En Centre-Ouest, la sépulture de La Font-Barbot, près de Pons (Charente-Maritime), montre l'application de ce rituel sur le fourreau et l'umbo, à la fin du $\mathrm{II}^{\mathrm{e}} \mathrm{s}$. avant notre ère (Gomez de Soto, 1986b).

A Nalliers ainsi qu'à Faye-l'Abbesse, la consécration des armes ne passe pas forcément par une destruction systématique et minutieuse comme elle a pu être observée à Gournay. C'est sur les épées que se concentrent le maximum d'efforts. Toutefois, il n'est pas toujours possible de différencier les coups assenés rituellement de ceux reçus au combat (Brunaux et alii, 1985, p. 176). Elles sont ployées (F.A. 1, 4; Nal. 4; épée à sphères de Germond, Deux-Sèvres) et le plus souvent brisées consécutivement à un ployage. Par sa cassure, à peu près à mihauteur, l'épée Ser. 1 s'apparente dans son traitement, tout comme l'une des lames de Mazerolles, à l'arme découverte dans un enclos funéraire près de Levroux (Colin, Buchsenschutz, 1984, p. 205). Les traces de pliage et de torsion ayant entraîné la rupture sont particulièrement évidentes dans le cas du fragment distal F.A. 7. D'autres pratiques plus "discrètes", mais aussi plus caractéristiques, telles que "crantage" et "pliage partiel des tranchants" sont perceptibles sur plusieurs épées (F.A. 6, 7 et 8; Ser. 2 ; Mazerolles 3). Les épées F.A. 7 et Mazerolles 3 offrent un répertoire assez complet des pratiques sacrificielles. L'épée F.A. 5, retrouvée avec son fourreau, ne présente aucune marque de destruction et peut être comparée en cela à certaines des armes les plus anciennes de Gournay, intactes ou uniquement pliées en V (Brunaux et alii, 1985, p. 123).

Ces marques sont également perceptibles sur les fers de lance, mais à moindre degré (ployage, pliage partiel des bords de la flamme et crantage). Deux talons de lance montrent une torsion de la soie qui peut être imputée au bris de la hampe (parallèle à Gournay : L'art cellique en Gaule, 1983/84, $\mathrm{n}^{\circ} 110$ ).

Se prêtant mal à ces pratiques, les chaînes ont été détachées des fourreaux comme le montre le brin long F.A. 34, enroulé et refermé sur lui-même. Certaines d'entre-elles ont été brisées.

A Gournay, site de référence en la matière, rares sont les objets, hormis les outils, demeurés intacts. La fouille a permis de mettre en évidence au sein de ces dépôts une évolution assez marquée dans la pratique sacrificielle. Dans les niveaux les plus anciens (milieu III $\mathrm{s}$. avant $\mathbf{J}$.-C.) les mutilations restent sommaires. Les couches supérieures offrent un tout autre panorama, les destructions se font plus complexes et touchent l'ensemble du mobilier.

Le sacrifice de l'objet en fer, par le traitement de la matière qu'il suggère, est à rapprocher du sacrifice animal; leur aboutissement spatial et temporel est le même : le fossé à exposition et la ruine des matériaux (rouille et pourriture ne sont que l'expression d'un retour à un état premier, minéral).

Nalliers et Faye-l'Abbesse, deux sanctuaires celtigues en Poitou

L'analyse de ces ensembles a permis de souligner l'hétérogénéité du mobilier ainsi que d'importantes variations chronologiques.

On distingue au sein de chaque site une phase d'occupation (ou plus exactement de dépôt) ancienne et une récente. L'existence d'une éventuelle phase intermédiaire n'a pu être définie de façon satisfaisante.

\section{FAYE-L'ABBESSE}

- Phase ancienne : elle est principalement illustrée par les chaînes de suspension de fourreau d'épée et les lames F.A. 5 et 3 (?) qui sont représentatives du groupe 1 défini à partir du descriptif de la publication de 1853.

- Phase récente : les épées F.A. 1 et 4, appartenant au groupe 2 , caractérisent cette phase de même que les fers de lance F.A. 20 et 21 et le couteau à douille (F.A. 44).

- Phase moyenne : elle peut être individualisée à partir des épées F.A. 7 et 8 et de l'agrafe (F.A. 42). Elle correspond à la fin $d_{u}{ }_{11}$ et au début du $\mathrm{I}^{\text {er }} \mathrm{s}$. avant J.-C. 


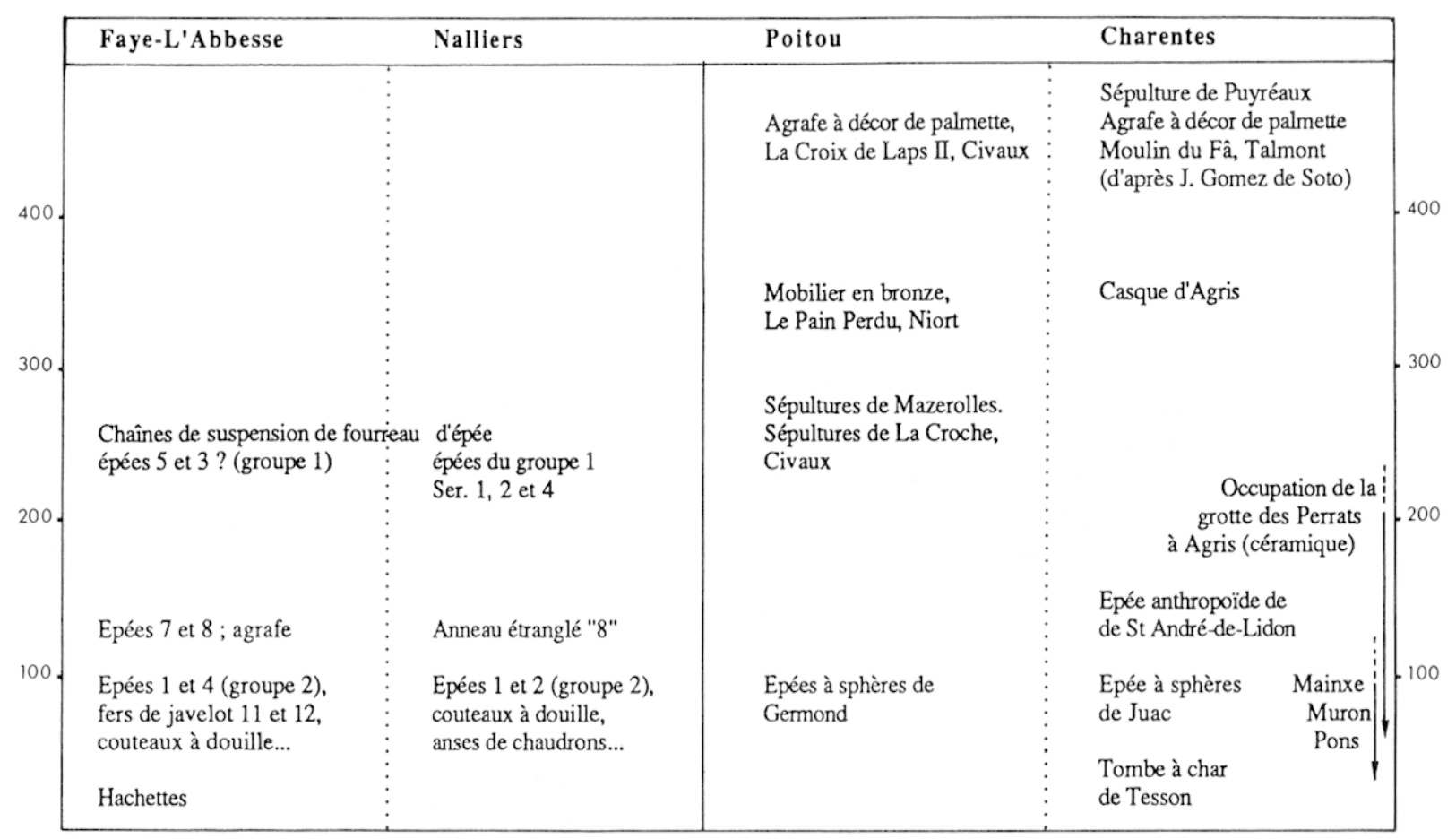

\section{NALLIERS}

- Phase ancienne : elle est représentée par les chaînes de suspension de fourreau d'épée ainsi que par les épées du groupe 1 (d'après B. Fillon). Les épées Ser. 1 et 4 appartiennent certainement à cette même période.

- Phase récente : les épées Nal. 1 et 2 , correspondant au groupe 2 , ainsi que les couteaux à douille et les anses de récipients témoignent de cette phase.

L'existence d'une phase intermédiaire est difficile à déterminer. L'anneau étranglé pourrait éventuellement s'y rapporter.

La datation des différentes phases de dépôt est mal assurée. La plus ancienne commence peut-être dès la fin de La Tène ancienne et se poursuivrait au début de La Tène moyenne, alors que la plus récente correspondrait à La Tène finale.

Les nombreuses similitudes avec les sanctuaires gaulois du nord-est de la France confortent l'hypothèse, précédemment formulćc, selon laquelle nous sommes à Nalliers comme à Faye-l'Abbesse, en présence de complexes cultuels préromains, insoupçonnés jusqu'ici. Un sanctuaire gallo-romain leur a succédé. S'il existe bien un important complexe monumental à Nalliers, sa destination cultuelle n'a pas encore été démontrée. Quoi qu'il paraisse, l'isolement des sites poitevins sur la frange occidentale du monde celtique n'est qu'apparent. Près du Fief-Sauvin dans les Mauges (Maine-et-Loire), un ensemble métallique de même nature fut mis au jour au siècle dernier. Découvert à quelque $500 \mathrm{~m}$ à l'ouest de l'oppidum, le mobilier de ce dépôt qui est uniquement connu par une planche gravée, se composait d'épées, de fers et talons de lance ainsi que de ceinturons métalliques et de divers accessoires non identifiés (Parenteau, 1870/71, p. 88-89). Plusieurs sanctuaires gallo-romains de l'ouest de la France ont, par le passé, livré eux aussi leur lot d'objets du second Age du fer, sans pour autant retenir davantage l'attention des fouilleurs (Brunaux, 1984, p. 125-128). Les sanctuaires de la Touraux-Fées à Allonnes (Sarthe), (Lambert, Riouffreyt, 1985), d'Andart (Maine-et-Loire), (Delestre, 1986) et du Mesnil à Baron-sur-Odon (Calvados), (Bertin, 1974) ont livré un certain nombre d'épées ou de fragments de lames; ce dernier site est surtout connu par son fourreau décoré d'une paire de dragons.

L'existence sur la façade atlantique de sanctuaires préromains est confirmée par Strabon qui, à la suite de Posidonios, décrit un temple proche de l'embouchure de la Loire (Strabon, IV, 4, 6). Ce sanctuaire, voué à Dionysos (?), était servi par des femmes Samnites (il s'agit certainement d'une faute de copiste, on pense immédiatement à Namnètes) qui avaient coutume une fois par an d'enlever le toit du temple pour le refaire le jour même selon un rituel bien particulier. Cette évocation où ne transparaît aucun caractère des cultes "guerriers" a l'avantage d'illustrer un autre aspect de la religion avec des rituels définis en fonction de la divinité honorée. 

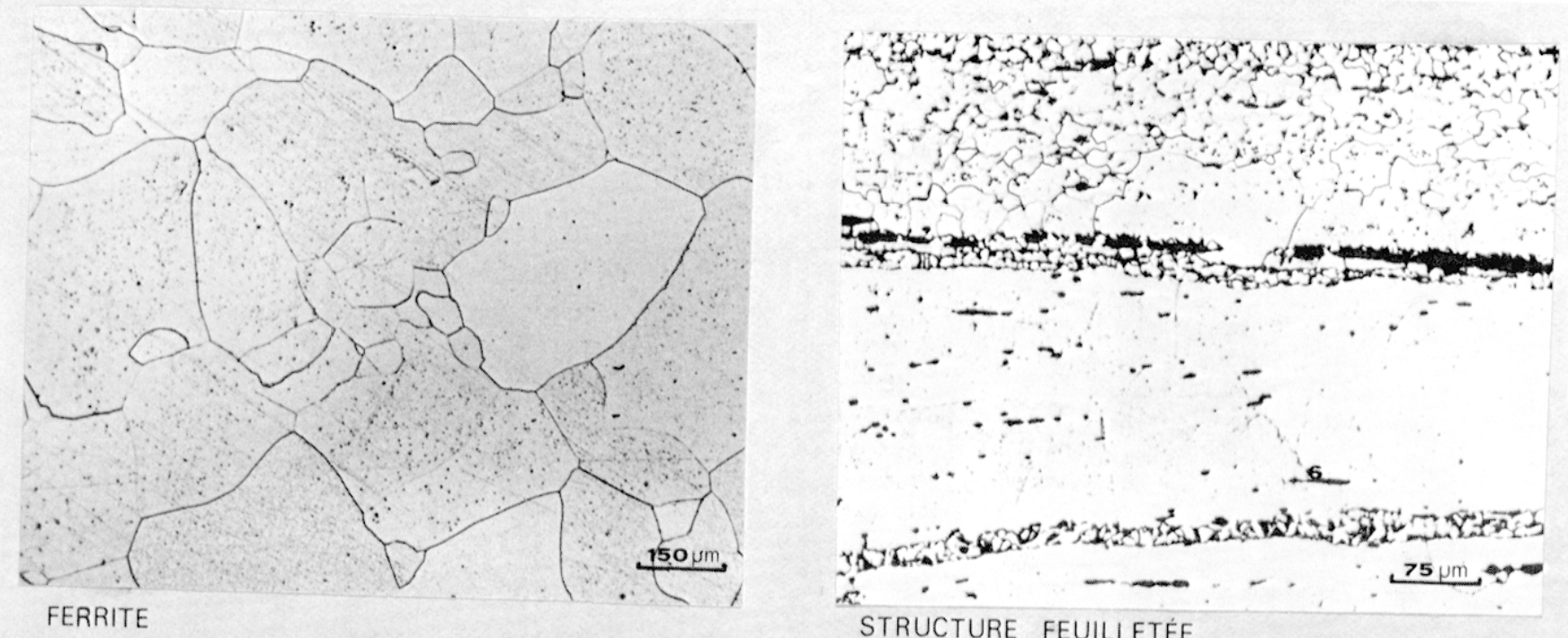

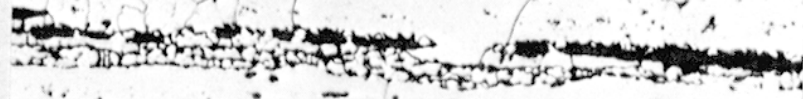

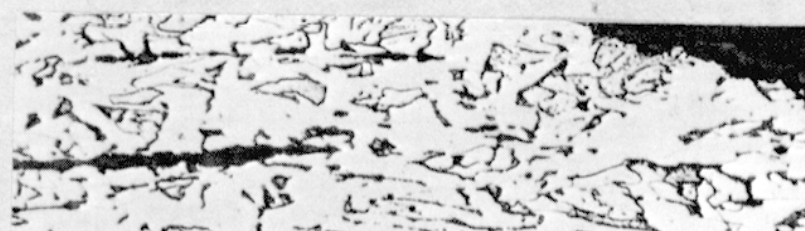

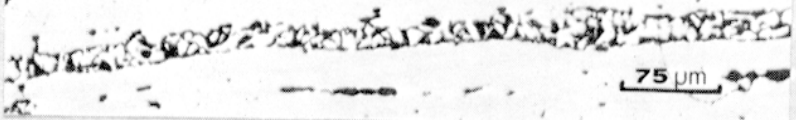
STRUCTURE FEUILLETÉE

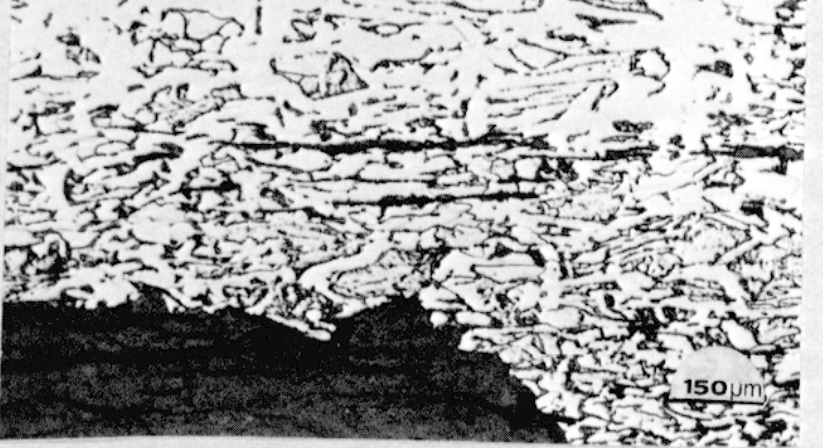

STRUCTURE ECROUIE
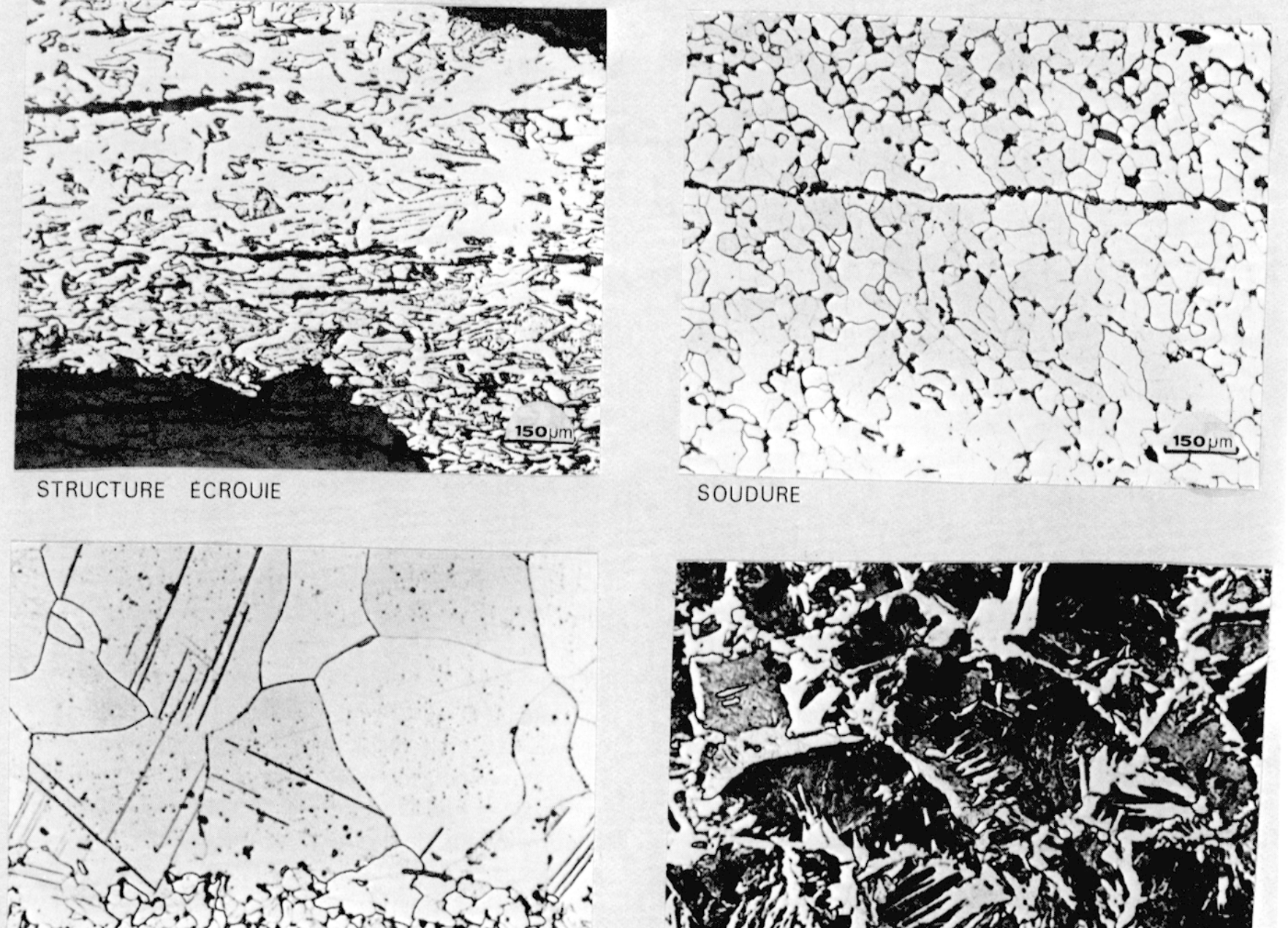

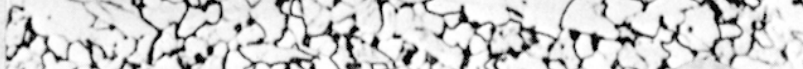

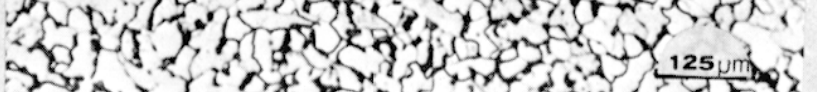
3. CRISTAUX MACLÉS

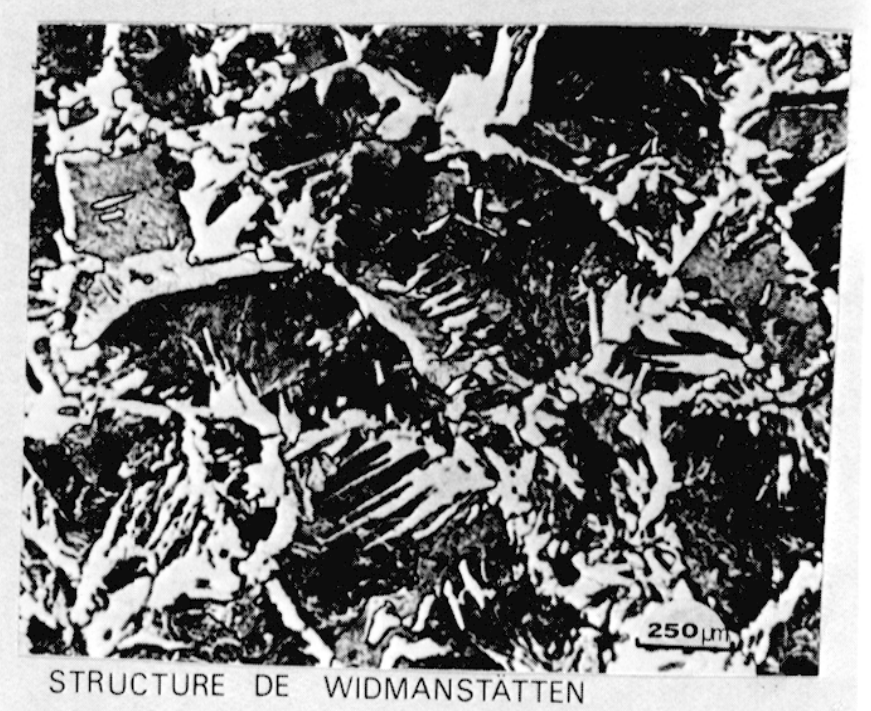

Fig. 17 - Métallographies. 


\section{$\stackrel{* *}{* *}$}

L'examen métallographique des structures d'épées constitue un moyen d'investigation complémentaire de l'analyse morphologique, avec lequel il nous faut désormais compter (fig. 17). Son apport est. essentiel pour la connaissance des techniques de forge et de leur évolution au cours du premier millénaire avant notre ère. En outre, il favorise à terme l'étude des structures économiques.

La corrosion, parfois importante, constitue un problème majeur qui tend à restreindre la portée de l'analyse structurale. Cette difficulté est cruciale pour le choix de l'échantillonnage qui doit être représentatif de l'objet considéré. Dans cette optique, l'étude de lames en parfait état de conservation présente de nombreux avantages (France-Lanord, 1964; Schulz, Pleiner, 1965). Mais elle demeure exceptionnelle et se heurte à la valeur muséographique de l'objet. Cette expérience a porté sur un ensemble d'objets relativement important, compte tenu de l'indigence de la documentation archéologique.

Nos observations nous éclairent sur la complexité de construction et la multiplicité d'aspects que recouvre l'élaboration des lames d'épées. Les structures essentiellement ferritiques et ferrito-perlitiques révèlent de nombreux défauts. Ils traduisent une connaissance et une maîtrise imparfaites des traitements thermomécaniques et de leurs propriétés.

L'efficacité de ces armes ne peut être totalement remise en cause malgré les nombreuses imperfections. Certaines d'entre elles, de meilleure qualité, dominent cependant l'ensemble (Mazerolles 1 et 2; Germond; et dans une moindre mesure Juac; F.A. 2; Nal. 1 et 2). Elles sont l'expression d'une volonté de mieux faire qui se traduit par une meilleure organisation interne des lames (ex. : structures feuilletées). Les poignées d'épées à sphères témoigent d'une même préoccupation.

En l'absence d'études systématiques, la question relative à l'origine des minerais reste en suspens. Les analyses structurales, pourtant riches en informations, apparaissent inadaptées à ce type de recherches. La détermination quantitative des différents composants chimiques du métal ou des impuretés est le plus souvent décevante. Ce problème, délicat pour les constituants du bronze, est encore plus sensible pour le fer étant donné l'importante disparité des gîtes métallifères.

Il semble donc que nous soyons, à Nalliers comme à Faye-l'Abbesse, en présence de complexes cultuels comparables au sanctuaire gaulois de Gour- nay. Nous avons déterminé à partir de l'analyse typologique deux grandes phases de "dépôt" pour chacun des sites. La première se caractérise par un mobilier datant de la fin de La Tène ancienne et des débuts de La Tène moyenne. La seconde est, pour sa part, représentative de la phase finale du second Age du Fer.

Nous ne saurions conclure si nous ne nous efforcions pas de replacer ces ensembles que nous nous sommes attachés à sortir de l'oubli à la suite de C. Gendron et J. Gomez de Soto, dans leur contexte régional et d'évoquer la question très controversée de la celtisation des provinces de l'Ouest; une région longtemps considérée comme marginale par rapport aux courants majeurs de la civilisation celtique.

Les sources écrites antiques décrivant le Grand Ouest sont rares et concernent surtout la fin du second Age du Fer.

César qui eut à maintes reprises l'occasion de parcourir le pays, distingue les Celtes des Belges au nord et des Aquitains au sud. La Marne et la Seine assuraient la frontière entre Celtes et Belges tandis qu'au sud, le cours de la Garonne les séparait des Aquitains (César, BG, I, 1). Au sujet des peuples armoricains, il parle de la suprématie des Vénètes qui tiraient leur puissance de leur flotte et du commerce transmanche (César, BG, III, 8). Lors du conflit de 56 , les Vénètes et leurs alliés de la première heure mobilisèrent l'ensemble du pays côtier, des bouches de l'Escault à l'embouchure de la Loire (César, BG, III, 9). Ces peuples constituaient l'assise de ce que l'on a coutume de nommer «la confédération armoricaine" qui, selon certains auteurs, se serait primitivement étendue du Pas-de-Calais (ou tout au moins de l'embouchure de la Seine) aux bouches de la Gironde (L'art cellique en Gaule, 1983/84, p. 147; Villard, 1983, p. 105; Hiernard, 1986, p. 116).

Le fait que les Pictons et les Santons n'aient pas pris part au conflit autrement qu'au côté des Romains, peut très bien s'expliquer au regard de la numismatique, (Hiernard, 1979). L'étude des numéraires ayant circulé en Poitou a permis de démontrer la sécession des Pictons, à l'exception du nord-ouest de la province qui a constitué ce qu'il est convenu de qualifier l'"Armorique poitevine" où l'on se propose de localiser les Ambiliati/Ambilatri et éventuellement les Anagnutes (César, BG, III, 9; Pline, IV, XXXIII). L'existence de cette enclave armoricaine semble confirmée par diverses sources. La présence d'un toponyme frontalier celtique sur la commune de La Réorthe, à proximité du cours du Lay en Vendée, ne peut s'expliquer par les structures politiques et 
administratives de l'époque historique. Il s'agit manifestement d'un témoignage d'une limite d'un état ayant précédé l'intervention romaine. On remarque par ailleurs l'absence des ces toponymes, issus de "Equoranda" et que l'on s'accorde à considérer comme typiquement celtique, à l'ouest d'une ligne reliant le Mont-Saint-Michel à l'embouchure de la Loire; doit-on tenir l'immigration bretonne $\mathrm{au} \mathrm{IV}^{\mathrm{e}} \mathrm{s}$. de notre ère pour responsable? Rien n'est moins certain! Pour terminer, il nous suffira d'évoquer les nombreuses similitudes que manifeste la céramique du Pays de Retz (LoireAtlantique) avec les productions armoricaines tout au long de la période: formes, décors estampés, cannelures labiales internes... Il en va de même des techniques mises en œuvre pour la fabrication du sel marin. Sur la façade atlantique, on distingue trois domaines technologiques assez bien délimités géographiquement qui pourraient, aux dires de $\mathrm{N}$. Rouzeau, coïncider avec les frontières littorales des cités avant les restructurations de l'administration romaine (Rouzeau, 1986, p. 24). Bien qu'il soit hasardeux de limiter des techniques de fabrication à des aires géopolitiques, il n'est pas inintéressant de constater, au nord, la présence d'une zone d'influence armoricaine s'étendant de l'embouchure de l'Odet (Finistère) au centre du linéaire côtier de la Vendée. Au sud de cette limite et jusqu'à la hauteur de la rivière Charente, nous trouvons un groupe "picton" caractérisé par des récipients troncprismatiques évasés. Ils se démarquent ainsi des vases cylindriques profonds de l'ensemble saintongeais qui s'est développé au sud jusqu'à l'estuaire de la Gironde. L'extension du groupe "picton" au nord des Charentes - la frontière entre ce peuple et les Santons est généralement située à une trentaine de kilomètres au nord - va dans le sens de l'analyse de J. Hiernard qui envisage, sur la base des différents monnayages du Centre-Ouest, une mainmise des Celtes du Poitou sur la fenêtre maritime charentaise, ainsi que sur les Santons, pour lesquels nous ne connaissons pas de numéraire propre.

Notre propos n'étant pas d'examiner la totalité des sources littéraires se rapportant au Grand Ouest, nous voudrions brièvement évoquer quelques points de la littérature ancienne qui nous renseignent sur les époques nettement antérieures à la Guerre des Gaules.

Strabon, faisant écho à Posidonios, se dissocie de César lorsqu'il place sur la Loire la limite atteinte par les peuples Belges, et ce, au grand étonnement des commentateurs (Strabon, Géographie, IV, 4, 1). Parmi ces peuples, il cite les Vénètes et les Osismes et, de façon plus générale, considère les peuples vivant au bord de l'Océan, entre Rhin et Loire, comme Belges. Quoi que l'on puisse en penser, il n'est pas moins vrai que les Vénètes demandèrent de l'aide à des peuples belges du nord de la France, témoignant des relations de "bon voisinage" ou de commerce qu'ils entretenaient avec eux (Giot, 1979, p. 26).

L'intérêt que portent les auteurs anciens aux domaines d'ordre économique est particulièrement évident en ce qui concerne les axes du commerce méditerranéen par les vallées de la Garonne ou de la Loire. A propos des échanges avec la Bretagne insulaire, Strabon nous apprend, en rapportant un texte disparu de Polybe, qu'il existait une place commerciale de première importance, du nom de Corbilo, sur le cours inférieur de la Loire (Strabon, Géographie, IV, 2, 1). Cet "emporion" était avec Narbonne l'une des villes les plus importantes du pays. Sa localisation reste incertaine (Hiernard, 1982). Pour Strabon, elle appartient au passé; sa prospérité date du $\mathrm{II}^{\mathrm{e}} \mathrm{s}$. mais peut remonter au siècle précédent si l'on en croit $\mathbf{J}$. Hiernard qui lui attribue un des tout premiers monnayages (Hiernard, 1982). Plus loin, il décrit sur la foi de Posidonios un sanctuaire indigène proche de l'embouchure de la Loire (Strabon, Géographie, IV, 4, 6). L'importance de la Loire est attestée par les nombreuses découvertes du Bronze final et du premier Age du Fer, la période suivante étant un peu moins bien représentée.

Évoquant l'antique puissance arverne, Strabon affirme que ce peuple avait étendu son hégémonie à la plus grande partie du territoire, englobant toutes les populations comprises entre le Rhin, l'Océan et les Pyrénées (Strabon, Géographie, IV, 2, 3). Les Arvernes auxquels on attribue traditionnellement les premières frappes monétaires, auraient perdu leur influence consécutivement à la défaite qu'infligea Rome en 121 à la coalition arverne-allobroge menée par Bituit. C'est en essayant de restaurer cette royauté que Celtille, le père de Vercingétorix, aurait trouvé la mort. C'est peut-être en souvenir de ces liens anciens que les peuples de l'Ouest se rallièrent les premiers avec ceux du Centre à Vercingétorix (César, BG, VII, 4). Malgré l'assurance des textes, il est bien difficile de reconnaitre la puissance et l'hégémonie arvernes au travers des sources archéologiques ou même numismatiques.

Pour compléter cette vision historique, il importe maintenant de reconsidérer la documentation archéologique dans sa globalité afin de définir l'impact du monde celtique sur les populations occidentales. 
Il n'est pas nécessaire d'attendre le second Age du Fer pour voir se dessiner une influence appréciable des groupes culturels orientaux. Alors que le SudOuest est plus enclin, de part sa situation géographique, à l'établissement de relations avec les domaines méditerranéen et ibérique, les ensembles septentrionaux depuis la Bretagne jusqu'aux Charentes témoignent de contacts avec les régions orientales dès la fin du premier Age du Fer. L'extension des tombes à char jusqu'en Poitou (Gros-Guignon à Savigné et Sénéret à Quinçay, Vienne, et Sublaine, Indre-etLoire) donne une parfaite illustration du rayonnement des modes orientales. Le rituel cinéraire reconnu dans deux des cas et le mobilier d'accompagnement (céramique peinte graphitée...) montrent l'importance du fond local tout en suggérant que l'on a bien affaire à un emprunt. Nous interprétons volontiers ce goùt pour l'apparat et le monumental comme une expression de phénomènes suciaux similaires.

L'époque charnière entre les deux Ages du $\mathrm{Fer}$ voit ces influences s'accentuer. Dans le cas de la tombe $\mathrm{n}^{\circ} 2$ des Planes à Saint-Yrieix en Charente, on est en droit de se demander si l'inhumée n'est pas une riche étrangère ou alors une autochtone bien au fait des usages orientaux (Gomez de Soto, 1986d). Les affinités culturelles que l'on perçoit au travers de cette sépulture, évoquent l'ambiance des cultures du nord-est pour la presque totalité des objets, à l'exception de la fibule de caractère plus aquitain. L'inhumation à l'intérieur d'un enclos carré de $10 \mathrm{~m}$ de côté constitue une autre nouveauté pour cette région où les structures circulaires sont prépondérantes. Une structure de ce genre a récemment été fouillée dans la Sarthe à Aubigné (Lambert, Riouffreyt, 1986, p. 10-12).

A ce groupe, il nous faut joindre l'incinération en enclos circulaire de La Croix de Laps $\mathrm{n}^{0} 2$ à Givaux (Vienne), (Pautreau, Villard, 1984). Le mobilier métallique de cet ensemble comprend, outre les trois fibules en fer de type aquitain (le petit module de ces pièces doit nous amener, comme pour l'exemplaire des Planes à Saint-Yrieix, à nuancer ce caractère et, à envisager une fois encore une influence des productions orientales), une agrafe de ceinture de même métal en forme de palmette. Ce type d'agrafe dont on connaît un second exemplaire au Moulin du Fà à Talmont (Charente-Maritime, renseignement $\mathbf{J}$. Gomez de Soto) est particulièrement représentatif du domaine marnien à La Tène ancienne I (Kruta, 1986, p. 39-40).

C'est très certainement à un même courant d'influences qu'il faut rattacher la sépulture à inhumation de Puyréaux en Charente (Gomez de
Soto, étude en cours). Son mobilier funéraire comprend notamment un couteau, un fourreau d'épée dont l'entrée et le pontet rappellent les exemplaires jogassiens et quatre anneaux de suspension. En Limousin, certaines sépultures tumulaires de la nécropole de Glandon (Haute-Vienne) ont livré en association avec le mobilier indigène (céramique peinte au graphite...) des fibules à schéma de construction de type laténien (Gomez de Soto, $1986 \mathrm{~d}$, note 30 ).

Les marques des influences orientales telles que nous les avons fait ressortir, ne doivent pas nous faire sous-estimer l'importance des traditions locales (mobilier céramique). Pour P.-R. Giot la continuité des populations locales, en Bretagne, depuis le Bronze final ou le début du premier Age du Fer ne fait aucun doute; l'acculturation n'étant que très progressive. Pour le Sud-Ouest, les influences continentales sont encore plus discrètes : fibules à timbalc hypertrophiée ou discoïdes des Pyrénées (Mohen, 1980 , p. 217). Si le mobilier métallique d'origine orientale trouvé en Centre-Ouest et dans la vallée de la Loire est plus important que partout ailleurs dans le Grand Ouest, il n'apparaît pas pour autant de véritable césure (épées à antennes: Lejars, 1987, p. 79; sépulture de Mia à Saint-Georges-les-Baillargeaux dans la Vienne: Gomez de Soto, 1986d, note 29); à l'ouest du Berry, les situles sont rares (Le Rocher au Bono, Morbihan, ainsi qu'un exemplaire de type tessinois à Château-Chervix, Haute-Vienne, et les œnochoés totalement absentes). Les dernières productions de céramique graphitée qui caractérisent la frange occidentale du massif Central à la fin du premier Age du Fer, perdurent alors que s'affirme déjà en d'autres lieux la culture laténienne. La persistance de rites funéraires locaux, à de rares exceptions, et la coexistence d'objets caractéristiques des deux périodes au sein de mêmes ensembles (enclos $\mathrm{n}^{0} 4 / 5$ de Coulon) confirment l'absence de rupture au $\mathrm{v}^{\mathrm{e}} \mathrm{s}$. avant $\mathrm{J}$.-C.

Si une telle rupture devait être envisagée, nous opterions pour la fin de la période qui est marquée par un abandon généralisé des petits habitats fortifiés de hauteur et de bon nombre de nécropoles, notamment dans le Sud-Ouest.

La période suivante apparait relativement pauvre. Hormis les belles poteries armoricaines datées du IV s. avant J.-C. par F. Schwappach, nous ne savons presque rien des contacts avec les groupes laténiens. L'absence de sépulture et d'habitat, notamment en Centre-Ouest, peut être attribuée au hasard des découvertes; toutefois, si des événements se sont produits, nous ne parvenons pas à en saisir la réalité. 
Le casque d'Agris dont le contexte est toujours mal défini appartient indiscutablement à cette période (Gomez de Soto, 1986c ; Eluère et alii, 1987). La restauration et les récentes recherches stylistiques et techniques ont pleinement permis de reconsidérer l'origine du casque. Si le décor et la technique de fabrication sont typiquement celtiques (zone centro-européenne) l'or provient de régions situées au sud-ouest de la Loire. La très grande pureté du métal l'apparente aux nombreux bijoux du SudOuest : Civray-de-Touraine (Indre-et-Loire), Montans, Lasgraïsses (Tarn) et Fenouillet (Haute-Garonne). A partir de ces considérations, J. Gomez de Soto envisage la venue d'orfèvres étrangers à la faveur des possibles déplacements de groupes humains à la suite de chefs "prestigieux" entraînant dans leur sillage leurs artisans attitrés pour le maintien de la production des biens de prestige nécessaires à leur rang. Ces déplacements de groupes humains sont parfaitement attestés en Italie et dans le bassin Danubien; rien n'interdit qu'un certain nombre de migrants aient choisi d'autres voies, emportant dans leurs bagages différents objets précieux comme le chaudron du sanctuaire du Pain-Perdu à Niort (Gomez de Soto, 1986a, p. 136). La fabrication du casque d'Agris dans un atelier celtique avec de l'or importé du Sud-Ouest est possible mais nous semble peu probable; il nous est difficile d'imaginer un "prince" occidental envoyant son métal précieux dans un atelier celtique renommé pour la confection d'un casque dont la conception et plus encore l'ornementation lui seraient étrangères.

Le III" s. avant notre ère est une période mieux connue. L'arrivée de nouveaux groupes celtiques originaires de la zone danubienne, peu avant le milieu du siècle, est particulièrement sensible en Champagne (mobilier funéraire) et en Languedoc (l'influence laténienne est perceptible dans le mobilier d'Ensérune dès les $v^{e}$ et $I^{e} s$. avant $J$.-C. avec notamment les agrafes de ceinture ajourées ou en forme de palmette) (Kruta, 1983; 1986). De façon générale, on considère la venue de ces groupes comme étant celle de populations belges. Ce siècle marque pour le monde celtique l'amorce d'une profonde transformation d'ordre économique et social. Pour la plupart des chercheurs, ce phénomène correspond à la "celtisation" de l'ensemble du territoire, même si cela est difficilement démontrable (les Aquitains qui parlent encore à l'époque de César une langue non celtique, en semblent exclus).

Dans les faits, ces transformations se traduisent par la présence, dans le mobilier funéraire, d'armes et de vases typiques de la fin de La Tène ancienne (par exemple : Mazerolles dans la Vienne). Le dépôt d'urnes cinéraires au centre d'un enclos quadrangulaire était déjà attesté dans l'Ouest au v $\mathbf{v}^{\mathbf{s}}$. avant J.C., cependant il n'est pas inutile de tourner notre regard vers les régions orientales où ce rite était également à l'honneur.

Cependant, si l'on doit s'attacher à démontrer la réalité d'un fait comme la celtisation, il nous paraît illusoire de nous fier aux seuls objets. Les rituels funéraires ne sont pas dépourvus d'intérêt mais sont trop souvent empreints de conservatisme. C'est donc dans un domaine proche, celui de la religion, que nous proposons de rechercher les indices témoignant de la celtisation du Grand Ouest. Par leurs analogies avec les sanctuaires du nord-est de la France, les dépôts de Nalliers et de Faye-l'Abbesse suggèrent, au-delà de la diffusion des cultes celtiques, une profonde mutation des mentalités qui résulte de ce qu'il est convenu d'appeler la celtisation. La répartition de ces sites selon un axe nord-sud pourrait éventuellement correspondre au sens de la pénétration celtique depuis le domaine "belge", en direction du Centre-Ouest. Ces lieux de cultes témoignent, à notre sens, de l'appartenance des populations de ces régions, toutes ou en partie, à la vaste communauté spirituelle du monde celtique. Ici, la celtisation peut donc être considérée comme l'aboutissement d'une longue infiltration culturelle et humaine mais dont l'impact sur l'ensemble des populations ne peut être évalué. Si ces lieux de culte sont ceux des nouveaux arrivants, on peut se demander dans quelle mesure ils concernent les groupes autochtones dont on ne sait rien (étaient-ils ou non celtophones?). L'abondance de l'armement dans ces dépôts confère à ces cultes un caractère essentiellement aristocratique.

Les mutations qui s'opèrent alors sont, ainsi que nous l'avons dit, d'ordre social et économique. Ces transformations annoncent l'avènement des grandes agglomérations qui caractérisent la "civilisation des oppida». Ces habitats, dont Corbilo dut être l'un des fleurons, se sont surtout développés au cours du II $^{\mathrm{e}} \mathrm{s}$. L'autre phénomène majeur réside dans l'apparition des premières monnaies, particulièrement bien représentées dans nos régions (imitations du statère de Philippe II ...). Leur "forte" concentration depuis le Languedoc jusqu'en Centre-Ouest témoigne des relations qui ont existé entre les différentes régions de cet axe (contrairement aux monnaies d'argent qui ont circulé un peu partout, celles en or n'ont pas eu cours au sud de la Dordogne).

A cette époque, la Bretagne, tout comme l'Aquitaine sub-garonnique, se démarque des principaux faciès de la culture laténienne et se distingue nettement des autres ensembles du Grand Ouest. Le problème est plus délicat pour les régions des Pays 
de Loire et du Centre-Ouest, où la présence celtique est plus forte. Toutefois, nous ne saurions suivre J. Hiernard lorsqu'il conclut à une celtisation tardive du Poitou (Hiernard, 1986); le fait que les populations poitevines (il ne peut encore être question de "Pictons") aient dépendu un temps du complexe armoricain ne prouve en rien leur appartenance ethnique à tel ou tel groupe. D'ailleurs, si l'on en croit les sources anciennes, les Arvernes les soumirent tous à leur autorité. L'évolution du monnayage indique tout au plus la constitution de l'état picton de l'époque de la guerre des Gaules.

La celtisation du Grand Ouest n'est certainement pas le fait d'une invasion d'ampleur et structurée, mais bien plus le résultat de la symbiose entre un fonds indigène et un apport proprement celtique, non négligeable en puissance sinon en nombre. L'appartenance ethnique des populations en place nous étant inconnue, nous ne saurions dire si elles étaient prêtes à cette synthèse. Quoi qu'il en soit, l'organisation sociale de ces gens ne devait pas être fondamentalement différente de ce que l'on observe plus à l'est : une société fortement hiérarchisée dominée par une aristocratie guerrière. En tout état de cause, les "nouveaux venus" ne s'imposèrent qu'en raison de conditions favorables, résultant d'un éventuel vide politique.

\section{Thierry LEJARS}

\section{BIBLIOGRAPHIE}

\section{Catalogue d'exposition}

1983/84 : L'art celtique en Gaule, Marseille, Paris, Bordeaux, Dijon.

\section{Bertin D.}

1974: Le fourreau d'épée celtique décoré de Baron-sur-Odon (Calvados), Gallia, 32, p. 243-248.

\section{Bonnamour L.}

1983 : Les découvertes des Ages du Fer dans le lit de la Saône (virie-1er s. avant notre ère), La vallée de la Saône aux Ages du Fer (vIre-ler s. avant notre ère), exposition du Chàteau SaintMichel de Rully. 12-19 mai 1983, Châlon-sur-Saône, p. 63-78.

Boudet R.

1987: L'Age du Fer récent dans la partie méridionale de l'esluaire girondin (du ve au ler s. avant notre ère), Périgueux, éd. Vesuna.

Boudet R., Chevillot C., Gomez de Soto J.

1986 : A propos de l'épée celtique décorée de Corgnac-sur-Isle (Dordogne), $1^{\text {er }}$ suppl. à Aquitania, p. 191-202.

\section{Bretz-Malher D.}

1971 : La civilisation de La Tène I en Champagne, le faciès marnien, $23^{\mathrm{e}}$ suppl. à Gallia, Paris, Éd. du C.NRS.

Brisson A., Hatt J.-J., Roualet P.

1970 : Cimetières gaulois et gallo-romains à enclos en Champagne. IV : Cimetière de Fère-Champenoise Faubourg de Connantre, Mémoires de la Société d'Agriculture, du Commerce, des Sciences et des Arts du département de la Marne, LXXXV, p. 5-26.

\section{Brunaux J.-L.}

1984 : Les sanctuaires indigènes : tradition, perduration, Actes du colloque : Ethno-histoire et archéologie, Paris, 7-8 mai 1983, Caesarodunum, 19, p. 125-131.

1986 : Les gaulois, sanctuaires et rites, Paris, éd. Errance, coll. des Hespérides.
Brunaux J.-L., Méniel P., Rapin A.

1980: Un sanctuaire gaulois à Gournay-sur-Aronde (Oise), Gallia, 38, p. 1-25.

Brunaux J.-L., Méniel P., Poplin F.

1985: Gournay I, les fouilles sur le sanctuaire et l'oppidum (1975-1984), numéro spécial de la Revue archéologique de Picardie.

\section{Cadoux J.-L.}

1986 : Les armes du sanctuaire gaulois de Ribemont-sur-Ancre (Somme) et leur contexte, $1^{\text {er }}$ suppl. à Aquilania p. 203-209.

Coghlan H. H.

1956/57a : A note upon Iron as a Material for the Celtic Sword, Sibrium, 3, p. 129-136.

1956/57b : Etruscan and Spanish Sword of Iron, Sibrium, 3, p. 167-171.

Colin A., Buchsenschutz O.

1984 : Cercles et sépultures protohistoriques dans le canton de Levroux, Revue archéologique du Centre de la France, 23, 2, p. 197-208.

\section{Dechelette J.}

1913 : La collection Millon, antiquités préhistoriques et galloromaines, Paris.

Degenne M., Duval A.

1983 : La nécropole de Breuil-le-Sec (Oise), Actes du colloque : Les Celles dans le nord du Bassin Parisien (vre-er s. avant notre ère), Revue archéologique de Picardie, I, p. 74-95.

Delestre X.

1986 : Sept pièces d'armement du second Age du Fer à Andard (Maine-et-Loire), Journées archéologiques régionales, Nantes, 12 janvier 1986, Direction des Antiquités historiques des Pays de Loire, 1 p.

De Navarro J. M.

1972 : The Finds from the Site of La Tène, I : Scabbards and the Swords found in them, Londres, 2 vol. 
Duval A., Gomez de Soto J., Perrichet-Thomas C.

1986: La tombe à char de Tesson (Charente-Maritime), $1^{\text {er }}$ suppl. à Aquitania, p. 35-45.

Eluère C., Gomez de Soto J., Duval A.-R.

1987: Un chef-d'œuvre de l'orfèvrerie celtique: le casque d'Agris (Charente), Bulletin de la Société Préhistorique Française, 84/1, p. 8-22.

Emmerling J.

1967/68 : Die metallographische Untersuchung der Schwertklingen aus Münsingen, Jarhbuch des Bernischen Hislorischen Museums in Bern, 47/48, p. 147-190.

1975: Metallkundliche Untersuchungen an Latènezeitlichen Schwertern und Messern, Alt-Thüringen, 13, p. 205-220.

Fillon B., de Rochebrune $\mathrm{O}$.

1862/87: Poilou et Vendée, éludes historiques et artistiques, Niort, 2 vol.

Flouest J.-L., Stead I. M.

1981: Iron Cemeteries in Champagne: in the third interim Report, British Museum Occasional Paper, 6.

Fluzin P., Uran L., Béranger G., Coddet C.

1983a : Structures et mise en forme d'armes gauloises, Les Celles dans le nord du Bassin Parisien (Vre-1er s. avant notre ère), Revue archéologique de Picardie, I, p. 181-194.

1983b : Structures métallurgiques des armes de Gournay-surAronde : lecture et interprétation, Journées de Paléomélallurgie, université de Technologie de Compiègne, 22-23 février 1983, prétirage, p. 85-101.

France-Lanord A.

1964: La fabrication des épées de fer gauloises, Revue d'Histoire de la Sidérurgie, V, 4, p. 315-327.

Gendron C., Gomez de Soto J.

1986: Le sanctuaire pré-romain de Faye-l'Abbesse (DeuxSèvres), $1^{\text {er }}$ suppl. à Aquitania, p. 89-95.

Gendron C., Gomez de Soto J., Lejars T., Pautreau J.-P., Uran L.

1986 : Deux épées à sphères du Centre-Ouest de la France, Aquitania, 4, p. 39-54.

Giot P.-R.

1979 : Stabilité ou instabilité des populations dans le NordOuest de la Gaule celtique. Les mouvements celtiques du Ve au Ier $s$. avant nolre ère, p. 21-27.

Gomez de Soto J.

1984 : L'Age du Fer dans le bassin de la Charente, Aspects des Ages du Fer en Centre-Ouest, livret-guide de l'exposition, 15 avril- 15 juin. Musée municipal d'Angoulême, Angoulême, p. 10-17.

1986a: Le Pain-Perdu, Niort, Au temps des Celtes, ve-jer $s$. avant $J .-C$., catalogue de l'exposition, abbaye de Daoulas, p. 136.

1986b: De nouvelles fouilles à Font-Barbot, Archéologie pontoise, $73,4 \mathrm{p}$.

$1986 \mathrm{c}$ : Le casque du Ive siècle avant notre ère de la grotte des Perrats à Agris, France, Archäologisches Korrespondenzblall, 16,2 , p. 179-182.

1986d: Une sépulture de la nécropole des Planes à SaintYrieix (Charente), $1^{\text {er }}$ suppl. à Aquitania, p. 105-111.

Gruet M.

1987: Fouille aux Pichelots, les Alleuds (Maine-et-Loire) La Tène III, Journées archéologiques régionales, Le Puy du
Fou, mai 1987, Direction des Antiquités historiques des Pays de Loire, 1 p.

Hiernard J.

1979 : Poitou et Vendée avant les romains : une enquête numismatique, Sociélé d'Émulation de la Vendée, p. 45-84.

1982 : Corbilo et la route de l'étain, Bulletin de la Société des Antiquaires de l'Ouest, p. 494578.

1986: Numismatique et protohistoire: existe-t-il un monnayage picton? $1^{\text {er }}$ suppl. à Aquilania, p. 113-121.

Jacobsthal P.

1969 : Early celtic Art, Oxford, 2 vol.

Joffroy R., Thenot A.

1976 : La nécropole de Beaulieu à Nogent-sur-Seine (Aube), Antiquités Nationales, 8, p. 38-59.

Kruta V.

1983 : Les Celtes orientaux et la Gaule, L'expansion des Celtes de la Gaule vers l'Orient, Dossiers Histoire et Archéologie, 77, p. 71-77.

1986 : Les Celtes des Gaules d'après l'archéologie, Geschichle und Kullur der Kellen, Vorbereitungskonferenz 25-28 okt. 1982 in Bonn, Heidelberg, p. 33-51.

Kruta V., Szabo M.

1982 : Canthares danubiens du $1 \mu^{\mathrm{e}} \mathrm{s}$. avant notre ère. Un exemple d'influence hellénistique sur les Celtes orientaux, Eludes Celtiques, XIX, p. 51-67.

Kruta-Poppi L.

1979 : La sépulture de Ceretolo (province de Bologne) et le

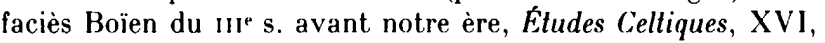
p. 7-25.

Lambert C., Riouffreyt J.

1985 : Les épées du sanctuaire de la Tour-aux-Fées d'Allonnes (Sarthe), Etudes préhistoriques el historiques des Pays de Loire, p. $69-72$.

1986 : Ombres et lumières sur les Cénomans, Pays de Loire des Gaulois au Moyen Age, Dossiers Histoire et Archéologie, 106, p. 10-11.

Lejars T.

1987 : Quelques considérations sur le second Age du Fer dans le Grand Ouest, mémoire de DEA, université de Paris I, dactylographié.

Leoni $\mathbf{M}$.

1973/75: Tradizione e realta delle spade galliche, Sibrium, p. 105-125.

Lintz G., Vuaillat D.

1984 : Les glaives à lame ondulée dans les sépultures galloromaines en Limousin, communication au $8^{\circ}$ colloque de l'AFEAF, Angoulème.

Lollini D. G.

1979 : I senoni nell' Adriatico alla luce delle recenti scoperte, Actes du colloque international : Les mouvements celliques du ve s. au rer s. avant notre ère, p. 55-79.

Lunier L., Monnet A.

1853 : Rapport sur les fouilles faites près de Faye-l'Abbesse, au lieu-dit des Crânières, Mémoires de la Socièté de Statistique des Deux-Sèvres, XVI, p. 65-87.

Maddin R., Muhly J. D., Wheeler T. S.

1977 : Les débuts de l'Age du Fer, Pour la Science, 2, p. 12-20. 
Marien M. E.

1961 : Le groupe de la llaine, la période de La Tène en Belgique, Bruxelles.

Massy J.-L., Mantel E., Méniel P., Rapin A.

1986: La nécropole gauloise de Tartigny (()ise), Revue archéologique de Picardie, 34, p. 13-81.

Mohen J. P.

1980: L'Age du Fer en Aquitaine du vIII' au II $^{\circ}$ siècle avant J.-C., Mémoires de la Société Préhistorique Française, 14, 342 p.

Müller F.

1986 : Der Latènezeitliche Massenfund von der Tiefenau bei Bern 1849-1851, Archäologisches Korrespondenzblalt, 16,2, p. 191-192.

Nicolini G.

1983 : Trois sépultures de l'Age du Fer à Mazerolles (Vienne), Gallia, 41, p. 7-24.

\section{Parenteau F.}

1870/71 : Segora (statio), Bulletin de la Socièté archéologique de Nantes, X, p. 81-91.

Pautreau J.-P.

1976 : Les civilisations de l'Age du Fer dans le Centre-Ouest de la France, La Préhistoire Française, Paris, Éd. du C.NRS, p. $770-780$

1984 : L'Age du Fer en Poitou, Aspects des Ages du Fer en Centre-Ouest, livret-guide de l'exposition, 15 avril-15 juin, Musée municipal d'Angoulème, Angoulème, p. 1-9.

1986 : Bulletin de liaison et d'information, Préhistoire/Histoire, Association des archéologues, Direction des Antiquités de Poitou-Charentes, 15, p. 50.

Pautreau J.-P., Villard A.

1984 : Les enclos circulaires de Civaux-Valdivienne (Vienne), Aspects des Ages du Fer en Centre-Ouest, livret-guide de l'exposition, 15 avril-15 juin, Musée municipal d'Angoulème, Angoulème, p. 26-28.

Petres E. F., Szabo M.

1986 : Notes on the so-called IIatvan-Boldog type Scabbards, $1^{\text {er }}$ suppl. à Aquilania, p. 257-272.

Pleiner $\mathbf{R}$.

1978: Die Metallkundliche Untersuchung von zwei Eisenschwertern aus den Gräbern 30 und 110 , in : Wal.DHAusER J. (èd.), Das Keltische Gräberfeld bei Jenišuv ljezd in Böhmen, I : Quellen und Gutachten, Teplice, p. 205-208.

1980 : Early Iron Metallurgy in Europe, The Coming of the Age of Iron, .New-Ilaven et Londres, p. 375-415.

1983 : De l'épée gauloise à l'outil de la période de La Tène tardive, Journées de Paléométallurgie, 22-23 février 1983, université de Technologie de Compiègne, suppl. au prétirage, p. 1-8.

\section{Rapin A.}

1983/84 : L'armement du guerrier celte au deuxième Age du Fer, L'art celtique en Gaule, catalogue de l'exposition, Marseille, Paris, Bordeaux, Dijon, p. 69-79.

1987: Le système de suspension des fourreaux d'épées laténiens au $\mathrm{III}^{\mathrm{e}} \mathrm{s}$. avant J.-C. Innovations techniques et reconstitution des éléments périssables, Actes du colloque international : Celti ed Etruschi nell' Italia centro-seltentrionale dal $V$ secolo a.C. alla romanizzazione, Bologne 12-14 aprile 1985, Imola, p. 529-539.

Roualet P., Rapin A., Fluzin P., Uran L.

1982: Sépultures du Crayon, à Écury-le-Repos (Marne),
Mémoires de la Socièté d'Agriculture, du Commerce, des Sciences et des Arts du département de la Marne, XCVII, p. 25-44.

1983: La sépulture du guerrier de Morains «Les TerresRouges" (Marne), Mémoires de la Société d'Agricullure, du Commerce, des Sciences et des Arts du département de la Marne, XCVIII, p. 7-23.

1985 : Deux groupes de tombes de l'époque de La Tène au lieu-dit Verboyon, à Hauviné (Ardennes), Mémoires de la Sociète d'Agriculture, du Commerce, des Sciences el des Arts du département de la Marne, C, p. 7-28.

Rouzeau N.

1986 : L'archéologie du sel sur le littoral, Pays de Loire des gaulois au Moyen Age, Dossiers Histoire el Archéologie, 106, p. 24-27.

Schulz E. H., Pleiner R.

1965 : Untersuchungen an Klingen Eisener Latène-Schwerter, Technische beitrage zur Archäologie, II, 2, p. 38-51.

Snodgrass A. M.

1980 : Iron and Early Metallurgy in the Mediterranean, The Coming of the Age of Iron, New-Haven et Londres, p. 335-374.

Stead I. M.

1983: La Tène Swords and Scabbards in Champagne, Germania, 61, p. 487-510.

1985 : Celtic art in Britain before the Conquest, British Museum Publications.

\section{Tisserand $\mathrm{G}$}

1980 : Les ex-voto du site de Flavier à Mouzon (08210), Revue archéologique de l'Est, XXXI, 1-2, p. 61-73.

Uran L.

1983 : Contribution à l'étude de la paléométallurgie du fer: structures d'épées celtiques, Institut universitaire de Technologie de Compiègne, thèse de $\mathrm{III}^{\mathrm{e}}$ cycle, dactylographiée.

1986: Observations métallographiques sur les épées celtiques en fer, ${ }^{\text {er }}$ suppl. à Aquitania, p. 299-308.

Verwers G. J., Ypey J.

1975: Six Iron Swords from the Netherlands, Analecta Praehistorica Leidensia, 8, p. 79-91.

Villard A.

1983 : Le second Age du Fer dans la Vienne, les Deux-Sèvres et la Vendée, mémoire de Maîtrise, université de Paris I, dactylographié.

Vouga $\mathrm{P}$.

1923 : La Tène, monographie de la station, Leipzig.

Vuaillat D.

1982 : Nouvelle contribution à la connaissance des civilisations de la fin de l'Age du Fer en Franche-Comté : études métallographiques, université de Tours, thèse de III ${ }^{e}$ cycle, dactylographiée.

Willaume $\mathbf{M}$.

1985 : Le Berry à l'Age du Fer HA C-La Tène II, précédé du calalogue des collections de l'Age du Fer du Musée de Bourges, British Archaeological Report, International Series, 247, Oxford.

Willaume M., Ferdière A., Lejour M., Pompée J.-C.

1977: La nécropole de "Mainville» à Bromeilles (Loiret), Tène I-II (45.056.01), Revue archéologique du Nord du Loiret, 3, p. 41-79. 